\title{
The wealth of nations: global imbalances and adjustments in a financially integrated world
}

Citation for published version (APA):

Holinski, N. (2010). The wealth of nations: global imbalances and adjustments in a financially integrated world. [Doctoral Thesis, Maastricht University]. Datawyse / Universitaire Pers Maastricht. https://doi.org/10.26481/dis.20101112nh

Document status and date:

Published: 01/01/2010

DOI:

10.26481/dis.20101112nh

Document Version:

Publisher's PDF, also known as Version of record

\section{Please check the document version of this publication:}

- A submitted manuscript is the version of the article upon submission and before peer-review. There can be important differences between the submitted version and the official published version of record.

People interested in the research are advised to contact the author for the final version of the publication, or visit the DOI to the publisher's website.

- The final author version and the galley proof are versions of the publication after peer review.

- The final published version features the final layout of the paper including the volume, issue and page numbers.

Link to publication

\footnotetext{
General rights rights.

- You may freely distribute the URL identifying the publication in the public portal. please follow below link for the End User Agreement:

www.umlib.nl/taverne-license

Take down policy

If you believe that this document breaches copyright please contact us at:

repository@maastrichtuniversity.nl

providing details and we will investigate your claim.
}

Copyright and moral rights for the publications made accessible in the public portal are retained by the authors and/or other copyright owners and it is a condition of accessing publications that users recognise and abide by the legal requirements associated with these

- Users may download and print one copy of any publication from the public portal for the purpose of private study or research.

- You may not further distribute the material or use it for any profit-making activity or commercial gain

If the publication is distributed under the terms of Article $25 \mathrm{fa}$ of the Dutch Copyright Act, indicated by the "Taverne" license above, 
The Wealth of Nations: Global imbalances and ADJUSTMENTS IN A FINANCIALLY INTEGRATED WORLD

NiLS HOLINSKI 
(C) Nils Holinski, 2010

All rights reserved. No part of this publication may be reproduced, stored in a retrieval system, or transmitted in any form, or by any means, electronic, mechanical, photocopying, recording or otherwise, without the prior permission in writing from the author.

This book was typeset by the author using $\mathrm{AT}_{\mathrm{E} X}$.

Published by Universitaire Pers Maastricht

ISBN: 978-90-5278-986-6

Printed in the Netherlands by Datawyse Maastricht

Cover design: Stephanie Blaschka 


\title{
The Wealth of Nations: Global imbalances and ADJUSTMENTS IN A FINANCIALLY INTEGRATED WORLD
}

\author{
NiLS HOLINSKI
}

\author{
Proefschrift
}

ter verkrijging van de graad van doctor aan de Universiteit Maastricht, op gezag van de Rector Magnificus, Prof. mr. G.P.M.F. Mols, volgens het besluit van het College van Decanen, in het openbaar te verdedigen op vrijdag 12 november 2010 om 10.00 uur

door

Nils Holinski 


\section{Promotores:}

Prof. dr. J. Muysken

Prof. dr. C. Kool (Utrecht University School of Economics)

\section{Beoordelingscommissie:}

Prof. dr. B. Candelon (voorzitter)

Prof. dr. E. de Jong (Radboud University Nijmegen)

Prof. dr. A.P. van Veen

Dit onderzoek werd gefinancieerd door de Maastricht Research School of Economics of Technology and Organizations (METEOR). 
To Stephanie and my parents, Sabine and Eberhard 



\section{ACKNOWLEDGEMENTS}

This is the point in time when you realize that your $\mathrm{PhD}$ journey comes to an end and you start reminiscing about the past four years. I have never envisioned myself writing these lines, yet here we are. I have shared this journey with many friends and colleagues to whom I owe a debt of gratitude. It is only for you that it has become such an amazing time and incredible experience.

First of all, I would like to thank my supervisors Joan Muysken and Clemens Kool for their continued trust in my person and my work. I have benefited greatly from the thought provoking discussions that we had during our joint meetings in Utrecht. I will not forget the enjoyable train rides with Joan to Utrecht and the perilous walks from the train station to Clemens' office. I appreciate that I always had the freedom to develop and pursue my own research interests, well knowing that you would get me back on track when things become rough. Your immense experience, not only as researchers, combined with your views on the economy were a challenging guide during the past four years and certainly left a profound impact on my own development as an economist. Thank you for the professional and amicable atmosphere that you created. I will take all of that for my future.

Next I'd like to thank the members of my assessment committee, Prof. dr. Bertrand Candelon (Maastricht University), Prof. dr. Tom van Veen (Maastricht University), and Prof. dr. Eelke de Jong (Radboud University Nijmegen), for their careful reading and insightful comments on my manuscript. Their expertise improved my work. I share a long history of teaching courses with Tom and Bertrand. It was always great being on your teams.

Although all colleagues of our department deserve to be mentioned here, I'd like to express my special appreciation to Fleur Keune, Silvana de Sanctis and Sylvia Beenen. Their administrative and organizational support made everything run smoothly over the years. And more importantly, it was always nice having a chat with you. 
This brings me to my dear $\mathrm{PhD}$ comrades. Sharing ideas and thoughts with all of you, the ups and downs, coffee and muffins, was definately the most important ingredient to an enjoyable life as a $\mathrm{PhD}$ student. Let me begin with thanking Martin Schmitz, Christiane Hellmanzik and Danielle Kedan for their special interest in my research and all the fun that we had during my visit at Trinity College in Dublin. Danielle has proof-read every single chapter of this dissertation. How to make up for that? My roommates, Stefan Kühn, Robert Vermeulen, Jan Piplack and Jeroen van den Berg, certainly made my working day. It was great having you at my side whenever my economic and econometric theory knowledge reached its limit and simply for hanging out together. The same holds true for Thies Lindenthal, Barbara Meller, Ehsan Vallizadeh, Lenard Lieb and all the other PhD colleagues. I also want to thank Henrik Brokmeier and Manuel Niermeier for their interest in my work. It means a lot to me.

Finally, I feel deeply indebted to all of my family members, in particular to my uncle Wolfgang for his genuine curiosity about my work and plans for the future, and to my aunt Anne who brought my attention to Maastricht University in the first place. I also like to thank Margit and Norbert for always supporting me.

My deepest gratitude goes to my parents, Sabine and Eberhard, and my brother Till. Your love, dedication and continuous encouragement provide the foundation for everything that I do. Thank you for having raised my curiosity in life and for always being there for me. Stefka, it is both wonderful and comforting to know that you are part of my life. It is all for you.

Nils Holinski

Maastricht, September 2010 


\section{CONTEnTs}

Contents

List of Tables

xiii

List of Figures

1 Introduction $\quad 1$

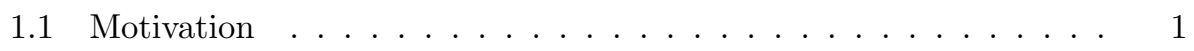

1.2 Global financial markets . . . . . . . . . . . . . . . 2

1.3 Global financial and real markets . . . . . . . . . . . . . 6

1.4 Structure of the dissertation . . . . . . . . . . . . . . . . 9

2 Taking home bias seriously: Absolute and relative measures explaining consumption risk-sharing 13

2.1 Introduction . . . . . . . . . . . . . . . . . . 13

2.2 Literature review . . . . . . . . . . . . . . . . . . . 15

2.3 Data sources and home bias measures . . . . . . . . . . . . 18

2.4 Consumption risk-sharing . . . . . . . . . . . . . . . . 22

2.5 Robustness of panel-data regressions . . . . . . . . . . . . 26

2.6 Conclusion . . . . . . . . . . . . . . . . . . 27

3 The international wealth channel: A global error-correcting analysis

3.1 Introduction . . . . . . . . . . . . . . . . . . . 29

3.2 The international wealth channel . . . . . . . . . . . . . . 32 
3.3 Constructing the GVAR model . . . . . . . . . . . . . . . 34

3.3.1 Variable selection and data considerations . . . . . . . . . 34

3.3.2 The GVAR methodology . . . . . . . . . . . . . . 36

3.3.3 Properties and specification of the data series . . . . . . . 40

3.4 Generalized impulse response analysis . . . . . . . . . . . 45

3.4.1 The international wealth channel for the US . . . . . . . 46

3.4.2 The international wealth channel for the UK . . . . . . . 48

3.4.3 The international wealth channel for France . . . . . . . . 51

3.4.4 The international wealth channel for Germany . . . . . . 53

3.4.5 The international wealth channel for Japan . . . . . . . 55

3.5 Forecast error variance decomposition . . . . . . . . . . 57

3.6 Stability and specification of the global VAR . . . . . . . . 59

3.7 Conclusion . . . . . . . . . . . . . . . . . . . . 62

3.8 Appendix: Data sources . . . . . . . . . . . . . . . 63

4 Causes of US external deficits: An international portfolio-balance modeling perspective $\quad 65$

4.1 Introduction . . . . . . . . . . . . . . . . . . . . . 65

4.2 Stylized facts and literature review . . . . . . . . . . 68

4.2.1 Stylized facts of international financial integration . . . . 68

4.2.2 Literature on the external adjustment process . . . . . . 70

4.2.3 Literature on the causes of US current account deficits . . . 72

4.3 Modeling the external adjustment . . . . . . . . . . . . . 73

4.3.1 Introduction of relevant concepts . . . . . . . . . . . 73

4.3.2 Portfolio balance . . . . . . . . . . . . . . . . . 75

4.3.3 Current account balance . . . . . . . . . . . . . . . . 77

4.3.4 Steady states and transitory dynamics . . . . . . . . . 79

4.4 Simulating the external adjustment . . . . . . . . . . . . 81

4.4.1 A first glance at the data . . . . . . . . . . . . 82

4.4.2 Scenario I - Current account balance shock . . . . . . . . 83

4.4.3 Scenario II - Portfolio balance shock . . . . . . . . . . . 86

4.4.4 Scenario III - Current account and portfolio balance shocks 88

4.5 Conclusion . . . . . . . . . . . . . . . . . . 90

5 Sustainability of US external imbalances: An international portfolio$\begin{array}{ll}\text { balance modeling perspective } & 91\end{array}$

5.1 Introduction . . . . . . . . . . . . . . . . . . . . . . . . . . 91

5.2 Sustainability issues of global external imbalances . . . . . . . . . 92

5.3 Augmenting the portfolio-balance model . . . . . . . . . . . . 95

5.4 Simulating the Wile E. Coyote moment . . . . . . . . . . . . . . 100 
5.4.1 RW investors realize excess US bond holdings . . . . . . . 100

5.4.2 RW investors reevaluate US net foreign bonds . . . . . . . 103

5.5 Conclusion . . . . . . . . . . . . . . . . . . 105

6 Origins of persistent macroeconomic imbalances in the Euro area107 6.1 Introduction . . . . . . . . . . . . . . . . . . . 107

6.2 Savings behavior and current account imbalances . . . . . . . . . 109

6.2.1 Public versus private net saving rates . . . . . . . . 112

6.2.2 Components of the current account . . . . . . . . 115

6.3 All a matter of economic convergence? . . . . . . . . . . . . . . . 119

6.4 Conclusion and future research directions . . . . . . . . . . . . . 124

$\begin{array}{ll}\text { Bibliography } & 127\end{array}$

Nederlandse Samenvatting (Summary in Dutch) 141

$\begin{array}{ll}\text { Short Curriculum Vitae } & 147\end{array}$ 



\section{LisT OF TABLES}

2.1 Absolute and relative equity home bias . . . . . . . . . . . . 20

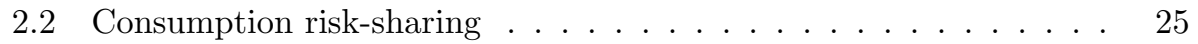

3.1 Countries and regions in the model . . . . . . . . . . . . . . 31

3.2 Trade weight matrix . . . . . . . . . . . . . . . 37

3.3 VARX order and number of cointegrating relationships . . . . . 38

3.4 Weighted symmetric unit root test results . . . . . . . . . . . 41

3.5 Weighted symmetric unit root test results, cont'd . . . . . . . . 42

3.6 Weak exogeneity test . . . . . . . . . . . . . . . 45

3.7 Proportion of the N-step ahead forecast error variance explained by conditioning on contemporaneous and future innovations of the

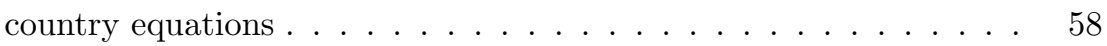

3.8 Tests of parameter constancy . . . . . . . . . . . . . . . 60

3.9 Correlation coefficients of country-specific foreign variables using constant and time-varying trade weights . . . . . . . . . 61

4.1 Market capitalization and allocation in 2006, USD trillions . . . . . 82

5.1 Market capitalization and allocation in 2000 and 2006, USD trillions 98

6.1 Disaggregation of average current accounts in the Euro area . . . 111

6.2 Disaggregation of average private net saving rates in the Euro area 115 



\section{List OF FiguRES}

1.1 Total and foreign portfolio equity holdings, USD trillions . . . . . . 4

3.1 Domestic response to a real effective exchange rate (first column), real stock price (second column) and real housing price shock (third column) in the United States . . . . . . . . . . . . . .

3.2 Domestic response to a real effective exchange rate (first column), real stock price (second column) and real housing price shock (third column) in the United Kingdom . . . . . . . . . . . . . . . . .

3.3 Domestic response to a real effective exchange rate (first column), real stock price (second column) and real housing price shock (third column) in France . . . . . . . . . . . . . . . . . . 52

3.4 Domestic response to a real effective exchange rate (first column) and real stock price shock (second column) in Germany . . . . . . 54

3.5 Domestic response to a real effective exchange rate (first column) and real stock price shock (second column) in Japan . . . . . . . 56

4.1 Stylized facts of international financial integration, 1980-2006 . . . 69

4.2 Current account and portfolio balance relationships . . . . . . . . . 80

4.3 Current account balance shock . . . . . . . . . . . . . . 84

4.4 Portfolio balance shock . . . . . . . . . . . . . . . . . 87

4.5 Current account balance and portfolio balance shocks . . . . . . . 89

5.1 Current account balances, USD billions . . . . . . . . . . . . 93

5.2 Simulation results for both scenarios . . . . . . . . . . . . . 101

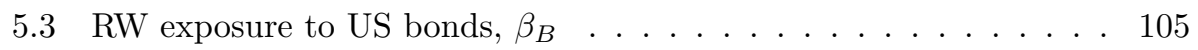

6.1 Current account (\% of GDP), 1992-2007 . . . . . . . . . . . 110 
6.2 Public net savings (\% of GDP), 1992-2007 . . . . . . . . . . . . . 112

6.3 Private net savings (\% of GDP), 1992-2007 . . . . . . . . . . . . 112

6.4 Private savings (\% of GDP), 1992-2007 . . . . . . . . . . . . 114

6.5 Private investment (\% of GDP), 1992-2007 . . . . . . . . . . . 114

6.6 Net foreign assets (\% of GDP), 1992-2007 . . . . . . . . . . . 116

6.7 Net factor income (\% of GDP), 1992-2007 . . . . . . . . . . . 117

6.8 Trade balance (\% of GDP), 1992-2007 . . . . . . . . . . . . 117

6.9 Net current transfers (\% of GDP), 1992-2007 . . . . . . . . . . . 118

6.10 Relative real GDP per capita (average $=100$ ), 1992-2007 . . . . . 120

6.11 Relative total factor productivity (average $=100$ ), 1992-2007 . . . 121

6.12 Producer price inflation, 1992-2007 . . . . . . . . . . . . . . 122

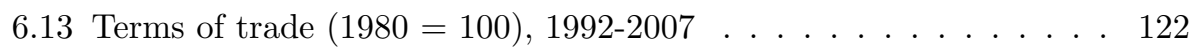




\section{1}

\section{INTRODUCTION}

\subsection{Motivation}

Try to imagine a world without a global financial system. For most of us it is impossible. Global financial markets have become a pervasive part of our lives: directly as we participate in financial markets by investing our savings, taking out loans or buying life insurance, but also indirectly through the close interrelations between financial and real markets. recently the unfolding of the current economic crisis that has its roots in the US subprime market provides evidence for the real effects of financial markets. We can read about financial markets in the press every day, often fueling negative sentiment and drawing a devastating picture of the global financial system. No doubts the merits of a global financial system have come under forceful attack recently.

Such a one-sided view is inappropriate, to state the least, and obscures the potential benefits of the globalization process. It shows however that a better understanding of the functioning of financial markets in general, and the interaction of financial and real markets in particular are key for the future welfare of the world economy. A balanced view on the opportunities and risks of financially integrated markets is warranted.

A contribution to this understanding is the aim of my doctoral dissertation entitled "The Wealth of Nations: Global imbalances and adjustments in a financially integrated world". The thesis consists of a collection of studies that address the far-reaching consequences of a global financial system for the new international macroeconomic order. The thesis includes both empirical and theoretical work. Each study deals with a seperate aspect of international financial integration, forms a self-contained chapter and can be read this way. Most of the chapters do not explicitly consider the current economic and financial crisis, but the obtained results also bear relevance for this period and can inform the current debate on policy implications.

To set the stage, we begin by reviewing the evolution and features of global financial markets and the increasing linkages between financial and real markets. 
The review provides further motivation and clarifies the aims of our research studies. We conclude with an overview of the structure of the dissertation.

\subsection{Global financial markets}

The financial system of today might be best understood as a global network in which national financial markets are growing together and borders are blurring. Of course, to date international financial markets remain partially fragmented for a variety of reasons - including political, cultural, and institutional backgrounds but progress towards a truly global financial market place is accelerating and the implications are certainly borderless. Financial markets have expanded greatly and evolved across borders in parallel to the rapid advance of information technologies since the 1990s. The process gained further momentum as financial account restrictions have been lifted and barriers to invest overseas are being dismantled. Today the opportunity set of anyone taking part in financial markets has increased along three important dimensions: (1) the diversity and volumes of financial instruments that are traded, (2) the geographical expansion of markets in which they are traded, and (3) the number and variety of players involved in these financial market transactions. We take a brief look at each dimension in turn.

Next to the more traditional foreign exchange, fixed-income and equity markets, we have witnessed an explosive growth in financial derivatives and other innovations over the past decade. Financial engineers have designed and created financial instruments according to the needs and risk positions of individual market participants. The sophistication and complexity of these instruments is staggering. Take as a prominent example mortgage-backed securities - the securitization of US subprime mortgage loans - and their role in the recent financial and economic crisis. To get a sense of magnitude, at the peak in 2007, the US had more than US-\$ 1,200 billion, or about 10 percent of US GDP, of asset-backed commercial paper outstanding (Bruinshoofd, 2009). Clearly, this kind of instrument facilitates the global diversification of local risk and serves as an important investment alternative in the fixed-income part of investor's portfolios. At the same time they are subject to heavy criticism as their complexity obscures the involved risk and the final bearer thereof.

In addition to the great diversification of financial instruments, we have observed a tremendous rise in their trading volumes and outstanding stocks. Financial markets have become deep and liquid. According to the BIS Triennial Central Bank Survey of Foreign Exchange and Derivatives Markets Activity, the daily turnover in the market for foreign exchange reached US-\$ 3.2 trillion in 2007, while a daily turnover of US-\$ 4.2 trillion was recorded in the over-the-counter 
market for interest and foreign exchange derivative contracts. Both constitute a liquidity increase of more than 70 percent compared to the previous survey in 2004. Equally impressive are the figures for the outstanding stocks of financial assets that provide for deep markets. Bearing in mind that worldwide GDP amounted to about US-\$ 52 trillion in 2007 , IMF and BIS data show that worldwide equity market capitalization reached US-\$ 44 trillion, or about 85 percent of worldwide GDP, and worldwide bond market capitalization US-\$72 trillion, or about 138 percent of worldwide GDP. The evolution of worldwide equity market capitalization is further shown in Figure 1.1. It combines information on changes in the amount and value of outstanding equity shares. In particular over the past decade, an explosion of equity market capitalization is evident, increasing from about US-\$ 15 trillion in 1997 to more than US-\$ 44 trillion in 2007. During the same time markets were highly volatile. At the end of the 1990s, equity markets culminated in the technology bubble, followed by its burst and plummeting stock prices in the early 2000s. The presented numbers on equity and bond market capitalizations are dwarfed as we turn to the new and growing markets for over-thecounter financial derivatives. The BIS reports that by the end of 2007 an amount of US-\$ 595 trillion were issued. This exceeds worldwide GDP by ten times. In this thesis we are dealing with the more traditional asset classes, bonds and equity in particular, as they comprise the majority of most household's financial asset wealth.

We analyze in Chapter 2 how changes in financial asset wealth impact on consumption risk-sharing. In Chapter 3 we empirically show how shocks to financial asset wealth are transmitted to the trade balance of a country. Also the portfolio-balance model that we develop in Chapters 4 and 5 includes such an international wealth channel in the dynamics of the current account balance.

The second dimension of the new opportunity set of financial market participants concerns the geography of international portfolio investment. The geography has changed fundamentally. It is now possible for investors to diversify their portfolios on a worldwide scale. Virtually any location is available as an investment destination. Moreover increasingly efficient communication technologies and international competition have lowered transaction costs and capital can cross borders free of regulatory constraints and government controls. Before the onset of financial globalization the international investment landscape was largely limited to the triumvirate of the US, Japan and Europe. Nowadays developing countries that previously belonged to the investment periphery provide attractive investment destinations. An important turning point in this process was certainly the Asian crisis in 1997 and the manner in which these countries quickly regained access to international capital markets. As a representative example of international financial integration we show in Figure 1.1 the share 
Figure 1.1: Total and foreign portfolio equity holdings, USD trillions

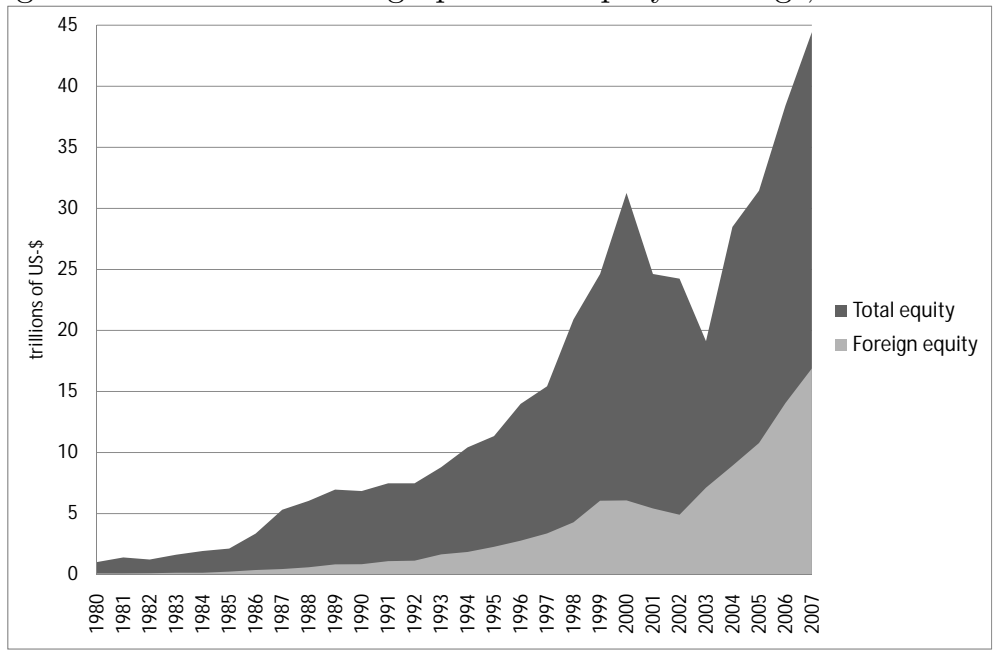

of worldwide equity capitalization that is held by investors abroad. In an absolute and relative sense we find that investment portfolios have grown across borders and investors increasingly realize the diversification potential that international capital markets have to offer. In 2007 more than one-third of worldwide equity market capitalization was held in foreign porfolios.

An alternative way to evaluate the extent to which investors make use of international capital markets is to look at the ratio of total foreign assets and liabilities relative to the GDP of countries. We show the evolution of these ratios for different groups of countries as stylized facts in Figure 4.1a of Chapter 4. The growth in private international asset trade is unprecedented, i.e. for OECD countries the ratio has increased almost sixfold since 1980 and stood at 3.73 in 2006. For small open economies the ratio was even substantially higher in 2007. IMF data for Ireland report a ratio of 25.73, 9.13 for Switzerland and 9.73 for the Netherlands. The UK with its financial center in London had a ratio of 9.33 in 2007. On the other hand we also find evidence that the Euro area and the US are relatively closed with ratios of 3.46 and 2.79 , respectively. The amount and geography of international portfolio investment are central aspects of this thesis.

In Chapter 2 we examine how equity investment in geographically relevant portfolios allows for the diversification of consumption risk. Chapter 3 considers the geography of portfolio investment as crucial for the transmission of asset price shocks within the international wealth channel. The particular situation of crossborder asset holdings in the Euro area is subject to an analysis in Chapter 6.

The third dimension concerns the number of new participants that have entered 
the international capital market. The group of market participants has expanded geographically, as discussed previously, but also within countries. The latter has taken place concomitantly to the proliferation of financial instruments. With low transaction costs and the great variety of financial products access to international capital markets is granted to investors independently of their financial stake. Today it is, for instance, easily possible for private portfolio investors to trade in the markets for commodities, oil or gold. Hence they can reap the benefits of global financial markets in the same way as institutional investors. This implies in return that more individuals and households are exposed to global financial markets - a consideration that is directly at the center of our analysis in Chapter 3 . In the same fashion, it is also easily possible for a growing number of governments and firms to hook up to the global network of financial markets to raise funds for their activities. We come back to this issue when we discuss the investment and savings behavior of private and public sectors in the Euro area in Chapter 6.

In summary, the process of international financial integration has enabled a growing number of individuals to trade a great variety of financial products across borders within instants. In the process the risk-return considerations of financial assets came to the fore. Access to international capital markets, the proliferation of financial instruments and the vast development of information technology are certainly the defining characteristics that set the current wave of financial globalization apart from its predecessors. Mentioning predecessors, it is interesting and informative to discover that the current openess of international capital markets is not unprecedented by historical standards. A short review provides some context for what we observe today.

Evaluating the evolution of international capital mobility over the past 150 years, Obstfeld and Taylor (2004) distinguish four time periods. Each coincides with the emergence of a distinct international monetary regime.

The first period relates to the classical gold standard and ended in 1914 with World War One. By the turn of the century the majority of countries had pegged their currency to gold, the resulting fixed-exchange rate regime was considered as a stable and credible regime such that a flourishing global market for capital emerged. First major technological advancements, an improving institutional frameworks and the absence of basically any capital controls had contributed to a first wave of financial globalization that is often placed on par with the current situation. Just before 1914, Britain, the most important country at that time, was exporting net savings of about 9 percent of GDP (Hirst and Thompson, 1996). This is exceptional also by current standards.

Thereafter, the second period from 1914 to 1945 covers both world wars and the period of the Great Depression. The world economy returned to autarky. The fixed-exchange rate mechanism of the gold standard was abolished during 
World War One. Its reconstructed postwar successor proved less resilient and was gradually abandoned until 1936. During this time monetary policy was governed by national goals and capital controls were reerected to guard against curreny crises and to protect gold (Eichengreen, 1992). Financial markets were local, not global during that time period.

The third period coincides with the Bretton Woods era and lasted from 1945 to 1971. Considering the devastating experience of floating exchange rates in the interwar period and the need for room for national monetary policies, the exchange rate regime under Bretton Woods was fixed, but allowed for occasional adjustments. As global trade in goods and services expanded rapidly in the 1960s, capital controls became increasingly difficult to maintain and most industrial countries retreated to floating exchange rates in 1973 (Bordo and Eichengreen, 2001). Financial markets remained relatively closed during that period. Capital flows were primarily allowed to pay for imports of goods and services

The fourth period is the post-Bretton Woods period of flexible exchange rates and lasts to this day. The dismissal of the Bretton Woods regime is often viewed as the starting point of the current process of financial globalization. Also it certainly holds that most momentum was not gained until the early 1990s.

Hence, in quantitative terms many countries already experienced periods of time in which their financial markets where comparatively open to foreign investors. It is rather that qualitative characteristics such as the proliferation of financial instruments define the current wave of financial integration.

\subsection{Global financial and real markets}

Global financial markets are of key importance for the proper functioning of economies. While a complete account of all functions is clearly beyond the scope of this introductory note, we will elaborate on those that are most prevalent for our own studies. Economic theory is very clear on the benefits of international financial asset trading: (1) the efficient allocation of capital spurs productivity and economic growth, and cross-border capital flows allow for (2) intertemporal and (3) intratemporal diversification of various types of risks. Although theory is clear, empirical studies that seek to substantiate these predictions find mixed results. Real benefits of international financial integration remain an intensely debated issue and no consensus has been reached whether risk or opportunities prevail. For an early discussion see Fischer (1998) and Summers (2000) as proponents and Bhagwati (1998) and Stiglitz (2002) as opponents of open capital markets. A more recent discussion is provided now.

Neoclassical theory predicts that international capital markets channel savings 
to their most productive use. In the process capital flows from rich and capital abundant to poor and capital deficient countries. It can be employed most efficiently there and generate the income that is necessary to repay the capital inflows eventually. The welfare of both country groups is enhanced and productivity and economic growth spurred in the latter. Comprehensive literature surveys by Eichengreen (2001) and Prasad et al. (2003) do not find empirical evidence indicating that international financial integration results in productivity and growth benefits through the direct channels emphasized by economic theory. Similarly, Kose et al. (2006, 2009) argue in a survey and study that growth benefits are more likely to be expected through indirect channels. Here access to international capital markets acts as a discipline device and promotes institutional quality, good government and corporate governance and efficieny gains among domestic firms.

In Chapters 4, 5 and 6 we show that stylized facts of international financial integration play havoc with theory-implied directions of capital flows. In Chapters 4 and 5 we discuss the empirical observation that in the aftermath of the Asian crisis in 1997 capital is flowing from developing Asian countries to the affluent US, mainly to finance consumption, not investment. A similar observation is made in our anaysis of the Euro area in Chapter 6. While capital is flowing from the relatively rich countries in the North to the South, the motives are not productive investment opportunites, but excessive consumption behavior.

The second and third benefits of international capital markets refer to the intertemporal and intratemporal diversification of risk. Intertemporal trade implies that households use capital markets to reallocate resources over time in order to raise efficiency and shield consumption streams from income fluctuations. In the face of a temporary fall in income, households can borrow on capital markets to maintain their consumption. The same mechanism is available on an aggregate level for the overall economy, in which case access to international capital markets is a prerequisite. A country hit by a temporary recession can borrow on international capital markets by running current account deficits that are repaid later as the business cycle picks up again. That implies with perfect financial integration there is no necessary link between domestic savings and investment as would prevail in closed economies. Since the early contribution of Feldstein and Horioka (1980) who documented a high savings-investment correlation for a group of OECD countries over the period 1960-1974, a vast literature has evolved that seeks to measure international capital mobility in that way. Surveys of this literature by Lapp (1996) and Coakley et al. (1998) show that the Feldstein-Horioka result has remained remarkably robust over time, indicating that international and economic integration is far from complete. Only recently the link between domestic savings and investment seems to deteriorate and large 
current account imbalances emerge (e.g. Kool and Keijzer, 2009).

Our analysis of the Euro area in Chapter 6 provides descriptive evidence of how a common market with strong financial and real links allows member countries decoupling of savings and investment decisions. Chapters 4 and 5 model current account imbalances of the US.

A basic function of international capital markets is to allow countries to pool their consumption risk, and thus to obtain a more efficient insurance than domestic capital markets have to offer. This brings us to the third benefit of global capital markets: the intratemporal diversification of consumption risks. Models with complete international financial markets, those that satisfy Arrow-Debreu conditions, show how countries can buy insurance against all future states of domestic output. For a textbook treatment of these models see Obstfeld and Rogoff (1996) or LeRoy and Werner (2001). As a result countries shield their consumption streams from fluctuations and worldwide consumption correlations should exceed output correlations. The lack of international consumption risksharing is subject to extensive empirical and theoretical research and commonly referred to as the consumption smoothing puzzle (e.g. Lewis, 1996, 1999, 2000; Obstfeld and Rogoff, 2001; Obstfeld, 2001). The puzzle is just another token by which the process of international economic and financial integration is shown to be underway, but not yet completed. Conceptually, the consumption smoothing puzzle and the corresponding literature is brought about by the so-called home bias in equity portfolios puzzles. Modern portfolio diversification theory and the international version of the CAPM find that the risk-return trade-off is optimal by investing in fully internationally diversified portfolios that resemble the world portfolio (Solnik, 1974). However empirical evidence shows that investor's equity portfolios remain largely biased towards domestic equity, see also Figure 1.1. Thus they do not reap the full potential of international capital markets.

Intratemporal diversification and the above mentioned puzzles are studied in Chapter 2 where we add a new dimension to the discussion - the relevance of the portfolio geography for the degree of consumption risk-sharing obtained. We also document that these puzzles appear to decrease in importance due to recent deveolpments in international financial integration. Additional literature is provided as well.

Clearly, international financial markets fulfill several important functions within economies and have contributed to their welfare during most of the time. The extent to which potential benefits of a global financial market place are shared-in differs over time, as the previous discussion shows, but also across countries. In particular the latter aspect is highly relevant for policy implications of international financial markets as the globalization process is often critized for exposing already vulnerable and less-developed countries to additional downside 
risks without having the option of securing the corresponding benefits. Important determinants in this respect are the governmental and institutional frameworks of countries. The Asian financial crisis of 1997 has provided a painful lessons of the vulnerability of financial systems that cannot build on strong institutions in the face of large capital inflows. Necessary prerequistes for developing countries to reap benefits of international financial markets are discussed in a rich literature, e.g. Prasad et al. (2003), Kose et al. (2007), Fratzscher and Imbs (2007), Meller (2009).

The process of financial integration cannot be viewed in isolation, instead it is part of an overall international economic integration process (Balassa, 1961). In the same way as cross-border trade in financial assets was facilitated by governments that dismantled capital controls and modern information technologies that lowered transaction costs, we observe an explosive increase in the international trade of goods and services that is brought about by the lifiting of tariffs and other impediments to trade, lower transportation costs and a growing industrial specialization (Imbs, 2004). There is consensus in the literature that both financial and real integration enforce each other (Portes and Rey, 2005; Aviat and Coeurdacier, 2007; Lane and Milesi-Ferretti, 2008). The world economy has become an integrated market place with a multitude of international transmission and propagation channels. We study one of these, the international wealth channel, in Chapter 3.

The most prominent example of financial and economic integration is certainly the common market of the European Union. The Euro area is additionally a unique example of monetary integration. Both show that international integration of financial and real markets necessitates and promotes political integration and coordination. It is the prerequisite for sustained peace and our future welfare.

\subsection{Structure of the dissertation}

The dissertation consists of an overall introduction to the research area and five chapters of self-contained studies. Each chapter provides an introduction and a literature review for the aspect of financial integration under study. Also individual conclusions are drawn. We aim at providing answers to both opportunities and risks of the international financial integration process. Although a clear cut is difficult, Chapters 2 and 3 are steered more towards the former, while Chapters 4 , 5 and 6 deal with the associated risks of sustainability issues.

Chapter 2 studies the consumption smoothing puzzle. Recent empirical work has shown that ongoing international financial integration facilitates cross-country consumption risk-sharing. While these studies typically employ absolute measures 
to account for a country's integration in international capital markets, we devise a relative measure that is motivated by the International Capital Asset Pricing Model (I-CAPM) literature. Our measure captures the composition of a country's international portfolio relative to the world portfolio, which all countries should optimally hold according to the I-CAPM. Using panel-data regression for a group of OECD countries during the financial globalization period 1980-2007, we show that the geography of international portfolios helps to explain the degree of consumption risk-sharing obtained.

Chapter 3 analyzes the empirical link between asset prices, consumption and the trade balance using a global macroeconometric model developed by Pesaran, Schuermann, and Weiner (2004). The model is estimated for 29 countries with quarterly data over the period 1981Q1 - 2006Q4. Motivated by increasing international financial and real integration, and pronounced cycles in stock and housing prices, we employ generalized impulse response functions for a group of five of the world's most industrialized countries and show that shocks to asset prices transmit into the trade balance. We refer to this transmission channel as the international wealth channel and find it to be present in the US, UK and, to a lesser extent, in France, but absent in Japan and Germany. More specifically, we find the international wealth channel at work as stock price changes are transmitted through consumption into the trade balance, whereas housing price changes appear to be transmitted through investment into the trade balance.

In Chapter 4 we derive a partial-equilibrium model to address the dynamics of macroeconomic imbalances. Unprecedented growth in private cross-border asset trade and asymmetric international balance sheets are well-documented stylized facts of financial integration. Moreover, we observe that current accounts are no longer the number one determinant of external balances. Advancing the work of Blanchard et al. (2005), this chapter develops a portfolio-balance model that recognizes these stylized facts and shows how they influence the joint dynamics of the current account, the exchange rate and relative asset prices. Calibrating the model to the US, we model the savings glut and US domestic policy arguments for causing US current account deficits and conclude that the combination of both seems to fit empirical findings best.

Chapter 5 continues the study of global external imbalances and examines associated sustainability issues. We employ and augment the portfolio-balance model of the previous chapter to provide model-induced answers to the question of what happens if foreign investors are no longer willing to accumulate low-interestbearing US treasury bonds and start reshuffling their international portfolio investments.

In Chapter 6 we turn our attention to the Euro area and document the growing dispersion of external and internal balances between countries in the North and 
South over the time period 1992 to 2007. We find a persistent divergence process that seems to have started with the introduction of the common currency and has its roots in the savings and investment behavior of private sectors. We dismiss the common argument in the literature that imbalances are the temporary outcome of an overall European economic convergence process and argue that future research should place greater emphasis on country heterogeneity in behavior to fully understand economic developments in the Euro area and to derive policy implications. The chapter is a descriptive analysis and concludes with directions for future research. 



\section{TAKING HOME BIAS SERIOUSLY: Absolute AND RElative MeAsures EXPLAINING CONSUMPTION RISK-SHARING}

\subsection{Introduction}

International financial integration has increased the investment opportunity set of financial investors fundamentally. Investors are no longer bound to domestic markets, but have access to international capital markets that allow a better hedging of their investment portfolios. (Lane and Milesi-Ferretti, 2001, 2003, 2007) show in a series of seminal papers that gross foreign asset and liability positions as a fraction of GDP for a group of OECD countries have grown almost fivefold over the past two decades and the composition of international balance sheets in terms of geographical allocation and currency denomination is highly heterogeneous.

This chapter explores the extent to which financial integration allows individuals to better hedge consumption risk across countries and over time. In answering this question we introduce a novel idea and view the geography of international portfolio investment as a decisive determinant.

Recent empirical research accumulates evidence on the outstanding role of foreign portfolio investment for international consumption risk-sharing (most notably Bracke and Schmitz, 2007; Fratzscher and Imbs, 2007; Sørensen et al., 2007; Artis and Hoffmann, 2008). These studies have in common that they all employ absolute measures to account for a country's integration in world capital markets. By emphasizing geographical diversification, we are the first to account for absolute and relative home bias in asset holdings. For a group of 23 OECD countries during the financial globalization period 1980-2007, we develop three measures that account for a country's overall portfolio equity wealth, 
its decomposition into domestic and foreign portfolio equity components and the degree of international diversification of the foreign component. These measures are consecutively included in a single panel regression framework. We begin by showing that the amount of a country's overall portfolio equity wealth matters for the degree of consumption risk-sharing obtained. Next we add the measure that accounts for the decomposition of a country's portfolio equity wealth into domestic and foreign portfolio equity components and find that conditional on a country's wealth its decomposition is equally relevant. The joint inclusion of these two determinants is novel, yet important. It allows studying their individual contributions to the amount of consumption risk that is shared. After all, a country with biased but large overall portfolio equity wealth is more likely to secure some risk-sharing relative to a country with tiny if unbiased overall portfolio equity wealth. Finally, the first two measures prepare the ground for the inclusion of our novel determinant - the geography of international portfolio equity investment. Conditional on a country's overall portfolio equity wealth and its decomposition into domestic and foreign components, we show that the diversification of the foreign component in geographically relevant markets bears additional relevance for consumption risk-sharing.

Conceptually, the derivation of our three measures builds on macroeconomic research into consumption home bias and financial research into asset home bias. The former concerns the correlation of consumption growth rates across countries. Models of complete international financial markets (Obstfeld and Rogoff, 1996; LeRoy and Werner, 2001) show how financial integration allows decoupling any idiosyncratic shock to domestic output from consumption decisions. In these models, countries can buy insurance against all future states of domestic output and thereby shield their income, and hence consumption, from fluctuations. If domestic output growth is outperfoming a world average, the insurance asks for premium payments, while it pays out in the reverse case. The insurance scheme is realized by cross-border trade in assets that constitute perpetual claims to each country's output stream. In our empirical analysis, a country's overall portfolio equity wealth aims at capturing the degree of financial market completeness. The measure is expressed relative to GDP.

Financial research into asset home bias centers around the theoretical predictions of the International Capital Asset Pricing model (I-CAPM) which holds in a fully integrated world as the international version of Sharpe's CAPM (Solnik, 1974). The I-CAPM predicts that investors maximize their risk-return trade-off by investing in identical international portfolios, which resemble the world portfolio. If not, they display so-called home bias. In our empirical analysis, we capture the idea of asset home bias with two measures.

First, we define an absolute home bias measure that splits each country's equity 
portfolio wealth into a domestic and foreign component. Their relative size is then compared to the size as implied by the I-CAPM, e.g. the relative size of the domestic equity market vis-à-vis the rest of the world (ROW). The absolute home bias measure is standard by now in empirical work. It was first developed by French and Poterba (1991) and subsequently applied, for instance, by Sørensen et al. (2007) and Bracke and Schmitz (2007).

Our second measure is novel. ${ }^{1}$ Next to the broad distinction between domestic and foreign investment, we develop a relative home bias measure that explains the geographic distribution of the international component of a country's portfolio equity wealth. Again, the predictions of the I-CAPM provide guidance in developing the measure. Research into the geography of foreign portfolio investment (e.g. Portes and Rey, 2005; De Santis, 2006; Lane and Milesi-Ferretti, 2008) has established a distance puzzle. These studies build on the gravity model literature and find that, accounting for economic masses through bilateral trade in goods and servives and stock market capitalization, there persists a general tendency of countries to refrain from investing in remote destinations. Instead countries prefer geographical proximity for their foreign investments, where cultural ties are strongest and information asymmetries lowest. Considering these findings, we entertain the strong suspicion that diversification in geographically relevant portfolios is equally important in unlocking the potential for consumption risk-sharing as international portfolio investment itself. We expect, for instance, that in 2005 Ireland's substantial 19.68 percent of foreign portfolio equity invested in the UK or Portugal's 21.99 percent invested in Spain provide less consumption risk-sharing than if the same shares were invested in a world portfolio. We elaborate that notion in this paper.

The rest of the chapter is organized as follows. Section 2.2 reviews two important branches of literature that are relevant for our study. Section 2.3 details the data sources, elaborates on the construction of our absolute and relative home bias measures and provides a first inspection. In Section 2.4, we carry out the empirical analysis and present our results. Section 2.5 elaborates on the robustness of our results and Section 2.6 concludes.

\subsection{Literature review}

This chapter is relevant to at least two strands of literature. It contributes to the discussion of the traditional consumption home bias literature as well as the more recent literature on the geography of international investment. Reviewing both

\footnotetext{
${ }^{1}$ Bekaert and Wang (2009) construct a similar measure to investigate determinants of home and foreign investment biases.
} 
strands provides motivation for our own approach.

Empirical studies on consumption home bias test the hypothesis that in the presence of complete financial markets, marginal utility growth is equated and consumption growth rates highly correlated across countries. Early research into correlation patterns points at the absence of international consumption risksharing - an empirical anomaly known as the consumption correlation puzzle or quantity anomaly (notably Backus et al., 1992; Obstfeld, 1994, 1995; Lewis, 1999). ${ }^{2}$ More recently, studies of international consumption risk-sharing interpret the hypothesis of perfect risk-sharing differently and seek to assess if consumption growth rates respond uniformly to aggregate, but not to country-specific output growth (Mace, 1991; Cochrane, 1991; Asdrubali et al., 1996; Sørensen and Yosha, 1998; Méliz and Zumer, 1999). This strand of empirical research takes the form of regression analysis, where perfect consumption risk-sharing is tested under the null hypothesis. Standard, by now, are regressions of idiosyncratic consumption growth on idiosyncratic output growth, where under the null hypothesis the $\beta$-coefficient is statistically indiscernible from zero, or else, can be read as the percentage deviation from the perfect risk-sharing case. Empirical results, to the extent that they coincide with the period of financial globalization, draw a more favorable picture, even though the lack of international consumption risk-sharing remains sizeable.

From here, empirical research directs its attention to the various channels through which consumption risk is shared and links it empirically to proceeding financial integration. Sørensen et al. (2007) document for a group of OECD countries a marked increase in international income and consumption risk-sharing associated with high levels of foreign portfolio equity and foreign direct investment. Fratzscher and Imbs (2007) extend the analysis to a bilateral context and confirm that intensity and composition (in terms of asset classes) of foreign assets are decisive determinants for the degree of risk-sharing between two countries. Kose et al. (2007) are most concerned with the apparent failure of developing countries to share in the benefits of financial integration. With a number of measures for financial openness (e.g. gross stocks and flows of foreign assets), they show that industrial countries are the main beneficiaries. Bracke and Schmitz (2007) refine the analysis by constructing a comprehensive dataset on capital gains on international portfolio equity holdings. They find that net foreign capital gains act in a countercyclical way and thus offer the desired insurance potential. The potential for risk-sharing is found to be increasing since the mid-1990s for industrial countries, while absent in emerging market economies.

\footnotetext{
${ }^{2}$ To reconcile empirical findings with theory, the benchmark model of perfect risk-sharing has been amended in several respects: (1) tradable versus nontradable goods (Lewis, 1996, 1999; Stockmann and Tesar, 1995), (2) market incompleteness (Kollmann, 1995; Shiller, 1993; Lewis, 1996), (3) transaction costs (Obstfeld, 2001). For an excellent survey see Kose et al. (2007).
} 
Artis and Hoffmann (2008) introduce a new aspect to the discussion - the time profile of consumption risk-sharing. They point out that consumption risksharing is a function of the structure of business cycles and that regression results are blurred by concurrent changes in them across countries. They account for transitory and persistent shocks to output and find that OECD countries are better able to insure against the former than the latter. Also Becker and Hoffmann (2006) and Leibrecht and Scharler (2008) evaluate international consumption risk-sharing in the short and the long run within a cointegrating panel vector autoregression framework. They come to similar results.

We employ a different methodology. This study ties in with the more recent empirical literature that accumulates evidence on the outstanding role of proceeding international financial integration for consumption-risk sharing. Hence, we also adopt the estimation strategy that is well-established in this strand of literature (Asdrubali et al., 1996; Méliz and Zumer, 1999; Sørensen and Yosha, 1998; Sørensen et al., 2007). In doing so, our research methodolgy neglects the literature on the time profile of consumption risk-sharing. To properly account for the time profile it requires data over an extended time horizon that stretches far before the period of financial integration. ${ }^{3}$ Moreover data on the potential determinants are only available for the more recent past. The focus in our study is on the potential determinants of consumption risk-sharing and our novel contribution to the literature is the examination of the geography of foreign portfolio investment for international consumption risk-sharing.

Drawing on the gravity model literature for international trade in goods, Lane and Milesi-Ferretti (2008) test an array of bilateral, host and source country characteristics to explain the structure of external equity portfolios for the year 2001. They show that underlying trade in goods and cultural and physical proximity are the key correlates for bilateral foreign equity holdings, e.g. all else equal, doubling physical distance reduces equity holdings by 61 percent. This constitutes a puzzle since investors should shift their portfolios to remote countries, as those countries usually provide better diversification potential due to less synchronous business cycles. Instead, Lane and Milesi-Ferretti (2008) find that investors seem to forego this potential by holding equity in destinations with similar business cycles (as measured by the correlation coefficient of GDP growth rates). Portes and Rey (2005) also build on gravity models and find that they perform at least as well in explaining asset trade as goods trade. According to their study, the size of asset markets in host and source countries, next to informational asymmetries, are the main determinants of gross transaction flows. They confirm the distance puzzle, but view distance as a proxy for informational

\footnotetext{
${ }^{3}$ Becker and Hoffmann (2006) and Artis and Hoffmann (2008) employ a data set that starts in 1960. Leibrecht and Scharler (2008) use data since 1951.
} 
asymmetries. Aviat and Coeurdacier (2007) directly address the study by Portes and Rey (2005) and find, not surprisingly, that the distance puzzle is drastically reduced once trade in goods is controlled for. They employ a simultaneous gravity equations framework and point out the complementarity of trade in goods and assets, e.g. all else equal, a 10 percent increase in bilateral goods trade raises bilateral asset holdings by 6 to 7 percent. The study by De Santis (2006) comes closest to ours by testing if investors trade assets as to reduce deviations from I-CAPM implied portfolio weights. The results are mixed. While bond flows seem to obey such diversification motives, they are absent for trade in portfolio equity.

\subsection{Data sources and home bias measures}

Our dataset comprises 23 OECD countries with annual data between 1980 and 2007. Data on GDP and private and public consumption are taken from the OECD Annual National Accounts database and are expressed in US-\$ at constant prices with base year 2000. To obtain per capita estimates, population data from the same source are used. In our study, we concentrate on country idiosyncratic shocks and thus define variables relative to a worldwide aggregate, which is approximated as the weighted sum of our sampled countries. Data for our portfolio equity wealth measure and the home bias measures are taken from various sources, including the International Monetary Fund's Coordinated Portfolio Investment Survey (CPIS) and International Financial Statistics (IFS), Datastream and the External Wealth of Nations Mark II (EWN II) dataset compiled by Lane and Milesi-Ferretti (2007). ${ }^{4}$

A number of influential studies have documented the tremendous growth in portfolio equity wealth owing to rapidly expanding equity markets over the past two decades. We define the measure of overall portfolio equity wealth as

$$
P E W_{i, t}=\frac{M C A P_{i, t}+F A_{i, t}-F L_{i, t}}{G D P_{i, t}}
$$

where $M C A P_{i, t}$ is the equity market capitalization of country $i, F A_{i, t}$ and $F L_{i, t}$ are country $i$ 's foreign asset and foreign liability holdings in portfolio equity, respectively. Data for $M C A P_{i, t}$ are retrieved from Datastream, and $F A_{i, t}$ and $F L_{i, t}$ are taken from the EWN II database and carefully updated with IFS data for recent years. The first two columns of Table 2.1 show the portfolio equity wealth measures for the years 1990 and 2005. Two characteristics stand out. The wealth measures, and therefore the potential for risk insurance, vary hugely across country, but are uniformly increasing over time. Countries like Mexico, Portugal

\footnotetext{
${ }^{4}$ We acknowledge the fact the CPIS data are possibly subject to measurement errors. Given that no comparable data source exists to date, it is the best data source available.
} 
and Greece with less mature and deep financial markets stand opposite to countries like Switzerland, the UK and Sweden with overall portfolio equity wealth positions exceeding GDP.

The past two decades not only experienced a pronounced increase in overall portfolio equity wealth, but also a concomitant decline in equity home bias (French and Poterba, 1991; Bracke and Schmitz, 2007; Sørensen et al., 2007). These studies define measures of equity home bias in an absolute way similar to

$$
\text { abs. } E H B_{i, t}=1-\frac{\frac{F A_{i, t}}{P E W_{i, t} G D P_{i, t}}}{1-\frac{M C A P_{i, t}}{M C A P_{w, t}}}
$$

where $F A_{i, t}, P E W_{i, t}$ and $M C A P_{i, t}$ are defined above and $M C A P_{w, t}$ is worldwide equity market capitalization. Important to note is that the absolute home bias measure relies on the wealth concept of our measure for overall portfolio equity wealth. This will ensure consistency in our empirical study. The absolute EHB measures, defined this way, take on values between zero and one. A value of zero implies the absence of equity home bias; the share of domestic equity in the investment portfolio is consistent with the relative size of the domestic to the world equity market. In contrast, a value of one implies that a country is exclusively invested at home.

Columns three and four of Table 2.1 show the absolute home bias measures for the years 1990 and 2005. It is apparent that financial globalization has changed the structure of portfolio equity wealth positions since its onset in the mid-1980s. All EHB coefficients, with the exception of Belgium and Mexico, are falling and it is not surprising that many small open economies like Austria, Norway, and foremost, the Netherlands lead the ranks of the most financially integrated economies. Nonetheless, an average coefficient of 0.56 for 2005 shows that investors' preferences are still tilted toward domestic portfolio equity and market integration remains far from perfect.

Next we define our relative EHB measure that assesses the geography of the international component of a country's portfolio equity wealth by comparing it to an empirical proxy of the world portfolio. The CPIS provides such information for the years from 2001 to 2007. It is the first and unique survey of its kind that records foreign portfolio equity and debt investment holdings for around 70 source and 240 host countries in a comprehensive and consistent way.

For our sample of 23 OECD countries, we are considering foreign portfolio equity holdings in 33 host countries - covering the destinations of about 98 percent of total foreign portfolio equity investments. The remainder is accounted for and grouped as $R O W$.

First we compute country individual world portfolios $\left(W P_{i}\right)$ as column vectors, 


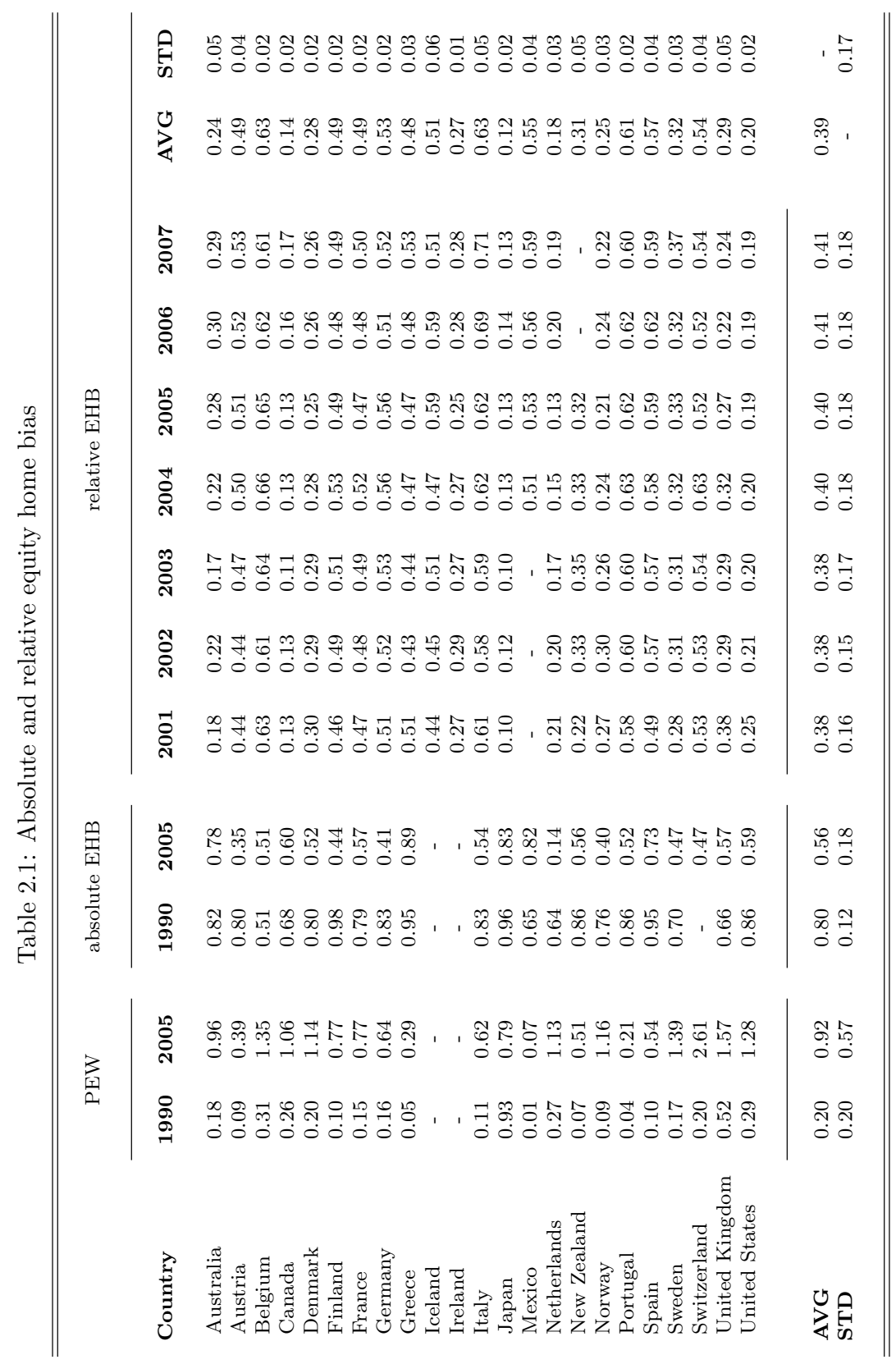


where each entry $w p_{i j, t}$ denotes the relative equity market size of our 33 considered host countries plus the remainder grouped as $R O W$ :

$$
W P_{i, t}=\left[\frac{M C A P_{1, t}}{M C A P_{w, t}-M C A P_{i, t}}, \ldots, \frac{M C A P_{R O W, t}}{M C A P_{w, t}-M C A P_{i, t}}\right]^{\prime} .
$$

Next we determine the actual allocation of the international component of a country's portfolio equity wealth $\left(I P E W_{i, t}\right)$ according to the CPIS data and obtain a column vector, where each entry $i p e w_{i j, t}$ denotes the share of total foreign equity allocated to the 33 host countries and $R O W$ :

$$
I P E W_{i, t}=\left[\frac{F E_{1, t}}{T F E_{i, t}}, \ldots, \frac{F E_{33, t}}{T F E_{i, t}}, \frac{F E_{R O W, t}}{T F E_{i, t}}\right]^{\prime} .
$$

$F E_{j, t}$ is foreign portfolio equity held in host country $j$ and $T F E_{i, t}$ is total foreign portfolio equity of country $i .^{5}$ Finally, we determine absolute over- and underinvestments according to the international CAPM and sum them over all 33 host countries and $R O W$ :

$$
\text { rel. } E H B_{i, t}=\frac{1}{2} \sum_{j=1}^{33+1}\left|w p_{i j, t}-i p e w_{i j, t}\right|
$$

The relative home bias measure as defined in (2.5) is bounded between zero and one. A value of zero implies that a country's international portfolio is a one-to-one replicate of the world portfolio, whereas the measure approaches one, the more idiosyncratic a country's investment strategy becomes. The right panel of Table 2.1 reports the relative EHB of all countries in our sample for the years 2001 to 2007. A number of characteristics are worth mentioning. They are important for the application of the relative EHB measure in our empirical study that follows. First, we observe a high dispersion of relative EHB measures across countries with many countries joining the ranks of Japan (e.g. Canada, the Netherlands) and Italy (e.g Belgium, Portugal) - our polar cases with average measures of 0.12 and 0.63 , respectively. The high dispersion across countries is also reflected in the standard deviation of the relative EHB measure. It varies between 0.15 and 0.18 for the years 2001 to 2007. Second, the relative EHB measures for each country appear to be time invariant. This can be seen from the standard deviations in the last column of Table 2.1, which only range from 0.01 to 0.06 . Moreover an ANOVA test fails to reject the null hypothesis of time invariant average relative

\footnotetext{
${ }^{5}$ Note that total foreign portfolio equity, $F A_{i, t}$, in (2.1) and (2.2) is quantitatively not the same as total foreign portfolio equity $T F E_{i, t}$, in (2.4). The former is sourced from IFS and EWN II databases, while the latter uses data from the CPIS.
} 
EHB measures. ${ }^{6}$ The time invariance of the relative EHB measure is further supported by the literature on the geography of international portfolio investment which find that cultural and physical proximity are key correlates, both being time invariant (Portes and Rey, 2005; Lane and Milesi-Ferretti, 2008). Third, we notice a remarkable pattern across countries that is of interest from an institutional point of view. Most Scandinavian and Anglo-Saxon countries, but also Japan and the Netherlands, do better in diversifying their foreign portfolio equity - their relative EHB measures are mostly below the overall average of 0.39 .

\subsection{Consumption risk-sharing}

Our estimation strategy proceeds in several steps. All estimations are carried out for two time horizons, the entire time period 1980-2007 and the more recent subperiod 1990-2007. It is often argued that cross-border portfolio investment accelerated only in the 1990s such that assuming a stable relationship back to 1980 is not warranted. Estimation results for both periods provide further insights. ${ }^{7}$ Moreover we understand consumption as either private consumption or the sum of private and public consumption as defined by the OECD Annual National Accounts database. Testing both consumption definitions is our answer to the dichotomy in past research. In addition, it serves as a robustness check for our own results and allows drawing conclusions about the role that governments play in smoothing consumption. We start with panel-data regressions of the form

$$
\Delta \log C_{i t}-\Delta \log C_{t}=\alpha+\beta\left(\Delta \log G D P_{i t}-\Delta \log G D P_{t}\right)+v_{i t}
$$

where the disturbance $v_{i t}$ is specified as the one-way error component model with a country-specific effect and a stochastic error term. All estimations are performed as weighted least squares to allow for cross-country heteroskedasticity in our data set. That is the model is estimated by ordinary least squared in the first stage and each cross-section weighted by the inverse of the standard deviation of the resiudals in the second stage. The estimation procedure is adopted from Sørensen et al. (2007). The $\beta$-coefficient measures the co-movement between idiosyncratic GDP and idiosyncratic consumption. Considering idiosyncratic variables is necessary in our analysis as even in the perfect risk-sharing case individuals cannot insure against fluctuations in aggregate output. In the perfect risk-sharing case the coefficient is equal to zero such that consumption decisions are decoupled from

\footnotetext{
${ }^{6}$ The corresponding F-statistic of the ANOVA test is 0.15 , which yields a probability of greater than 0.99 .

${ }^{7}$ Estimation results for the earlier subperiod 1980-1989 are available from the authors upon request. They are not central for our analysis and have been omitted for expositional matters.
} 
current output levels.

Next, we allow for slope heterogeneity by consecutively augmenting the $\beta$ coefficient in (2.6) with interaction terms. We start with the measure for portfolio equity wealth by imposing the following structure

$$
\beta=\beta_{0}+\beta_{1}\left(P E W_{i t}-\overline{P E W}\right)
$$

where the measure enters in deviation to an (un-weighted) average across countries and time to ease the interpretation. A country with an average overall portfolio equity wealth position will experience consumption risk-sharing according to the coefficient $\beta_{0}$. Since the portfolio equity wealth measure captures a country's degree of financial market completeness, we expect the coefficient $\beta_{1}$ to be negative. The size of the overall portfolio equity wealth is assumed to matter, regardless whether it is invested domestically or abroad. Both investments provide consumption risk insurance.

Next, we further augment the coefficient structure in (2.7) by adding the measure for absolute EHB. We obtain

$$
\beta=\beta_{0}+\beta_{1}\left(P E W_{i t}-\overline{P E W}\right)+\beta_{2}\left(a b s . E H B_{i t}-a b s . \overline{E H B}\right) .
$$

with an absolute EHB measure in deviation to an (un-weighted) average across countries and time. The inclusion of a volume-based wealth measure and its decomposition into domestic and foreign components in a single consumption risk-sharing regression is novel. Past research employed either volume-based measures of different classes of foreign asset and liability holdings (Sørensen et al., 2007; Kose et al., 2007; Fratzscher and Imbs, 2007; Bracke and Schmitz, 2007) or decomposition measures like our absolute EHB measure (French and Poterba, 1991; Sørensen et al., 2007). We argue that only the joint inclusion in a consumption risk-sharing framework is able to single out the ceteris paribus contributions of the two measures. We expect $\beta_{2}$ to have a positive sign. That is consumption risk-sharing is reduced (for a given level of portfolio equity wealth) if countries exhibit above-average equity home bias measures.

Finally, we test our initial suspicion that diversification of international portfolio equity wealth is a decisive determinant of consumption risk-sharing. Many authors have pointed at the potential role of investment geography, yet we are the first to substantiate the assertion by imposing

$$
\begin{aligned}
\beta & =\beta_{0}+\beta_{1}\left(P E W_{i t}-\overline{P E W}\right)+\beta_{2}\left(a b s . E H B_{i t}-a b s . \overline{E H B}\right) \\
& +\beta_{3}\left(\text { rel.EHB } B_{i}-\text { rel. } \overline{E H B}\right)
\end{aligned}
$$


on the consumption risk-sharing coefficient $\beta$. Lane and Milesi-Ferretti (2008) state for instance that "the geography of investment positions also heavily shapes international risk-sharing pattern". The use of our relative EHB measures is driven by the availability of the underlying data. Since information on the geography of portfolio investment is only available for the years 2001 to 2007, we focus on the cross-country dimension and work with time invariant measures. They are obtained as averages over the period 2001-2007. This is a limitation of our study, but evidence in Table 2.1 suggests that most information in the relative EHB measures stem from the cross-country dimension and a time-invariant treatment is warranted. Again we employ the relative home bias measures as deviation from cross-country averages and expect the corresponding coefficient $\beta_{3}$ to have a positive sign, i.e. for a given level of portfolio equity wealth and a given share invested abroad countries that pursue a more idiosyncratic international investment strategy will experience less consumption risk-sharing.

Table 2.2 presents our results. The upper panel gives the regression results for the more recent subperiod 1990-2007 and the lower panel for the entire data period 1980-2007, respectively. Our results for the standard risk-sharing regressions in Eq. (2.6) confirm past research. We find values for the $\beta$-coefficient that are high and significantly different from zero. Considering the recent data period, we obtain a value of 0.83 for the narrow definition of consumption, suggesting that consumption risk-sharing is far from perfect. The value of the $\beta$-coefficient is lower (0.70), when we consider the sum of public and private consumption in our regressions. Governments use fiscal policies to contribute to smoothing of overall consumption. Considering the entire data period, we find consumption risk-sharing to be marginally lower for both the narrow and broad consumption definitions.

All coefficients of the portfolio equity wealth and absolute and relative home bias measures enter with correct signs and are statistically significant at the conventional levels. It is remarkable to note that the magnitude and statistical significance of the coefficients of the individual interaction terms remain relatively stable as we proceed in our estimations from (2.7) to (2.9). We interpret this as evidence that all three measures convey distinct information about a country's ability to share in consumption risk. It proves, in particular, our earlier suspicion that the geography of international investment conveys information in explaining consumption risk-sharing that is distinct from information about the absolute integration in international financial markets. Comparing both time periods and consumption definitions, we notice the increased importance of relative and absolute EHB in explaining consumption risk-sharing in the more recent subperiod for the narrow consumption definition. In (2.9) and for private consumption, the coefficients on absolute and relative EHB increase from 0.17 to 0.66 and 0.32 


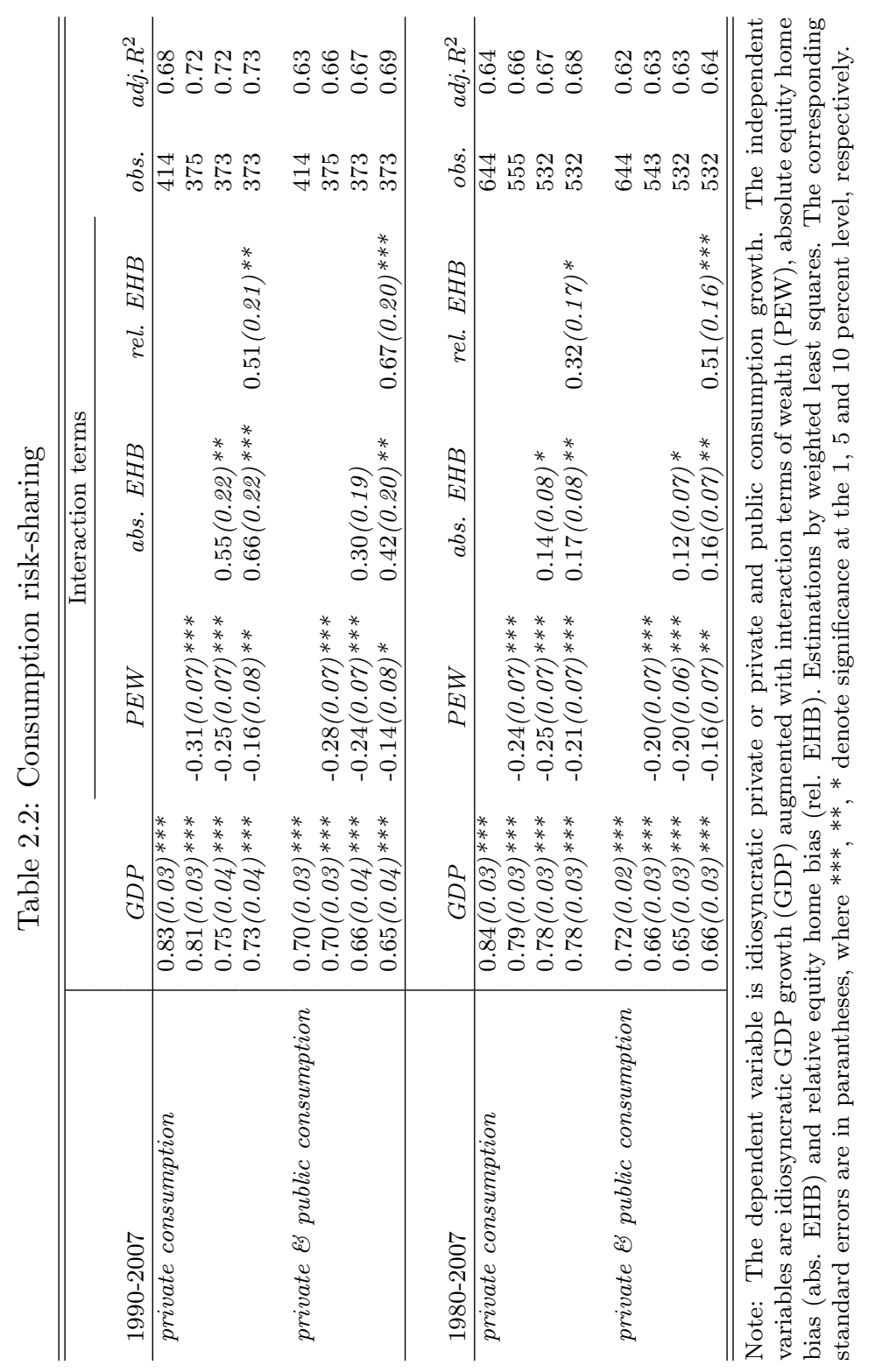


to 0.51 , respectively. Moreover, absolute and relative EHB measures provide more precise information for consumption risk-sharing as their increased statistical significance and a higher adjusted- $\mathrm{R}^{2}$ level indicate.

\subsection{Robustness of panel-data regressions}

An obvious limitation of our study is the time-invariant inclusion of the relative EHB measure in the regression framework above. Given that data on the geography of portfolio investment are only available for recent years, we believe that Table 2.1 provides convincing evidence that most information is contained in the cross-section of the data and a time-invariant treatment is warranted for the time being. A final conclusion about the role of international diversification for consumption risk-sharing can only be drawn once data over a longer time horizon are available. To further verify that the results obtained from time-invariant relative EHB measures are credible, we also examine their time-varying treatment by estimating all regressions over the time period 2001-2007. We find that all three measures exhibit individually the correct sign and are statistically significant at conventional levels. However their joint inclusion leads to diminishing statistical significance, which we attribute to the limited number of observations over the reduced time period. They are insufficient to discriminate the idiosyncratic effects of all three measures on consumption risk-sharing.

The regression specifications of the consumption risk-sharing estimations in (2.6) to (2.9) are adopted from earlier work by Asdrubali et al. (1996), Méliz and Zumer (1999), Sørensen and Yosha (1998) and Sørensen et al. (2007). We have additionally included time trends as interaction terms in the estimations to account for developments in international capital markets, other than captured by our downward trending home bias measures, that might spuriously influence the sharing of consumption risk. They turned out to be statistically insignificant and changed the results hardly. We have dropped them from our panel-data regressions and in the exhibition of the results in Table 2.2. They are still included in an earlier working paper version of this chapter. ${ }^{8}$

Finally we deal with the issue of cross-sectional dependence in the error terms that may result from the presence of common shocks and components. Proceeding financial and economic integration make the case for cross-country interdependencies in panel estimations. In the presence of unobserved common factors that are uncorrelated with the included regressors, our fixed-effects estimator remains consistent, but not efficient, and the estimated standard errors are biased, if they are correlated with the included regressor, the fixed-effects

\footnotetext{
${ }^{8}$ See Meteor Research Memorandum 08/25.
} 
estimator will be biased and inconsistent (de Hoyos and Sarafidis, 2006). We conduct two tests for cross-sectional dependence in our data sample that are proposed in the literature by Pesaran (2004) and Friedman (1937). Both tests do not provide for conclusive evidence. Depending on the model specification the test by Pesaran (2004) finds mixed results for the presence of cross-sectional dependence, while the test by Friedman (1937) predominantly accepts the null hypothesis of no cross-sectional dependence. The dichotomy in these results might be attributable to the small sample period that we are considering. For the time being, we do not abandon our estimation framework, but acknowledge that the case of cross-sectional dependence will become more relevant as financial integration proceeds further and data over a longer time horizon become available.

\subsection{Conclusion}

The main goal of this study is the inclusion of the geography of international portfolio holdings into the discussion of international consumption risk-sharing. Many authors have pointed at the potential role of investment geography, but, to our knowledge, we are the first to empirically test the assertion and take it to the data. In this respect, our paper brings together the literature on the geography of portfolio investments and international consumption risk-sharing. We find that asymmetries in international portfolio investment positions are reflected in the ability of economies to share in consumption risk via international financial markets. This holds true even after controlling for a country's overall portfolio equity wealth position and its absolute integration in international financial markets. Hence, we argue that there are conceptually two different channels through which financial integration enhances consumption risk-sharing: the first concerns the question of how much is being invested abroad, while the second channel recognizes the destinations of international portfolio investments. The first channel is well-documented in the literature, whereas the second needs further investigations in the future once more data are available. Our relative home bias measures is a first innovation in this direction and shows that it is an important research avenue. Addressing both channels jointly, helps us in understanding the degree of consumption risk-sharing obtained. 



\section{THE INTERNATIONAL WEALTH CHANNEL: A GLOBAL ERROR-CORRECTING ANALYSIS}

\subsection{Introduction}

Households in the 1990s have witnessed substantial movements in their financial wealth, mainly owing to price changes in domestic and international stock markets. Over this decade, US and Scandinavian stock prices more than doubled in real terms, while many European countries experienced only moderate increases, and Asian countries, inflicted by the financial crisis in 1997, even saw considerable stock price decreases. At the end of the 1990s, stock markets culminated in the technology bubble, followed by its burst and plummeting stock prices in the early 2000s. Later, a remarkable and prolonged rebound set in which lasted until the unfolding of the current economic crises in the US. As stock market wealth comprises the majority of most household's financial assets, housing wealth generally comprises the majority of non-financial assets. Although most countries shared a marked and almost exponential increase in housing prices over the past ten years, housing wealth was also exposed to country-specific cycles. ${ }^{1}$

Much research emanates from this background and pursues the question of how these pronounced swings in financial and non-financial household wealth affect consumption decisions. This question refers to the so-called consumptionwealth effect, which is theoretically motivated by Friedman's (1957) work on the consumption function and Modigliani's and Brumberg's (1954) life cycle consumption hypothesis. Empirical work on quantifying the impact of wealth on consumption dates back to the early contribution of Ando and Modigliani (1963)

\footnotetext{
${ }^{1}$ A notable exception is Switzerland, which experienced a stagnating housing market prior to the subprime mortgage crisis.
} 
and has generated much interest among academics and policymakers thereafter. ${ }^{2}$

The objective of the present paper is to expand on the notion of the consumption-wealth effect and to ask the question of how changes in financial and non-financial household wealth transmit into trade balances. Considering the process of international integration of financial and real markets, we have all reasons to believe that changes in stock and housing prices transmit into countries' decisions on importing and exporting goods and services. We refer to the channel where asset price movements are transmitted to the trade balance as the international wealth channel. Its existence is investigated for a group of five of the world's most industrialized economies (G5) - the US, UK, Japan, Germany and France. We are particularly interested in studying the relative strength of the international wealth channel and test whether or not it can emerge as a potent alternative to the traditional exchange rate channel in correcting global current account imbalances.

Real and financial integration warrant an international perspective for our study. Real integration, for instance the removal of barriers in trade of goods and services, brings about changes in aggregate consumption and investment decisions that impact not only the given country's trade balance, but also those of its trading partner. In addition, financial integration implies that countries hold a considerable share of their aggregate wealth in foreign assets. In 2006 one-third of worldwide equity market capitalization was owned by foreign investors. Similarly, mortgage securitization allows investors to easily participate in foreign housing markets without actually owning property. All this bears the consequence, that, if stock or housing prices move in one country, it will affect the configuration of wealth positions across borders. In order to account properly for this new macroeconomic order, we base our empirical study of the international wealth channel on the global vector autoregression (GVAR) model introduced by Pesaran et al. (2004) - hereafter PSW - and advanced in Dees et al. (2007). Following PSW, we first capture the impact of movements in stock market and housing wealth on the trade balance by estimating country-individual vector error-correcting models (VECM). In addition to relevant domestic variables, we include the corresponding weakly-exogenous, trade-weighted foreign variables in these models. They fulfill two purposes: first, they proxy global unobserved common factors that serve as important international transmission channels, and second, they allow simultaneously solving the country-specific VECMs into an error-correcting GVAR representation. We proceed accordingly and first estimate a total of 29 countryspecific VECMs with data at quarterly frequency over the time period 1981Q1 to 2006Q4. The models cover all countries and regions that figure prominently in

\footnotetext{
${ }^{2}$ For a comprehensive review of preceding studies on the domestic wealth effect, see Poterba (2000).
} 
Table 3.1: Countries and regions in the model

\begin{tabular}{llll}
\hline \hline Country & Country code & Country & Country code \\
\hline United States & USA & Other OECD & \\
China & CHN & Australia & AUS \\
India & IND & Canada & CAN \\
Japan & JPN & Mexico & MEX \\
& & New Zealand & NZL \\
Europe & & & \\
Austria & AUT & South-East Asia & \\
Belgium & BEL & Indonesia & IDN \\
Denmark & DNK & Korea & KOR \\
Finland & FIN & Malaysia & MYS \\
France & FRA & Philippines & PHL \\
Germany & DEU & Singapore & SGP \\
Italy & ITA & Thailand & THA \\
Luxembourg & LUX & & \\
Netherlands & NLD & Oil & \\
Norway & NOR & Saudi Arabia & SAU \\
Spain & ESP & & \\
Sweden & SWE & & \\
Switzerland & CHE & & \\
United Kingdom & GBR & & \\
\hline
\end{tabular}

the current debate on global imbalances - the US, China, Europe, Asia and oilexporting countries. A complete list of the included countries is presented in Table 3.1. Next, we combine the country-individual models into a single error-correcting GVAR which allows studying the international wealth channel with an explicit account of the complex international transmission structure of an integrated world economy. To date, empirical evidence on the international wealth channel is scarce. Despite the potential importance of asset prices for international trade balance positions, we are aware of only one previous study that addresses the issue. Fratzscher et al. (2007) investigate the relative importance of stock market and housing prices for the US current account. ${ }^{3}$ Using a Bayesian structural vector autoregressive model, they find that asset prices account for up to 32 percent of movements of the US trade balance, while real exchange rates explain only around 7 percent and at shorter horizons. Their results suggest that the international wealth channel exerts considerable influence on the external adjustment process of the US. To account for the international dimension, they define US variables in differences to a proxy for the rest of the world. Our empirical methodology is therefore much more comprehensive than the one by Fratzscher et al. (2007). Instead of leaving the rest of the world unmodeled, our GVAR methodology explicitly accounts for the rest of the world by means of the 29 country models. Considering, for instance, a shock to US asset markets, our international wealth

\footnotetext{
${ }^{3}$ See Fratzscher and Straub (2009) for a more recent application.
} 
channel allows for the possibility that the shock translates into the asset markets, and subsequently consumption and investment decisions, of the other 28 countries from where it potentially feeds back into the US trade balance.

To preview the results, our main findings are: first, movements in the real effective exchange rate affect consumption decisions only in the US. This points at the prominent role that the foreign sector plays for US consumption. Second, the international wealth channel, following a shock to domestic real stock prices, can not be generalized. It is at work in the US, UK and, to a lesser extent, in France but cannot be confirmed for Germany and Japan. Third, we observe an improving trade balance in the US, UK and France, following a negative shock to domestic real housing prices. It seems, however, that movements in housing prices do not transmit to the trade balance through consumption decisions but are possibly induced by business and private expenditures on investments. Fourth, domestic stock and housing prices exert at least as much influence on the trade balance as the real effective exchange rate does.

The rest of the paper is organized as follows. Section 3.2 discusses the theory on the international wealth channel. Next, Section 3.3 sets out the empirical setup and the data series that we have used. Section 3.4 analyzes the dynamic properties of our model by means of impulse response functions, while Section 3.5 shows the corresponding forecast error variance decomposition. In Section 3.6 we expose our models to stability tests. Section 3.7 concludes.

\subsection{The international wealth channel}

There are many different mechanisms through which fluctuations in international asset prices transmit into the trade balance of countries. We summarize all of them in our notion of the international wealth channel, but seek to identify the exact transmission mechanisms whenever possible. Two, potentially, important transmission routes work through the consumption and investment behavior of households and firms. We will review them shortly.

The transmission through consumption decisions of households refers to the above-mentioned consumption-wealth effect. We will explicitly account for it in our empirical investigation. The consumption-wealth effect states that households consume out of their discounted value of total lifetime resources. That is, they smooth consumption over their life span by borrowing against future income when they are young, accumulating wealth during working age through saving and running down their wealth in retirement. Hence, any unexpected change in household wealth that is perceived as permanent will trigger households to adjust their consumption plans by a fraction of this change in wealth. The marginal 
propensity to consume out of different forms of household wealth is ultimately an empirical issue and it has been found to be larger if the asset meets one or more of the following criteria: (1) the asset is liquid, (2) its value is easy to determine, (3) it is deemed appropriate to finance consumption and (4) the price change is considered to be permanent and certain.

Considering these criteria, it is not clear a priori if consumption, and hence trade balances, are more responsive to changes in stock market or housing wealth. The first three criteria seem more applicable to stock market wealth (although mortgage deregulations make it increasingly possible to extract wealth from houses), while the last criterion is more applicable to housing wealth. A number of recent empirical studies on the domestic wealth effect find mixed evidence.

Ludvigson and Steindel (1999) and Mehra (2001) employ cointegration techniques to study the domestic wealth effect in the US with quarterly data over the time periods 1953 to 1997 and 1959 to 2000, respectively. They both arrive at the result that a dollar increase in wealth leads to a 3 to 5 percent increase in aggregate consumption. Moreover, Ludvigson and Steindel (1999) emphasize that the impact of movements in wealth appear to affect consumption contemporaneously and not with a lag. Lettau and Ludvigson (2001, 2004) argue in their studies that the linkage between wealth and consumption cannot be understood without distinguishing between permanent and transitory movements. Using a cointegration framework that allows discriminating permanent from transitory behaviour, they find for the US that only permanent movements in wealth affect aggregate consumption in the range of the aforementioned 3 to 5 percent. Case et al. (2005) extend the analysis to a panel of 14 countries and distinguish between stock market and housing wealth. They find at best a weak effect of stock market wealth on consumption, but strong evidence of a housing wealth effect. The estimated marginal propensity to consume out of housing wealth ranges between 11 to 14 percent. On the other hand, Ludwig and Sløk (2004) find no clear evidence that the responsiveness of consumption differs between changes in stock market and housing wealth for a panel of 16 OECD countries. However, they report that the structure of the financial system and the time period considered are decisive determinants for the estimated marginal propensity to consume out of wealth. Economies with market-based financial systems report on average higher marginal propensities than economies with bank-based financial systems. Moreover, the marginal propensity is found to be higher in the period between 1985 to 2000 as compared to the earlier years between 1960 to 1984 .

The second important channel through which asset prices transmit to the trade balance of a country is business and private expenditures on investment. We do not explicitly include investment in the empirical framework, but recognize its role in the interpretation of our results. The theoretical roots of this alternative 
are based on Tobin's q-theory of business investment. It posits that firms find it worthwhile to invest in their capital stock in bullish asset markets as the ratio between the market value and the replacement value of its capital stock increases (Tobin, 1969). Moreover the financing of business investment is facilitated during these times. Also, the $q$-theory can be generalized to private housing investment and explain how shocks to real housing prices transmit to the trade balance without affecting consumption decisions.

\subsection{Constructing the GVAR model}

In this section, we first motivate the variables that are included in the countryindividual models and discuss data considerations. Next we briefly outline the GVAR methodology and then address a number of issues surrounding the proper fitting of the models to the data generating process. ${ }^{4}$ The GVAR methodology is sometimes criticized for being a sort of black box given the many modeling choices that need to be made. We test the robustness of our results over alternative choices and proceed with the most robust version. Whenever the results hinge crucially on a modeling decision we shall point that out. ${ }^{5}$

\subsubsection{Variable selection and data considerations}

The inclusion of variables in the country-individual models is guided by simple aggregate demand functions of open economy models. ${ }^{6}$ Moreover, we subject the models to a number of specification tests to ensure reliable inference on all included variables. We consider the following $k_{i} \times 1$ vector of endogenous variables,

$$
\mathbf{y}_{i t}=\left[\begin{array}{lllllllll}
t b_{i t} & r c_{i t} & r y_{i t} & r e e r_{i t} & r s_{i t} & r h_{i t} & r_{i t}^{s} & r_{i t}^{l} & p_{i t}^{o i l}
\end{array}\right]^{\prime} .^{7}
$$

for the country-individual VECM, $i$. The trade balance $\left(t b_{i t}\right)$ is defined as the log of exports over imports; real consumption $\left(r c_{i t}\right)$ is the log of household consumption deflated by the consumer price index; real gross domestic product $\left(r y_{i t}\right)$ is the log of nominal gross domestic product deflated by the consumer price index; the real effective exchange rate $\left(\right.$ reer $\left._{i t}\right)$ is expressed in logs; real stock market prices $\left(r s_{i t}\right)$ are the $\log$ of a broad stock market index deflated by the consumer price

\footnotetext{
${ }^{4}$ For a full exposition of the GVAR methodology, we refer the interested reader to Pesaran et al. (2004) and Dees et al. (2007).

${ }^{5}$ The estimations are based on the GAUSS code of L. Vanessa Smith (2006).

${ }^{6}$ See for instance, Obstfeld and Rogoff (1996) or Sørensen and Whitta-Jacobsen (2005) for a textbook treatment.

${ }^{7}$ Depending on the availability of data, we include fewer variables in some country models. See the Appendix for data availability and sources.
} 
index; real housing prices $\left(r h_{i t}\right)$ are the log of a housing price index deflated by the consumer price index; the short term real interest rate $\left(r_{i t}^{s}\right)$ is the log of a threemonth money market rate deflated by the consumer price index and adjusted for quarterly frequency and the real long term interest rate $\left(r_{i t}^{l}\right)$ is the log of the rate on ten-year government bonds deflated by the consumer price index and adjusted for quarterly frequency.

A notable exception constitutes the treatment of the oil price $\left(p_{i t}^{\text {oil }}\right)$, which controls for global political events as an observable common factor to all countries in our sample. Despite the growing importance of other regions in the world, we follow Dees et al. (2007) and include $p_{i t}^{\text {oil }}$ as an endogenous variable only in the US model, while retaining it as weakly-exogenous in all other country models.

Note that we include $r y_{i t}$ and $r c_{i t}$ in the country models. We see at least two reasons for the inclusion of both. First, it allows for careful study of the various transmission channels of shocks to asset prices and the exchange rate, e.g. we are able to observe how savings - the difference between $r y_{i t}$ and $r c_{i t}$ - react to these shocks. Second, we seek to get a grip on the often leveled criticism that the observed wealth effect is spurious. Poterba and Samwick (1995) argue for instance that observed correlations between asset prices and consumption stem from the fact that asset prices convey information about future income growth.

Movements in financial and non-financial household wealth are captured by $r s_{i t}$ and $r h_{i t}$, respectively. The use of price indices as proxies for household wealth can be viewed as a limitation of our analysis, but studies by Ludwig and Sløk (2004) and Fratzscher et al. (2007) confirm that differences to volume based proxies for wealth are immaterial in estimations. Moreover, price indices allow exploiting the quarterly frequency at which these data are available.

In the academic debate about causes and solutions to recent global current account imbalances, common arguments include necessary exchange rate adjustments (Blanchard et al., 2005) and relative output growth rates due to productivity differentials (Corsetti et al., 2008; Bems et al., 2007). We control for these arguments with the variables reer $_{i t}$ and $r y_{i t}$.

Moreover, we decided to include $r_{i t}^{s}$ and $r_{i t}^{l}$ in the country models since specification tests show their importance for a sound modeling of stock market and housing prices. Additionally, by including both we allow for possible effects of bond markets.

In order to link the individual country-models and create international transmission channels, we match the domestic variables with trade-weighted foreign variables. The foreign variables remain unmodeled in the country models and thus need to satisfy weak exogeneity requirements for inference and impulse response analysis. We test and elaborate on the weak-exogeneity condition below. 
The $k_{i}^{*} \times 1$ vector of foreign variables is denoted by

$$
\mathbf{y}_{i t}^{*}=\left[\begin{array}{lllllll}
r c_{i t}^{*} & r y_{i t}^{*} & r s_{i t}^{*} & r h_{i t}^{*} & r_{i t}^{s^{*}} & r_{i t}^{l^{*}} & p_{i t}^{o i l}
\end{array}\right]^{\prime}
$$

and constructed as trade-weighted averages

$$
\begin{array}{rlrl}
r c_{i t}^{*} & =\sum_{j=1}^{N} w_{i j}^{r c} r c_{j t}, & r y_{i t}^{*}=\sum_{j=1}^{N} w_{i j}^{r y} r y_{j t}, & r s_{i t}^{*}=\sum_{j=1}^{N} w_{i j}^{r s} r s_{j t}, \\
r h_{i t}^{*}=\sum_{j=1}^{N} w_{i j}^{r h} r h_{j t}, & r_{i t}^{s^{*}}=\sum_{j=1}^{N} w_{i j}^{r^{s}} r_{j t}^{s}, & r_{i t}^{l^{*}}=\sum_{j=1}^{N} w_{i j}^{r^{l}} r_{j t}^{l},
\end{array}
$$

where the country-specific trade-weights, $w_{i j}^{r c}, w_{i j}^{r y}, w_{i j}^{r s}, w_{i j}^{r h}, w_{i j}^{r^{s}}$ and $w_{i j}^{r^{l}}$ for $i, j=$ $1,2, \ldots N$, are the sum of bilateral exports and imports between country $i$ and $j$ relative to total exports and imports of country $i .^{8}$ We employ time-invariant trade-weights in the construction of foreign variables, which we obtain as averages over the years $2000-2004 .^{9}$ Obviously, the correct choice of the weights is key in creating the international transmission channels. The use of information on bilateral trade in goods and services seems to be the natural choice for our study of the international wealth channel. An alternative choice is information on bilateral capital flows. However, data are not consistently available for all countries in our sample and we do not expect significant differences. The literature on the geography of portfolio investment shows that underlying trade in goods and services are key correlates for the observed patterns of capital flows (Portes and Rey, 2005; Lane and Milesi-Ferretti, 2008). The 29x29 trade share matrix that has been used in constructing the country-specific foreign variables is provided in Table 3.2 below.

\subsubsection{The GVAR methodology}

The GVAR methodology proceeds in two stages. The first stage is the estimation stage of the following reduced form augmented vector autoregression, $\operatorname{VARX}(p, q)$, model for each country $i$ in our sample

$$
\begin{aligned}
& \mathbf{y}_{i t}=\boldsymbol{\delta}_{i 0}+\boldsymbol{\delta}_{i 1} t+\sum_{l=1}^{p} \boldsymbol{\Phi}_{i l} \mathbf{y}_{i, t-l}+\sum_{m=0}^{q} \boldsymbol{\Psi}_{i m} \mathbf{y}_{i, t-m}^{*}+\boldsymbol{\epsilon}_{i t}, \quad i=1,2, \ldots, N \\
& t=1,2, \ldots, T
\end{aligned}
$$

\footnotetext{
${ }^{8}$ We adjust the trade-weights if data are not available for some countries and some variables.

${ }^{9}$ Section 3.6 discusses the implications of using time-varying trade-weights on the construction of the starred variables and the number of cointegrating relationships.
} 


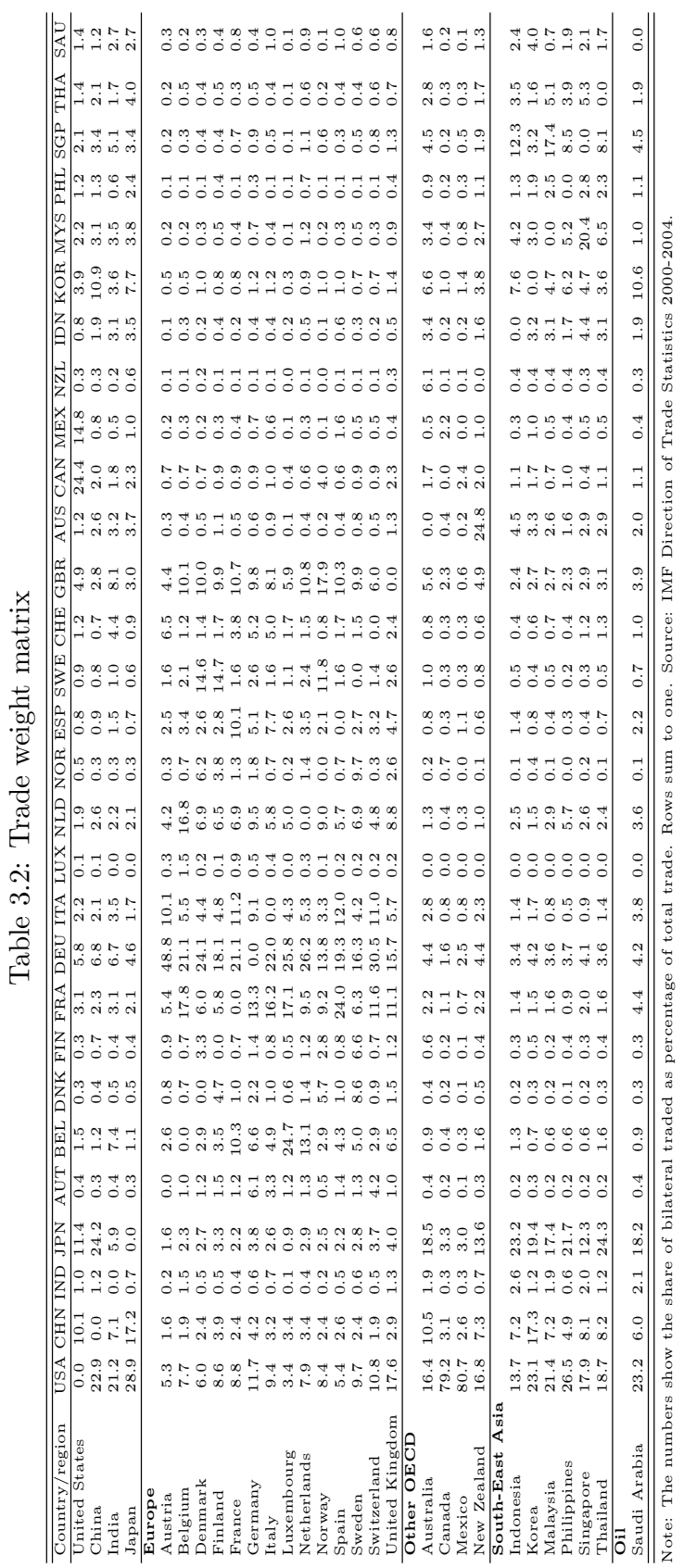


where $\boldsymbol{\delta}_{i 0}$ and $\boldsymbol{\delta}_{i 1}$ are $k_{i} \times 1$ coefficient vectors of the deterministic intercept and time trend. $\mathbf{y}_{i t}$ is a $k_{i} \times 1$ vector of country-specific variables with corresponding $k_{i} \times k_{i}$ matrices of lagged coefficients, denoted by $\boldsymbol{\Phi}_{i l} . \mathbf{y}_{i t}^{*}$ is a $k_{i}^{*} \times 1$ vector of tradeweighted foreign variables with corresponding $k_{i} \times k_{i}^{*}$ matrices of contemporaneous and lagged coefficients, denoted by $\boldsymbol{\Psi}_{i m} . \boldsymbol{\epsilon}_{i t}$ is a $k_{i} \times 1$ vector of zero mean, idiosyncratic country-specific shocks, assumed to be serially uncorrelated with time invariant covariance matrix $\Sigma_{i i}$. We determine the order of the dynamic specification according to the Akaike information criterion (AIC). To reduce the number of estimated parameters and avoid problems with the degrees of freedom,

Table 3.3: VARX order and number of cointegrating relationships

\begin{tabular}{|c|c|c|c|}
\hline \multirow[b]{2}{*}{ Country/region } & \multicolumn{2}{|c|}{$\operatorname{VARX}\left(\mathrm{p}_{i}, \mathrm{q}_{i}\right)$} & \multirow{2}{*}{$\begin{array}{c}\text { \# Cointegrating } \\
\text { relationships }\end{array}$} \\
\hline & $\mathrm{p}_{i}$ & $\mathrm{q}_{i}$ & \\
\hline United States & 2 & 1 & 3 \\
\hline China & 2 & 1 & 2 \\
\hline India & 2 & 1 & 1 \\
\hline Japan & 2 & 1 & 4 \\
\hline \multicolumn{4}{|l|}{ Europe } \\
\hline Austria & 2 & 1 & 4 \\
\hline Belgium & 2 & 1 & 5 \\
\hline Denmark & 2 & 1 & 5 \\
\hline Finland & 2 & 1 & 3 \\
\hline France & 2 & 1 & 3 \\
\hline Germany & 1 & 1 & 3 \\
\hline Italy & 2 & 1 & 3 \\
\hline Luxembourg & 2 & 1 & 3 \\
\hline Netherlands & 2 & 1 & 3 \\
\hline Norway & 2 & 1 & 4 \\
\hline Spain & 2 & 1 & 5 \\
\hline Sweden & 2 & 1 & 6 \\
\hline Switzerland & 2 & 1 & 4 \\
\hline United Kingdom & 2 & 1 & 3 \\
\hline \multicolumn{4}{|l|}{ Other OECD } \\
\hline Australia & 2 & 1 & 3 \\
\hline Canada & 2 & 1 & 4 \\
\hline Mexico & 2 & 1 & 3 \\
\hline New Zealand & 2 & 1 & 3 \\
\hline \multicolumn{4}{|c|}{ South-East Asia } \\
\hline Indonesia & 1 & 1 & 2 \\
\hline Korea & 2 & 1 & 4 \\
\hline Malaysia & 2 & 1 & 2 \\
\hline Philippines & 2 & 1 & 3 \\
\hline Singapore & 1 & 1 & 3 \\
\hline Thailand & 2 & 1 & 3 \\
\hline \multicolumn{4}{|l|}{$\overline{\text { Oil }}$} \\
\hline Saudi Arabia & 2 & 1 & 2 \\
\hline
\end{tabular}

Note: VARX order determined by the AIC, with $\mathrm{p} \leq 2$ and $\mathrm{q}=1$. 
we allow at maximum for a $\operatorname{VARX}(2,1)$ specification. The lag orders of the individual countries are reported in Table 3.3.

The modeling approach is well-suited to deal with variables that are approximately integrated of order one, in which case the $\operatorname{VARX}(2,1)$ can be written and estimated in a compact error-correction representation as

$$
\Delta \mathbf{y}_{i t}=\boldsymbol{\delta}_{i 0}+\boldsymbol{\delta}_{i 1} t-\left(\mathbf{A}_{i}-\mathbf{B}_{i}-\mathbf{C}_{i}\right) \mathbf{z}_{i, t-1}+\boldsymbol{\Psi}_{i 0} \Delta \mathbf{y}_{i, t}^{*}-\boldsymbol{\Phi}_{i 2} \Delta \mathbf{y}_{i, t-1}+\boldsymbol{\epsilon}_{i t}
$$

where

$$
\mathbf{z}_{i t}=\left(\begin{array}{c}
\mathbf{y}_{i t} \\
\mathbf{y}_{i t}^{*}
\end{array}\right)
$$

$$
\mathbf{A}_{i}=\left(\mathbf{I}_{k_{i}},-\boldsymbol{\Psi}_{i 0}\right), \quad \mathbf{B}_{i}=\left(\boldsymbol{\Phi}_{i 1}, \boldsymbol{\Psi}_{i 1}\right), \quad \mathbf{C}_{i}=\left(\boldsymbol{\Phi}_{i 2}, \mathbf{0}_{k_{i}^{*}}\right) .
$$

$\mathbf{A}_{i}, \mathbf{B}_{i}$ and $\mathbf{C}_{i}$ are matrices of dimension $k_{i} \times\left(k_{i}+k_{i}^{*}\right)$. The error-correcting properties of each country model are thus summarized in the $k_{i} \times\left(k_{i}+k_{i}^{*}\right)$ matrix

$$
\boldsymbol{\Pi}_{i}=\left(\mathbf{A}_{i}-\mathbf{B}_{i}-\mathbf{C}_{i}\right)
$$

where the rank, $r_{i}$, of $\mathbf{\Pi}_{i}$ determines the number of long-run relationships between domestic and country-specific foreign variables, $\mathbf{y}_{i}$ and $\mathbf{y}_{i}^{*}$. To identify the rank of the cointegrating space for each country model, we use the trace test statistic which is known to be more robust to departures from normal errors than the maximum eigenvalue test (Cheung and Lai, 1993). ${ }^{10}$ The number of long-run relationships according to the trace test statistic is listed for each country in Table 3.3. Below we elaborate on the integration properties of our variables and the long-run relationships between them. Note that the contemporaneous dependence of the domestic variables, $\mathbf{y}_{i t}$, on the foreign variables, $\mathbf{y}_{i t}^{*}$, in (3.4) and (3.5) makes it necessary to solve the country-specific models simultaneously for all of the domestic variables, $\mathbf{y}_{i t}$. This is the second stage of the GVAR methodology, where we cast the country-specific models into its global representation. First rewrite $(3.5)$ as

$$
\mathbf{A}_{i} \Delta \mathbf{z}_{i t}=\boldsymbol{\delta}_{i 0}+\boldsymbol{\delta}_{i 1} t-\left(\mathbf{A}_{i}-\mathbf{B}_{i}-\mathbf{C}_{i}\right) \mathbf{z}_{i, t-1}-\boldsymbol{\Phi}_{i 2} \Delta \mathbf{y}_{i, t-1}+\boldsymbol{\epsilon}_{i t}
$$

and stack the endogenous variables of all individual country models in a $k \times 1$ global variable vector $\mathbf{y}_{t}=\left(\mathbf{y}_{1 t}, \mathbf{y}_{2 t} \ldots \mathbf{y}_{N t}\right)^{\prime}$ with $k=\sum_{i=1}^{N} k_{i}$. Next stack the country individual models of (3.6) and solve for the global VECM representation

$$
\mathbf{F} \Delta \mathbf{y}_{t}=\boldsymbol{\delta}_{0}+\boldsymbol{\delta}_{1} t-(\mathbf{F}-\mathbf{G}-\mathbf{H}) \mathbf{y}_{t-1}+\boldsymbol{\Phi}_{2} \Delta \mathbf{y}_{t-1}+\boldsymbol{\epsilon}_{t}
$$

\footnotetext{
${ }^{10}$ Departure from normal errors is particularly relevant in our study which includes equity and housing prices, interest rates and the real effective exchange rate.
} 
where

$$
\boldsymbol{\delta}_{0}=\left(\begin{array}{c}
\boldsymbol{\delta}_{10} \\
\boldsymbol{\delta}_{20} \\
\vdots \\
\boldsymbol{\delta}_{N 0}
\end{array}\right), \quad \boldsymbol{\delta}_{1}=\left(\begin{array}{c}
\boldsymbol{\delta}_{11} \\
\boldsymbol{\delta}_{21} \\
\vdots \\
\boldsymbol{\delta}_{N 1}
\end{array}\right), \quad \phi_{2}=\left(\begin{array}{c}
\boldsymbol{\Phi}_{12} \\
\boldsymbol{\Phi}_{22} \\
\vdots \\
\boldsymbol{\Phi}_{N 2}
\end{array}\right), \quad \boldsymbol{\epsilon}_{t}=\left(\begin{array}{c}
\boldsymbol{\epsilon}_{1 t} \\
\boldsymbol{\epsilon}_{2 t} \\
\vdots \\
\boldsymbol{\epsilon}_{N t}
\end{array}\right),
$$

and

$$
\mathbf{F}=\left(\begin{array}{c}
\mathbf{A}_{1} \mathbf{W}_{1} \\
\mathbf{A}_{2} \mathbf{W}_{2} \\
\vdots \\
\mathbf{A}_{N} \mathbf{W}_{N}
\end{array}\right), \quad \mathbf{G}=\left(\begin{array}{c}
\mathbf{B}_{1} \mathbf{W}_{1} \\
\mathbf{B}_{2} \mathbf{B}_{2} \\
\vdots \\
\mathbf{B}_{N} \mathbf{W}_{N}
\end{array}\right), \quad \mathbf{H}=\left(\begin{array}{c}
\mathbf{C}_{1} \mathbf{W}_{1} \\
\mathbf{C}_{2} \mathbf{W}_{2} \\
\vdots \\
\mathbf{C}_{N} \mathbf{W}_{N}
\end{array}\right)
$$

The $\mathbf{W}_{i}$ s are country-specific $\left(k_{i}+k_{i}^{*}\right) \times k$ matrices of fixed constants defined by the trade-weights that were used above in the construction of the foreign variables. $\mathbf{W}_{i}$ is best thought of as the link matrix that allows the country individual models to be written in terms of the global variable vector, $\mathbf{y}_{t}$. The global VECM of (3.7) allows for interaction among the included economies through three different but interrelated channels: (i) the contemporaneous dependence of domestic variables, $\mathbf{y}_{i t}$, on foreign variables, $\mathbf{y}_{i t}^{*}$, and on its lagged values, (ii) the dependence of all endogenous variables on common global exogenous variables (e.g. oil price), and (iii) the nonzero contemporaneous dependence of shocks in country $i$ on shocks in country $j$. Cross-country shocks are allowed to be weakly correlated in $\Sigma_{i j}$.

Note that in the global VECM representation, domestic variables are no longer contemporaneously dependent on foreign variables. This implies that we can solve the global model forward recursively, obtain future values of all endogenous variables and conduct impulse response analysis. We do so in Section 3.4. Before, we have a closer look at the statistical properties of the data series that we include in our model.

\subsubsection{Properties and specification of the data series}

As a first step in specifying the country individual model, we have to determine the integration properties of the included variables. The error-correction representation of the GVAR methodology assumes that the included variables are approximately integrated of order one. We follow PSW and base our unit root tests on weighted symmetric estimations of ADF type regressions that possess superior power performance compared to standard ADF tests (Park and Fuller, 1995). 


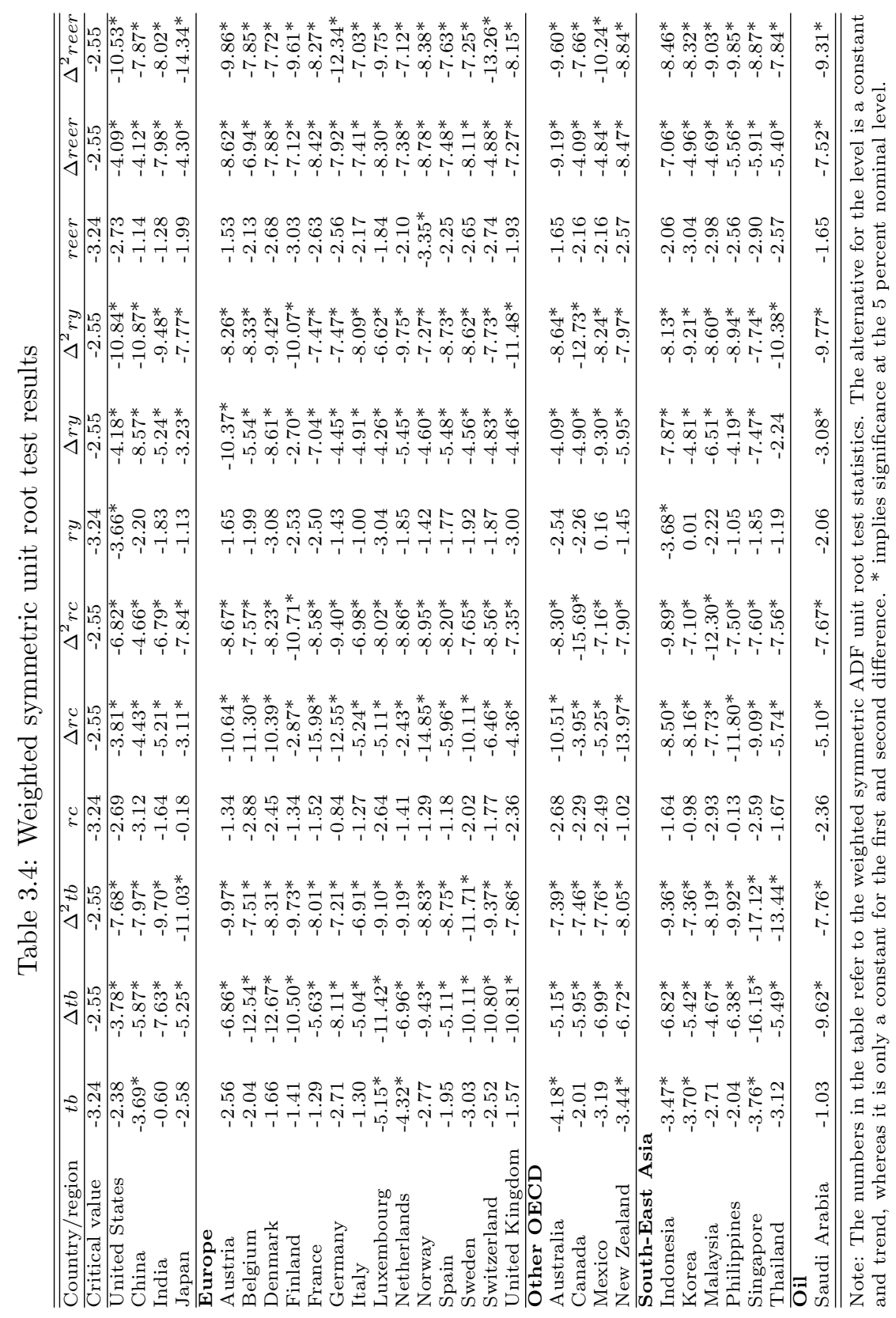




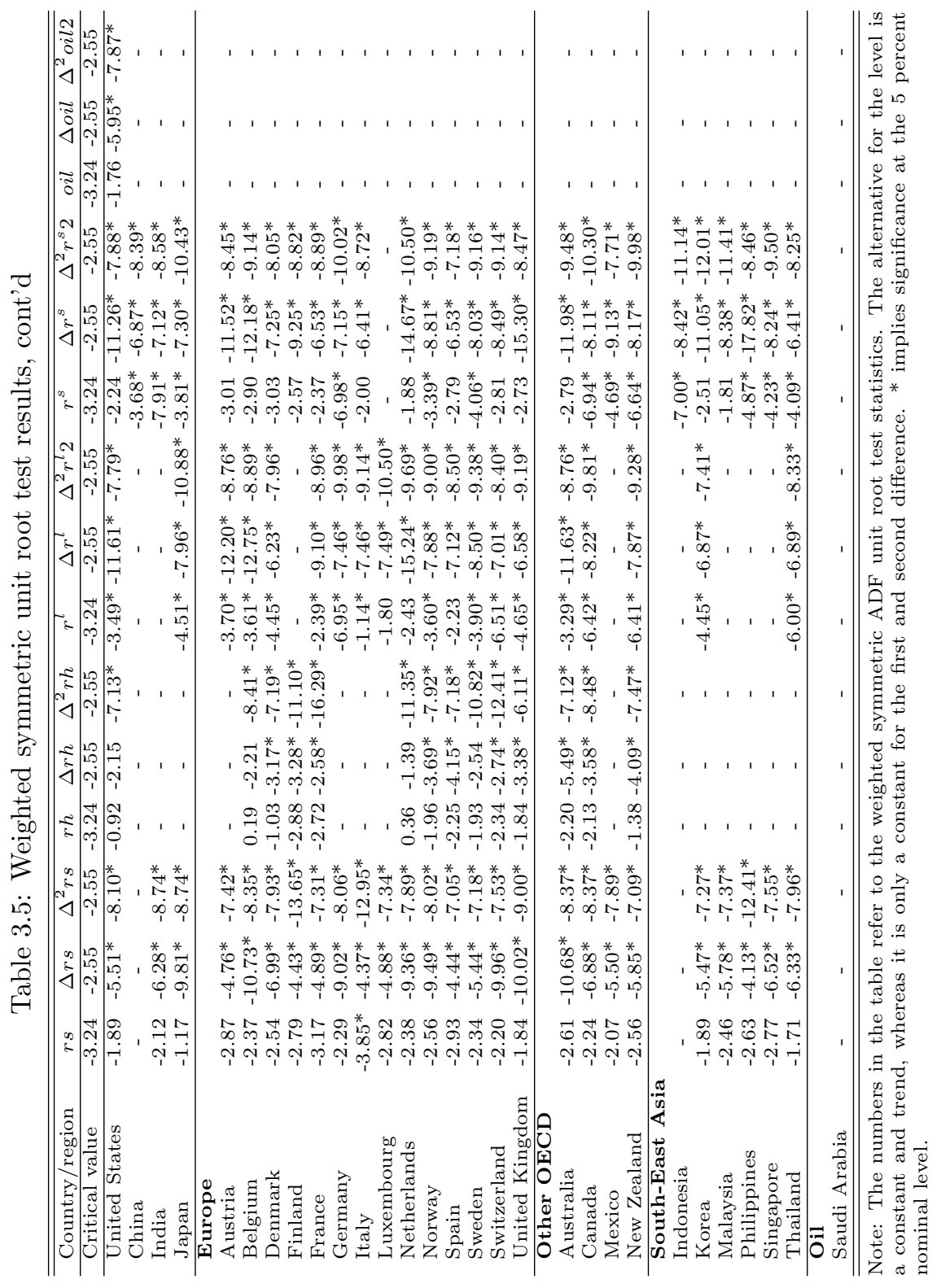


Tables 3.4 and 3.5 present unit root $t$-statistics for the levels, first and second differences of the country-specific endogenous variables. The lag length of the tests is selected according to the AIC. The test results largely confirm well known results from previous literature. Real consumption, real output, real effective exchange rates and real stock and oil prices are unambiguously $I(1)$ processes for the vast majority of countries, or else $\mathrm{I}(0) / \mathrm{I}(1)$ borderline cases. A different picture emerges for the unit root tests of the trade balances. Here, we find for a number of countries stationary data series, however, the trade balances of our focus countries are unambiguously $I(1)$. The real housing price series are $I(1)$ processes with four notable exceptions: the US, Belgium, the Netherlands and Sweden. For these countries, we observe an exponential increase in housing prices over the past years of the sample period that renders the processes $I(2)$. Reducing the sample period by the last eight quarters produces $I(1)$ real housing price processes for all countries in our sample. From the impulse response analysis below and the eigenvalues of the GVAR model we can conclude that the obtained integration order of housing prices does not impair the model's stability. Finally, the hypothesis that interest rates are $I(1)$ is rejected for many countries and may result in an efficiency loss in estimation. Overall, however, it seems appropriate for our modeling strategy to treat all variables as approximately $I(1)$. The estimation of the country individual models and the impulse response analysis below lend credibility to this conclusion.

Having established the integration properties, we proceed with specifying the number of long run cointegrating relationships that exist between domestic and foreign variables in each country model. Empirical evidence in the literature provides suggestions. Lettau and Ludvigson (2001) find a cointegrating vector between consumption, wealth and personal income for the US. Case and Shiller (2003) and Black et al. (2006) document cointegrating relationships between housing prices, income and interest rates for the US. Specifically, Case and Shiller (2003) find stable price to income ratios for over 40 US states. There is some evidence that international stock markets are cointegrated (Kasa, 1992), but these results are challenged by Richards (1995). Meese and Rogoff (1988) investigate the cointegrating properties of real exchange rates and real interest rate differentials, but reject a stable relationship between both variables. On the other hand, Bergvall (2004) finds a single cointegrating relationship between the trade balance, exchange rates, relative GDP and the real oil price for Scandinavian countries.

Based on the trace statistic, Table 3.3 shows the number of cointegrating relationships in our country models. The number ranges from 1 for India to 6 for Sweden, but for the great majority of countries, including our G5 countries, we find 3 to 4 cointegrating relationships. The number of cointegrating relationships is in part determined by the availability of data for each country model. We find, for instance, for China and India, but also for Indonesia, Malaysia and Saudi 
Arabia fewer cointegrating relationships since their country-individual VECMs do not consist of all endogenous variables in (3.1). ${ }^{11}$ Moreover it is important to note that the GVAR methodolgy allows for the possibility of long-run relationships within domestic variables, $\mathbf{y}_{i t}$, and between domestic and country-specific foreign variables, $\mathbf{y}_{i t}$ and $\mathbf{y}_{i t}^{*}$. Hence it is not surprising to find that countries which are relatively more integrated with their main trading partners also exhibit more cointegrating relationships. This holds for instance for European and OECD countries.

Finally, a key assumption underlying our estimation strategy is the weak exogeneity of the country-specific foreign variables, $\mathbf{y}_{i t}^{*}$. It is best understood as the statistical formalization of the standard assumption in the small openeconomy literature where it is generally assumed that most economies are too small relative to the size of the world economy to have an impact on the latter. The weak exogeneity assumption rules out any long run feedback from the endogenous variables, $\mathbf{y}_{i t}$, to the foreign variables, $\mathbf{y}_{i t}^{*}$ and can be formally tested following Johansen (1992) and Harbo et al. (1999). They provide an F-test for the joint significance of the estimated error-correcting terms of (3.5) in the marginal model of the country-specific foreign variables, $\mathbf{y}_{i t}^{*}$. To test, for instance, the weak exogeneity of foreign real output in the US country model, we need to consider the joint hypothesis that $\gamma_{U S, j}=0, j=1,2,3$ in the auxiliary regression

$$
\begin{array}{r}
\Delta r y_{U S, t}^{*}=\delta_{U S}+\sum_{j=1}^{3} \gamma_{U S, j} E C M_{U S, t-1}^{j}+\sum_{k=1}^{l} \xi_{U S, k} \Delta \mathbf{r y}_{U S, t-k} \\
+\sum_{m=1}^{n} \vartheta_{U S, m} \Delta \mathbf{r y}_{U S, t-m}^{*}+\epsilon_{U S, t}
\end{array}
$$

where $E C M_{U S, t-1}^{j}$ are the three long-run relationships found in the US country model and $\Delta \mathbf{r y}_{U S}$ and $\Delta \mathbf{r y}_{U S}^{*}$ are defined above. Table 3.6 reports the $F$-statistics for all country-specific foreign variables based on the lag order of the underlying VAR model. We find 8 out of 172 cases to be statistically significant at the 5 percent nominal level. All other foreign variables pass the weak exogeneity test. For our study, it is reassuring that for our set of focus countries, weak exogeneity can only be rejected for foreign real output in the Japanese country model, while all other foreign variables are weakly exogenous. ${ }^{12}$ Given the size and importance of the US equity market, we exclude foreign real stock prices from the US country model because these cannot be considered as weakly exogenous.

\footnotetext{
${ }^{11}$ See for instance Table 3.4 and 3.5 for the data availability of all countries.

${ }^{12}$ As a robustness check, we excluded those foreign variables that do not pass the weak exogeneity test from the country models. The differences in estimation are immaterial.
} 
Table 3.6: Weak exogeneity test

\begin{tabular}{|c|c|c|c|c|c|c|c|c|}
\hline Country/region & F-test & $r y^{*}$ & $r c^{*}$ & $r s^{*}$ & $r h^{*}$ & $r^{l *}$ & $r^{s *}$ & oil $^{*}$ \\
\hline United States & $\mathrm{F}(3,74)$ & 0.40 & 1.19 & - & 0.92 & 0.26 & 1.34 & - \\
\hline China & $\mathrm{F}(2,83)$ & 2.34 & 0.41 & - & - & - & 0.50 & 0.47 \\
\hline India & $\mathrm{F}(1,81)$ & 0.48 & $4.88^{*}$ & 3.32 & - & - & 0.67 & $5.48 * *$ \\
\hline Japan & $\mathrm{F}(4,75)$ & $2.60^{*}$ & 0.21 & 1.64 & - & 1.54 & 1.16 & 1.36 \\
\hline \multicolumn{9}{|l|}{ Europe } \\
\hline Austria & $\mathrm{F}(4,75)$ & 0.57 & 0.27 & 1.61 & - & 0.94 & 1.02 & 0.52 \\
\hline Belgium & $\mathrm{F}(5,72)$ & 0.76 & 0.28 & 0.55 & 1.16 & 0.85 & 1.18 & 1.04 \\
\hline Denmark & $\mathrm{F}(5,72)$ & 0.99 & 0.56 & 0.68 & 1.10 & 1.03 & 1.03 & 0.49 \\
\hline Finland & $\mathrm{F}(3,77)$ & 1.85 & 0.96 & 0.33 & 0.53 & - & 1.50 & 0.52 \\
\hline France & $\mathrm{F}(3,74)$ & 0.87 & 0.87 & 0.26 & 2.28 & 1.39 & 2.15 & 0.15 \\
\hline Germany & $\mathrm{F}(3,83)$ & 1.67 & 0.37 & 1.18 & - & 3.36 & 2.37 & 1.02 \\
\hline Italy & $\mathrm{F}(3,76)$ & 1.84 & 1.12 & 0.47 & - & 0.29 & 0.53 & 1.32 \\
\hline Luxembourg & $\mathrm{F}(3,79)$ & 0.82 & 0.93 & 1.50 & - & $3.40^{*}$ & - & 0.58 \\
\hline Netherlands & $\mathrm{F}(3,74)$ & 0.10 & 0.06 & 0.73 & 0.25 & 0.42 & 0.41 & 0.10 \\
\hline Norway & $\mathrm{F}(4,73)$ & 1.24 & 0.12 & 0.33 & 1.78 & 0.68 & 0.90 & 0.54 \\
\hline Spain & $\mathrm{F}(5,72)$ & 1.12 & 0.08 & 0.91 & $2.39^{*}$ & 0.69 & 1.00 & 1.22 \\
\hline Sweden & $\mathrm{F}(6,71)$ & 0.82 & 1.50 & 0.64 & 0.54 & 0.71 & 1.63 & 0.56 \\
\hline Switzerland & $\mathrm{F}(4,73)$ & 0.22 & 0.30 & 1.93 & 2.34 & 1.49 & 1.08 & 0.35 \\
\hline United Kingdom & $\mathrm{F}(3,74)$ & 0.77 & 0.66 & 0.91 & 0.27 & 0.45 & 0.89 & 0.34 \\
\hline \multicolumn{9}{|l|}{ Other OECD } \\
\hline Australia & $\mathrm{F}(3,74)$ & 0.23 & 0.30 & 1.39 & 0.65 & 1.50 & 0.42 & 1.12 \\
\hline Canada & $\mathrm{F}(4,73)$ & 0.60 & 0.71 & 0.43 & 0.70 & 0.25 & 0.16 & 0.85 \\
\hline Mexico & $\mathrm{F}(3,79)$ & 0.20 & 4.33 & 0.02 & - & - & 3.88 & 0.31 \\
\hline New Zealand & $\mathrm{F}(3,74)$ & 1.04 & 0.63 & 2.29 & $4.07^{* *}$ & 0.44 & 0.74 & 0.10 \\
\hline \multicolumn{9}{|c|}{ South-East Asia } \\
\hline Indonesia & $\mathrm{F}(2,88)$ & $3.29 *$ & 1.00 & - & - & - & 0.89 & 0.36 \\
\hline Korea & $\mathrm{F}(4,75)$ & $4.32^{* *}$ & 1.08 & 1.72 & - & 1.62 & 0.73 & 0.62 \\
\hline Malaysia & $\mathrm{F}(2,80)$ & 0.88 & 0.07 & 0.15 & - & - & 0.01 & 0.98 \\
\hline Philippines & $\mathrm{F}(3,79)$ & 0.18 & 0.03 & 1.88 & - & - & 0.69 & 0.06 \\
\hline Singapore & $\mathrm{F}(3,85)$ & 0.22 & 2.18 & 0.52 & - & - & 0.29 & 0.53 \\
\hline Thailand & $\mathrm{F}(3,76)$ & 0.41 & 0.70 & 0.94 & - & 1.39 & 0.69 & 0.91 \\
\hline \multicolumn{9}{|l|}{ Oil } \\
\hline Saudi Arabia & $\mathrm{F}(2,86)$ & 2.44 & 0.56 & - & - & - & - & 1.81 \\
\hline
\end{tabular}

Note: * implies significance at the 5 percent nominal level and $* *$ at the 1 percent nominal level.

\subsection{Generalized impulse response analysis}

The complex cross-border interdependencies that are an integral part of our global model are best summarized by investigating the dynamic response of the system to exogenous shocks in the error of a given variable. The analysis is carried out by making use of generalized impulse response functions (GIRF) which have been introduced by Koop et al. (1996) for non-linear systems and advanced by Pesaran and Shin (1998) for vector error-correcting systems. The GIRF is an alternative to the orthogonalized impulse response (OIR) function that is proposed in the traditional VAR literature (Sims, 1980). While OIR functions rely on a set of orthogonalized shocks, the GIRF considers the shock to an individual 
error and integrates out the effects of the other shocks based on the historically observed distribution of all errors. Unlike OIR functions, the GIRF neither requires imposing identification restrictions, nor is it variant to the ordering of the endogenous variables in the global vector, $\mathbf{y}_{t}$. Both are clearly important considerations in our model that considers a total of 204 endogenous variables in 29 country models. As there is no strong a priori belief on the exact ordering of these variables, we do not aim to identify structural shocks. The GIRF does not allow for a structural interpretation of the impulse-response results, but provides valuable information on the dynamics of the transmission of shocks.

In what follows, we will investigate the time profiles and dynamic responses of domestic variables to a one standard error negative shock to (1) the real effective exchange rate, (2) domestic real stock prices and, if available, (3) domestic real housing prices. We will focus mainly on the response of the trade balance to these shocks and investigate if the trade balance movements can be attributed to consumption changes. The figures show the bootstrapped median impulse responses for the first 20 quarters following the shock together with the associated 90 percent confidence bounds. ${ }^{13}$ To stay focused we will concentrate on the G5 countries in the exposition of our results.

\subsubsection{The international wealth channel for the US}

The first column of Figure 3.1 shows the GIRFs for a one standard error negative shock to the US real effective exchange rate. This shock is equivalent to a currency depreciation of about 2 percent per quarter. The shock is highly persistent and thus the real effective exchange rate converges only slowly back to its mean as implied by long run PPP theory. Interestingly, the exchange rate depreciation translates immediately into a statistically significant improvement of the US trade balance by about 0.3 percent. We do not observe the initial J-curve effect, which confirms previous studies (e.g Rose and Yellen, 1989).

Figure 3.1 shows also that the exchange rate depreciation leads to a statistically significant fall in real consumption of about 0.1 percent on impact and up to 0.4 percent after 20 quarters. Taken together, the responses of real consumption and the trade balance lend support to the view that US trade balance deficits are, by and large, driven by US demand for imported goods and services. This view contrasts with Goldberg and Tille (2006) and Gust and Sheets (2006). Both studies argue that exchange rate movements are largely passed through to the trade balance via exports, leaving US expenditure on imports relatively unchanged.

Next, we expose US real stock prices to a one standard error negative shock.

\footnotetext{
${ }^{13}$ The confidence bounds are obtained using the sieve bootstrap procedure analogous to Dees et al. (2007) with 2000 replications.
} 
Figure 3.1: Domestic response to a real effective exchange rate (first column), real stock price (second column) and real housing price shock (third column) in the United States
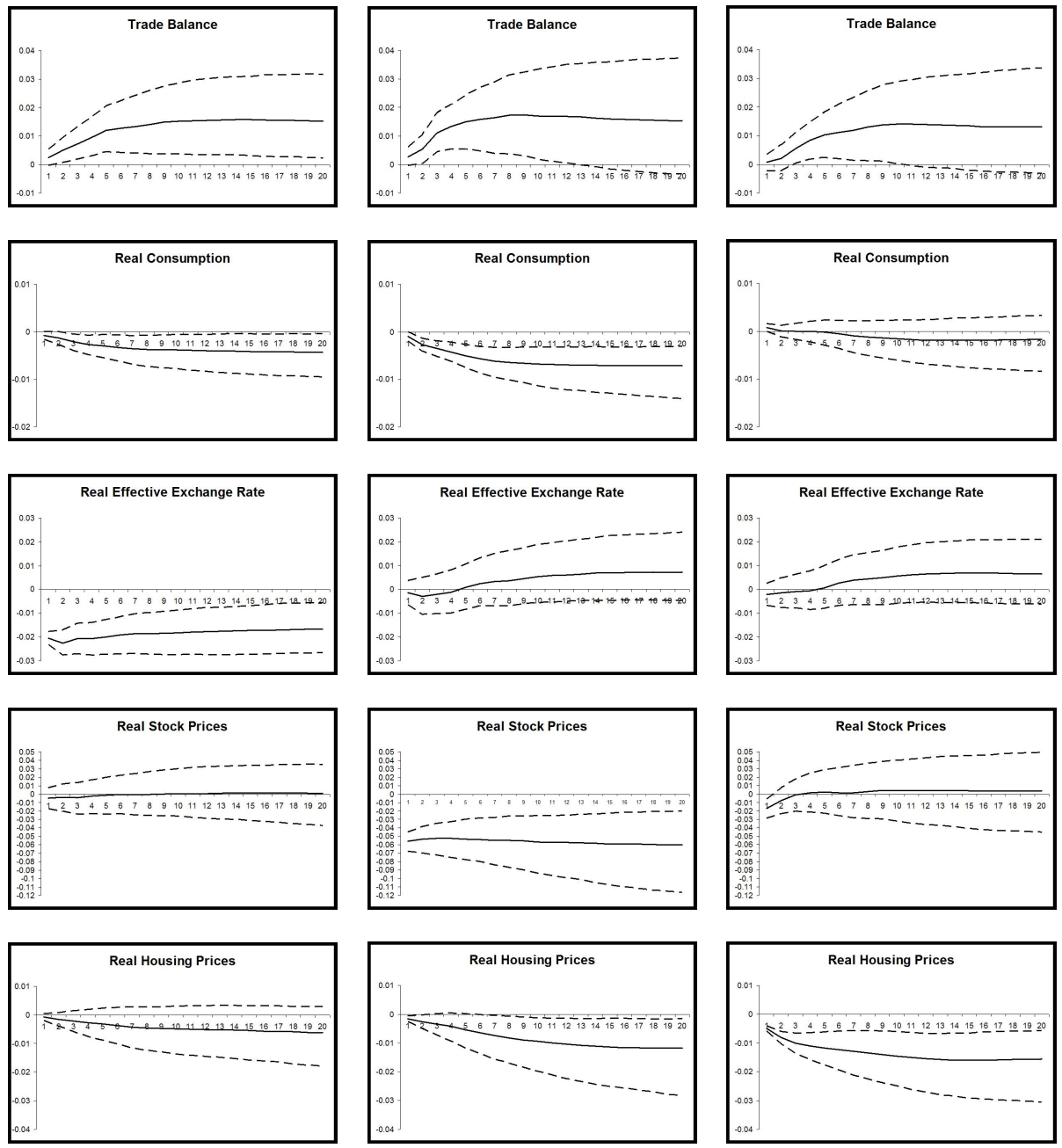
The associated GIRFs are shown in the second column of Figure 3.1. The shock amounts to a drop in real stock prices of 5 to 6 percent per quarter over the entire time horizon. The high persistence in the stock price behaviour following an initial shock can be attributed to the data series being integrated of order unity. Initially, the US trade balance improves by 0.3 percent, but it improves further by up to 1.7 percent after 8 quarters. The trade balance improvement is statistically significant over the first 12 quarters.

Most importantly, we find a strong response of consumption to the stock price shock. US real consumption falls by 0.1 percent on impact, by 0.5 percent after 4 quarters and by 0.7 percent after 20 quarters. This response of US real consumption is statistically significant throughout. Within the international wealth channel the stock price shock is transmitted through consumtion.

Note that real housing prices deteriorate significantly following a negative stock market shock. This decrease becomes significant after about 8 quarters and remains significant after 20 quarters. The combined decrease in stock and housing prices may explain the strong effect of the stock market shock on consumption and consequently on the trade balance.

Finally, in the third column of Figure 3.1 a similar, yet less pronounced and statistically significant picture emerges for a one standard error negative shock to US real housing prices. The shock to US housing prices implies initially a 0.5 percent price decrease that stabilizes as a price decrease of about 1.5 percent over time. The trade balance improves following the negative shock to US real housing prices by 1.3 percent after 20 quarters and is statistically significant between quarters 1 and 10 .

We observe that US real consumption turns negative after 4 quarters by up to 0.2 percent. However, the decrease in consumption ceases to be statistically significant. Given the insignificant response of US real consumption, the transmission channel of housing price movements to the US trade balance is less clear cut. We conjecture that private and business investments are likely transmission mechanisms.

When comparing the relevance of the real effective exchange rate and real stock and housing prices for the US trade balance, we find that all three variables bear equal importance. A one standard error negative shock to any variable improves the US trade balance on impact and, even more, over time (between 1.3 to 1.5 percent).

\subsubsection{The international wealth channel for the UK}

In the first column of Figure 3.2, we show the GIRFs of a one standard error negative exogenous shock to the UK real effective exchange rate. The shock results 
Figure 3.2: Domestic response to a real effective exchange rate (first column), real stock price (second column) and real housing price shock (third column) in the United Kingdom
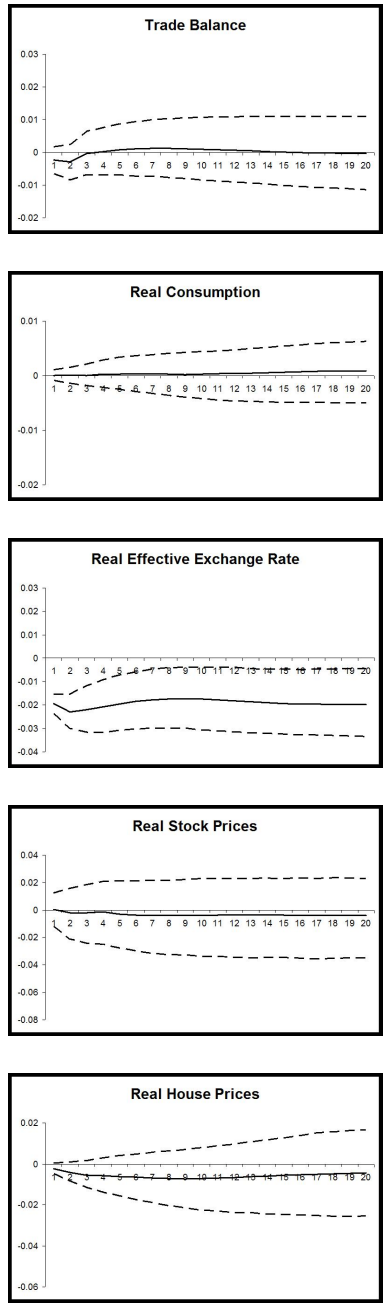
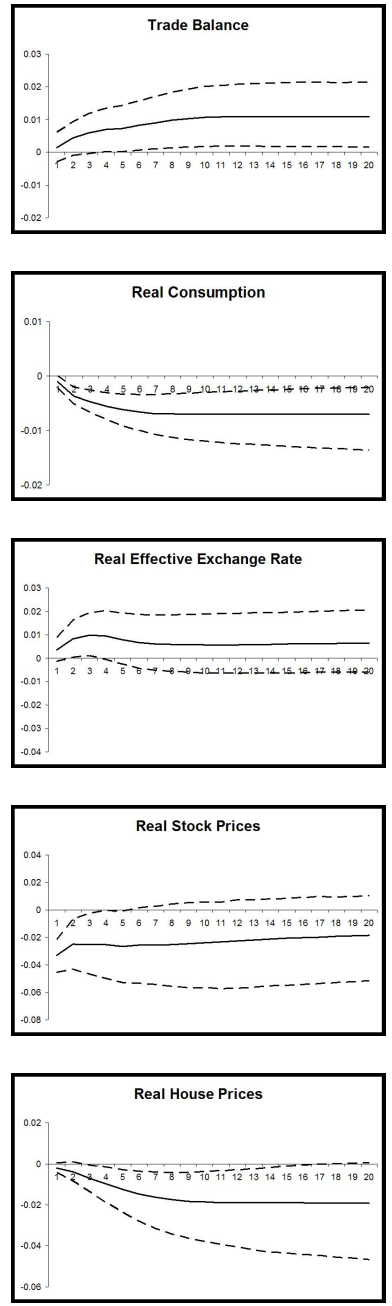
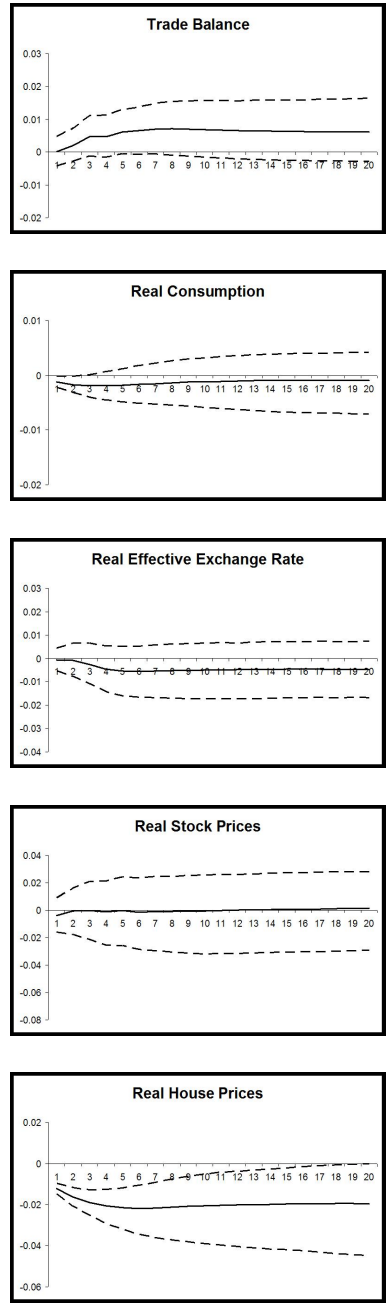
in a 2 percent depreciation of the UK real effective exchange rate per quarter. The depreciation is persistent over time. Apparently, the UK trade balance is less responsive to real effective exchange rate changes than the US trade balance. We find the classical J-curve behaviour of the UK trade balance in response to a real effective exchange rate depreciation - an initial worsening over the first 3 quarters followed by an improvement over the subsequent 11 quarters. Note, however, that the trade balance response is not statistically significant at any point in time.

Unlike in the US, we do not observe a statistically significant effect of the relative price change on UK real consumption. It appears that UK consumption is less sensitive to foreign price changes. This suggests that the foreign sector plays a less pivotal role for UK consumption decisions than it does for the US.

The shock to the real effective exchange rate serves as a benchmark against which we now evaluate shocks to UK real stock and housing prices. The second column of Figure 3.2 shows the GIRFs of a one standard error negative shock to UK stock prices. The shock implies a fall in stock prices of about 3.3 percent on impact, 2.7 percent after 4 quarters and 1.8 percent after 20 quarters. Initially, the UK trade balance does not react, but after 5 quarters the trade balance improves significantly to about 1.1 percent. The trade balance improvement remains significant after 20 quarters.

Similar to the US, we observe that the fall in stock prices translates on impact into a statistically significant contraction of UK real consumption of about 0.1 percent, from where it further accelerates to 0.6 percent after 4 quarters and 0.7 percent after 20 quarters. The contraction is statistically significant over the entire time horizon. By way of comparison, we find the domestic wealth effect in the UK to be of the same order of magnitude as in the US.

Also, for a one standard deviation negative shock to UK real housing prices, we observe responses of UK real consumption and the UK trade balance that are, by and large, comparable to the respective responses in the US. The associated GIRFs are shown in the third column of Figure 3.2. The shock amounts to a fall in UK real housing prices of about 1.2 percent on impact and up to 2.2 percent after 5 quarters. We find that the UK trade balance improves considerably following the negative shock to UK real housing prices - in quarters 7 and 8 by up to 0.7 percent. The trade balance improvement is statistically significant between quarters 2 and 11.

On impact, the shock to real housing prices leads to the same statistically significant contraction of UK consumption as the shock to real stock prices - in both cases about 0.1 percent. Over time, however, UK real consumption continues to contract by about 0.1 to 0.2 percent, but its statistical significance ceases after the second quarter. This is reminiscent of the US real consumption response to the shock in real US housing prices. Again, a likely transmission channel are private 
and business expenditures on investments.

Similar to the United States, the response of UK real consumption to shocks to real stock and housing prices provide support for the likely transmission of wealth shocks through consumption into the trade balance. Unlike with the US, however, we observe that movements in the real effective exchange rate neither have a significant impact on the UK trade balance, nor on UK consumption decisions.

\subsubsection{The international wealth channel for France}

Similar to the two preceding countries, we also investigate for France the responses to a one standard negative shock to the French real effective exchange rate and compare it to the respective responses that are induced by shocks to French real stock and housing prices. The first column of Figure 3.3 shows the GIRFs of the negative shock to the French real effective exchange rate. The one standard error corresponds to an exchange rate depreciation of 1.2 percent on impact. Over time, the depreciation settles around 1.6 percent. Like before, we can attribute the persistence of the shock to the integration property of the underlying data series. As for the UK, we observe that the French trade balance displays the aforementioned J-curve behaviour without being statistically significant. The insignificance is surprising when we take into account that France and the UK are much more open economies than the US. However, these results are in line with Lee and Chinn (2006), who do not find a significant response of the French current account to a real exchange rate shock.

As with the UK, we do not observe a statistically significant effect of the real effective exchange rate change on French real consumption. We take from it that the dependence of US consumption on the relative prices of foreign goods and services is special in this respect.

Columns 2 and 3 show the GIRFs of one standard error negative shocks to French real stock and housing prices, respectively. The first shock implies a fall in French real stock prices of around 4.4 percent on impact and 3.7 percent over time. Similar to the UK and US, the French trade balance improves as well. However, the improvement is much smaller, i.e. only half of the UK and US improvements. Moreover, it is only significant between quarters 3 and 10 . Note also that the 5 percent lower bound is always close to zero.

Following the shock to domestic stock prices, French consumption contracts initially by 0.2 percent, and further by up to 0.4 percent in quarter 20 . The statistical significance of the contraction ceases after 3 quarters. It is interesting to note that the response of French real consumption is about half of the respective response of real consumption in the US and UK and less statistically significant. This is suggestive of the finding that the domestic wealth effect is less pronounced 
Figure 3.3: Domestic response to a real effective exchange rate (first column), real stock price (second column) and real housing price shock (third column) in France
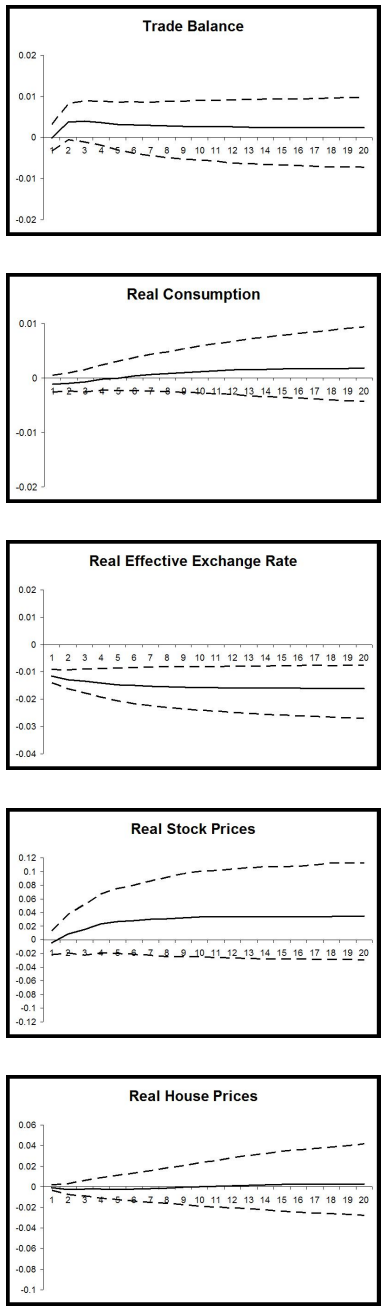
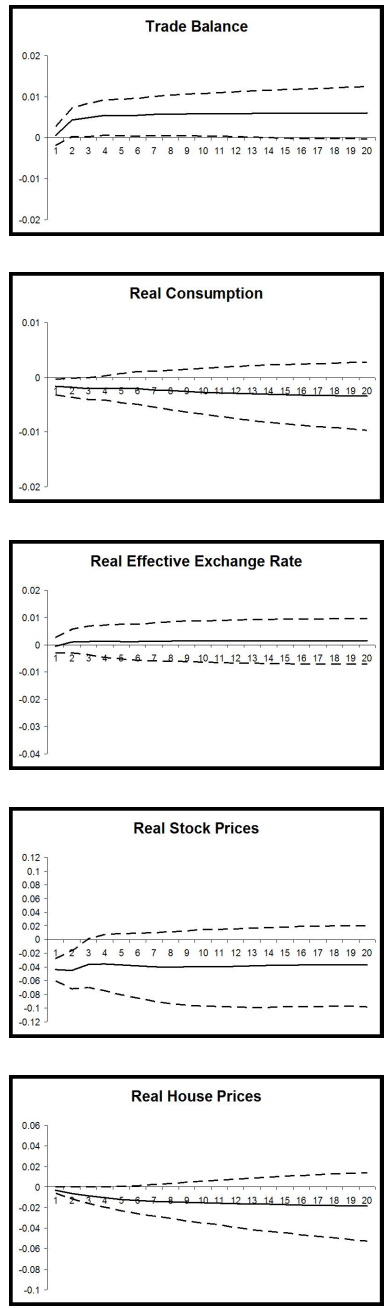
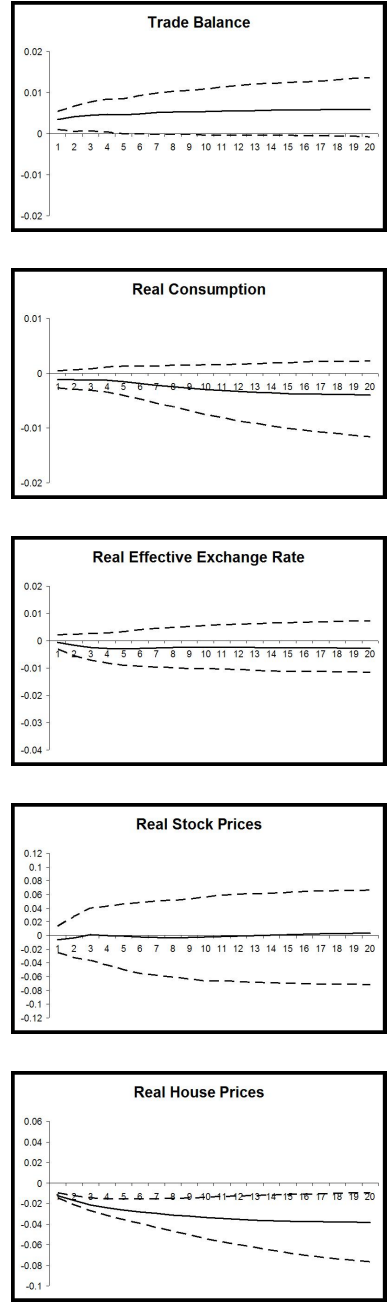
for countries with bank-based, in contrast to market-based, financial systems (Ludwig and Sløk, 2004). These authors also show that French stock ownership is much lower compared to the US and UK, which is an important explanation for the observed smaller effect.

Next, a one standard deviation negative shock to French real housing prices leads to a fall in real housing prices of 1.2 percent on impact that accelerates to 2.6 percent after 4 quarters and 4.1 percent after 20 quarters. The responses to the shock resemble, by and large, our findings for the US and UK. We observe an improved French trade balance of 0.3 percent on impact, 0.5 percent after 4 quarters and eventually 0.6 percent after 20 quarters. The response is statistically significant over the first 4 quarters and becomes marginally insignificant thereafter.

French real consumption contracts by 0.1 to 0.4 percent, but the contraction turns out to be statistically insignificant. Here, consumption is only a minor factor in explaining the trade balance effects. Muellbauer and Murphy (2008) show that collateral and downpayment constraints have been relaxed in the UK, facilitating consumption out of housing wealth. Since this is not the case in France and thus we should expect a smaller effect in France.

Overall, the results for France are in line with what we have found for the US and UK. Movements in real effective exchange rates matter most for the US trade balance, less for the UK and France. Shocks to real stock prices appear to be transmitted via consumption to the trade balance for all three countries, but to a lesser extent for France. Finally, shocks to real housing prices transmit into the trade balances for all three countries, but real consumption does not seem to be the most prominent candidate channel.

\subsubsection{The international wealth channel for Germany}

Housing prices are not available for Germany and Japan. Therefore, we consider only the effects of an exchange rate shock and a stock price shock on these countries' trade balances. The first column of Figure 3.4 shows the GIRFs for a one standard deviation negative shocks to the real effective exchange rate. For Germany we find that the trade balance first significantly worsens by 0.5 percent on impact, before returning to balance. Initially, there appears to be some evidence of the J-curve, but without a subsequent trade balance improvement.

This result seems surprising, because Germany is one of the largest exporters in the world and the demand for these exports should depend on the exchange rate. However, it is important to realize that about half of Germany's trade is with eurozone countries and a real exchange rate depreciation is quickly passed on to the other eurozone countries. ${ }^{14}$ Therefore, the effect on the trade balance may

\footnotetext{
${ }^{14}$ Even before the introduction of the euro in 1999 many European countries pegged their
} 
Figure 3.4: Domestic response to a real effective exchange rate (first column) and real stock price shock (second column) in Germany
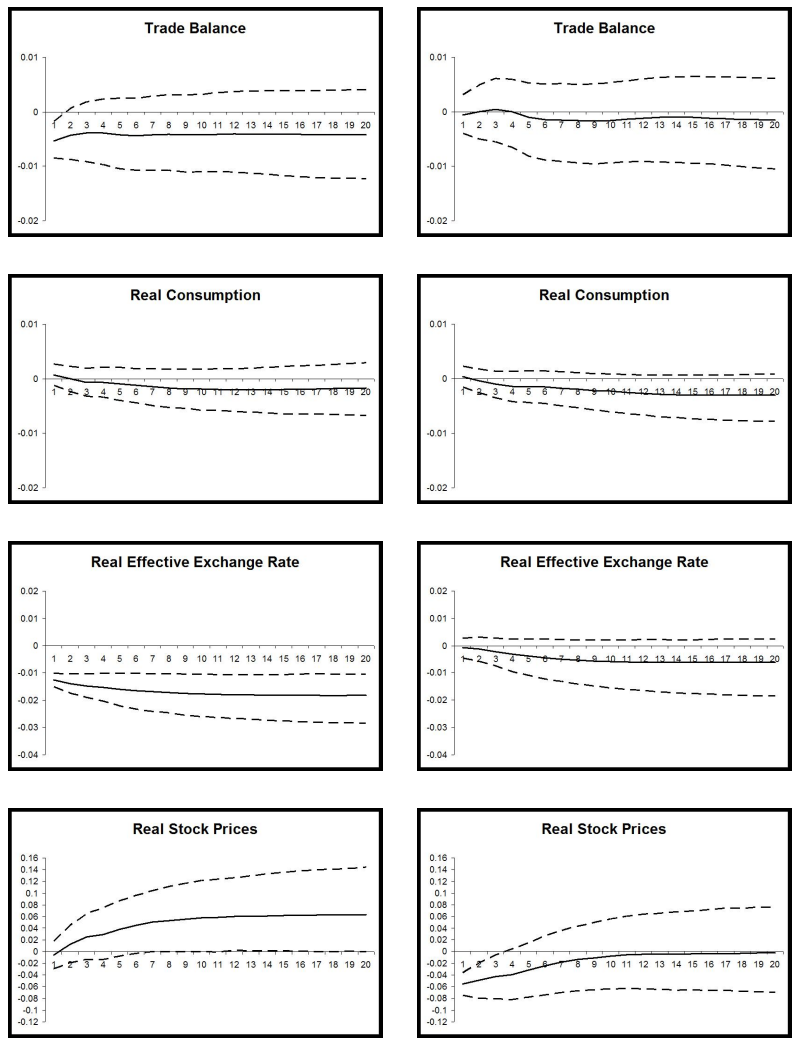
be quite limited, which confirms the findings of Lane and Milesi-Ferretti (2002). These authors also find a much weaker dependence of German, French and UK trade balances on real exchange rate movements compared to the US. We also do not see any effect on consumption.

Similarly, we find that the stock price decrease neither exerts a significant influence on the trade balance nor does it affect consumption in Germany. A plausible reason for this finding is the low stock ownership rate in Germany. Therefore stock price changes will not have a very large effect, because they do not constitute the majority of German households' financial assets.

The results of the forecast error variance decomposition will be discussed in more detail in Section 5, but these results are also relevant for the discussion here. The variance decomposition shows that the German trade balance is very persistent and exogenous shocks only have a very limited impact on the German trade balance. The reunification of the country also plays a role here by producing breaks in the first quarter of 1991 in most German data series. While the GVAR methodology copes with co-breaking data series, we also transformed the data series and included a dummy in the short-term dynamics of the model. The above described results are found to be robust across specifications.

\subsubsection{The international wealth channel for Japan}

The first column of Figure 3.5 shows the GIRFs for a negative shock to the real effective exchange rate of Japan. The shock corresponds to a depreciation of about 3 percent on impact and remains at this level after 20 quarters. The Japanese trade balance displays the classic J-curve behaviour, which is only statistically significant on impact. Gupta-Kapoor and Ramakrishnan (1999) provide empirical evidence in favour of the existence of the J-curve for Japan, for which there is some evidence here as well. However, similar to Germany we do not see an improving trade balance, while we would expect a strong dependence of the export driven Japanese economy on the real effective exchange rate.

We observe that the depreciation of the exchange rate translates into reduced real consumption, 0.07 percent after 4 quarters and 0.27 percent after 20 quarters, the response is statistically insignificant. Albeit only significant on impact, we observe an increase in stock prices in Japan. This effect mitigates the negative effects of an exchange rate depreciation on consumption, because stock price increases have a positive effect on consumption and consequently imports.

Next we expose Japanese real stock prices to a one standard deviation negative real stock price shock. It implies a fall in stock prices of 6.2 percent on impact

currency (or allowed exchange rate bands) to the German Mark under the European Exchange Rate Mechanism. 
Figure 3.5: Domestic response to a real effective exchange rate (first column) and real stock price shock (second column) in Japan
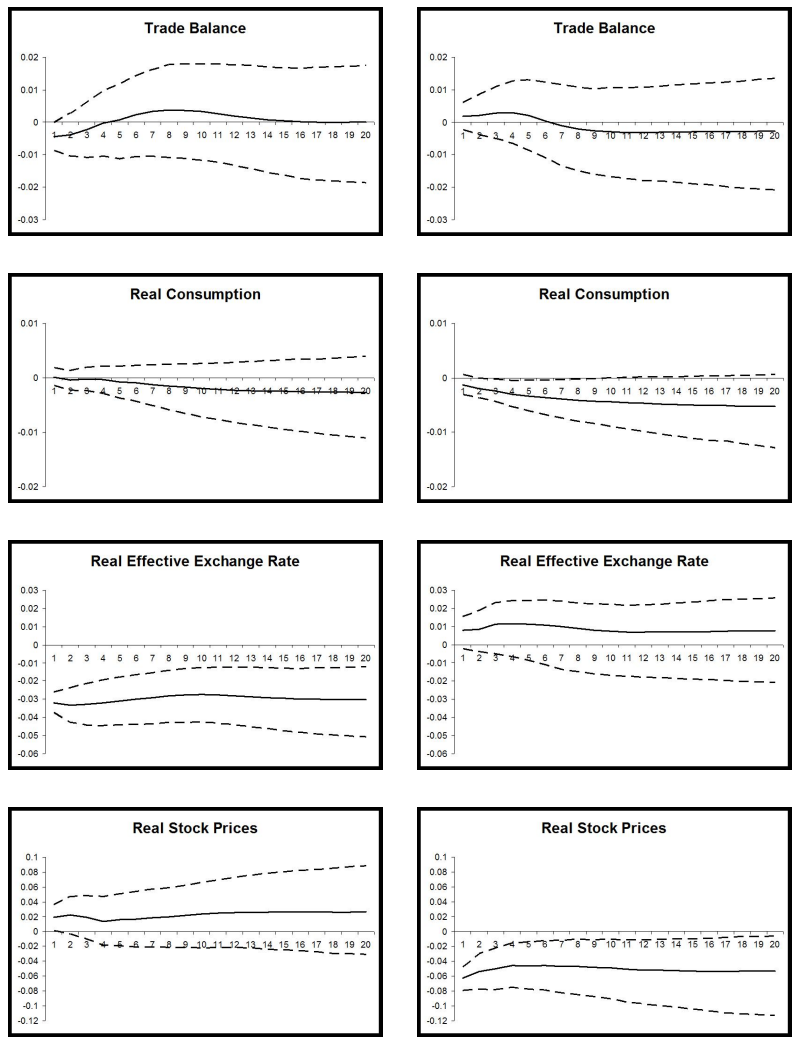
and about 5.3 percent after a few quarters. The corresponding GIRFs are shown in the second column of Figure 3.5 and these do not show an effect on the trade balance.

Following the shock to Japanese real stock prices, we find that real consumption in Japan drops by 0.1 percent on impact, and further by up to 0.5 percent after 20 quarters. The drop is statistically significant over the first 10 quarters. This implies that the decrease in consumption is primarily a drop in consumption of domestic goods and not imported goods.

\subsection{Forecast error variance decomposition}

Complementary to the GIRF analysis in the previous section, we conduct a generalized forecast error variance decomposition (GFEVD) to answer the question of how much of the error variance in forecasting the trade balance and real consumption can be attributed to shocks in the real effective exchange rate, real stock market and real housing prices. The results are shown in Table 3.7 and strongly confirm our previous findings from the generalized impulse response analysis.

First, shocks to the real effective exchange rate are by far most influential for real consumption and the trade balance in the US. Over all time horizons, these shocks explain up to 18.3 percent of the variation in real consumption and 21.6 percent of the variation in the trade balance. By contrast, in all other G5 countries, shocks to the real effective exchange rate contribute at most 2.5 percent to the variation in real consumption and 9.4 percent to the variation in the trade balance. Particularly, the pronounced impact that shocks to the real effective exchange rate have on US consumption decisions provides a strong case for the prominent role that the foreign sector plays in the US.

These results confirm the findings of Lane and Milesi-Ferretti (2002), who find a strong relationship between the real exchange rate and the trade balance for the US, a weaker relationship for Germany and no connection for France and the UK. However, Lane and Milesi-Ferretti (2002) find a strong dependence of the Japanese trade balance on the real exchange rate, whereas we find that the real effective exchange rate does not play a role.

Second, except for Germany, we find in all other G5 countries that shocks to real stock prices explain a substantially greater share of the variation in real consumption and the trade balance than real effective exchange rates do. We take from it that domestic stock price movements constitute a potent alternative to the traditional exchange rate channel in shaping a country's external adjustment process. 
Third, in all G5 countries, shocks to real housing prices contribute a greater share to the forecast error variance of the trade balance than of real consumption. This points at the potential relevance of business and private investment decisions for passing through housing price shocks to the trade balance. Finally, the forecast error variance decomposition confirms the idiosyncratic behaviour of the German trade balance and real consumption - about 84 percent of the variation in the trade balance and up to 66 percent of the variation in real consumption are explained by their own shocks.

Table 3.7: Proportion of the N-step ahead forecast error variance explained by conditioning on contemporaneous and future innovations of the country equations

\begin{tabular}{lcccccccc}
\hline GFEVD & \multicolumn{3}{c}{ Trade Balance } & \multicolumn{5}{c}{ Real Consumption } \\
\hline Country & $t b$ & $r e e r$ & $r s$ & $r h$ & $r c$ & $r e e r$ & $r s$ & $r h$ \\
\hline USA & & & & & & & & \\
4 quarters & 27.9 & 19.2 & 29.1 & 13.4 & 38.4 & 15.9 & 33.8 & 0.3 \\
8 quarters & 12.5 & 21.6 & 30.8 & 18.6 & 33.0 & 17.6 & 41.1 & 1.4 \\
12 quarters & 7.6 & 21.4 & 28.4 & 19.8 & 31.4 & 18.0 & 43.0 & 2.7 \\
16 quarters & 5.7 & 21.3 & 26.2 & 19.8 & 30.6 & 18.2 & 43.2 & 3.3 \\
20 quarters & 4.7 & 21.1 & 24.8 & 19.5 & 30.1 & 18.3 & 43.2 & 3.7 \\
\hline UK & & & & & & & & \\
4 quarters & 39.0 & 4.2 & 13.0 & 8.2 & 10.2 & 0.1 & 20.4 & 3.2 \\
8 quarters & 21.6 & 2.0 & 18.8 & 8.8 & 4.8 & 0.2 & 22.9 & 1.5 \\
12 quarters & 15.7 & 1.2 & 21.1 & 7.8 & 3.2 & 0.2 & 24.0 & 0.9 \\
16 quarters & 13.1 & 0.9 & 21.6 & 6.8 & 2.4 & 0.1 & 24.5 & 0.6 \\
20 quarters & 11.6 & 0.7 & 21.5 & 6.2 & 1.9 & 0.1 & 24.6 & 0.5 \\
\hline FRA & & & & & & & & \\
4 quarters & 62.7 & 2.3 & 6.5 & 1.7 & 24.0 & 2.3 & 4.6 & 0.8 \\
8 quarters & 57.1 & 2.1 & 7.3 & 1.9 & 7.3 & 1.5 & 2.5 & 1.5 \\
12 quarters & 52.0 & 1.3 & 7.2 & 2.0 & 4.6 & 1.9 & 1.8 & 1.6 \\
16 quarters & 47.4 & 0.9 & 6.9 & 2.0 & 3.7 & 2.3 & 1.5 & 1.5 \\
20 quarters & 43.7 & 0.7 & 6.7 & 2.1 & 3.4 & 2.5 & 1.4 & 1.4 \\
\hline GER & & & & & & & & \\
4 quarters & 85.3 & 6.5 & 0.6 & - & 65.6 & 0.3 & 5.8 & - \\
8 quarters & 83.9 & 8.0 & 1.4 & - & 33.6 & 0.2 & 10.2 & - \\
12 quarters & 83.6 & 8.7 & 1.9 & - & 18.0 & 0.1 & 10.5 & - \\
16 quarters & 83.6 & 9.1 & 2.2 & - & 11.3 & 0.1 & 9.5 & - \\
20 quarters & 83.7 & 9.4 & 2.4 & - & 7.9 & 0.1 & 8.2 & - \\
\hline JPN & & & & & & & & \\
4 quarters & 49.3 & 0.5 & 2.3 & - & 73.1 & 0.3 & 17.7 & - \\
8 quarters & 37.7 & 0.8 & 1.7 & - & 54.2 & 1.2 & 26.9 & - \\
12 quarters & 32.8 & 0.6 & 1.2 & - & 41.1 & 1.7 & 28.3 & - \\
16 quarters & 30.6 & 0.5 & 0.9 & - & 32.9 & 1.8 & 27.8 & - \\
20 quarters & 29.5 & 0.4 & 0.8 & - & 27.7 & 1.6 & 27.2 & - \\
\hline \hline
\end{tabular}

Note: The numbers show the percentage of the forecast error variance explained of the trade balance and consumption, by the domestic real effective exchange rate, stock prices and housing prices. 


\subsection{Stability and specification of the global VAR}

The possibility of structural change is an issue of fundamental importance in economic and econometric modeling, but also one that is notoriously difficult to assess. Although the associated literature is huge, it is not conclusively known how best to model breaks in forecasting and policy analysis (Pesaran, 2006; Dees et al., 2007). In the context of our GVAR model, structural stability refers to the stability of the long-run and short-run coefficients and the error variances. Within the GVAR framework the problem of structural stability is mitigated however as the country-specific models are conditioned on foreign variables. Hence, to the extent that country-individual variables are subject to breaks around the same time, consider for instance the stock market crash in the early 2000s, the GVAR framework is able to accomodate this so-called co-breaking phenomenon. ${ }^{15}$ As a consequence, the GVAR model proves more robust to the possibility of structural breaks than reduced-form single-equation models (Dees et al., 2007).

Following Dees et al. (2007) we conduct a battery of structural stability tests of the short-run coefficients. These coefficients determine predominantly the transmission through the international wealth channel that we are interested in. Moreover a meaningful test of the stability of the long-run coefficients might be infeasible given the limited time series dimension available. Before discussing the test results a few remarks are in order. First, all tests that we employ are based on the residuals of the equations of the country individual models, thus depend only on the rank of the cointegrating vectors, but not on the exact identification of the long-run parameters. Second, all tests assume an unknown structural change point. Third, all tests employ an analytical procedure as compared to bootstrap procedures. The latter might provide better approximations to finitesample behavior (Diebold and Chen, 1996). Candelon and Lütkepohl (2001) show for instance that standard Chow tests reject the stability hypothesis far too often for multivariate dynamic models if the sample size is small relative to the number of parameters. A corresponding size adjustment may be based on bootstrap procedures. We have to bear this result in mind when interpreting our stability tests that do not provide for these bootstrap-based size corrections.

The stability tests that we adopt from Dees et al. (2007) include the Ploberger and Krämer (1992) maximal OLS CUSUM statistic ( $\left.\mathrm{PK}_{\text {sup }}\right)$, its mean square variant $\left(\mathrm{PK}_{m s q}\right)$, the Nyblom (1989) test (Nyblom), which considers a nonstationary alternative, the Wald form of the Quandt (1960) likelihood ratio statistic (QLR), the mean Wald statistic (MW) of Hansen (1992) and Andrews and Ploberger (1994) and the Andrews and Ploberger (1994) Wald statistic based on the exponential average (APW). For the latter four tests we also apply the

\footnotetext{
${ }^{15}$ For more details see Hendry (1996) and Hendry and Mizon (1998).
} 
Table 3.8: Tests of parameter constancy

\begin{tabular}{|c|c|c|c|c|c|c|c|c|c|c|}
\hline \multirow[t]{2}{*}{ Test } & \multicolumn{9}{|c|}{ Domestic variables } & \multirow[t]{2}{*}{ Total } \\
\hline & $t b$ & $r y$ & reer & $r c$ & $r s$ & $r h$ & $r^{l}$ & $r^{s}$ & oil & \\
\hline$\overline{P K_{s u p}}$ & 3.4 & 0.0 & 6.9 & 10.3 & 0.0 & 14.3 & 5.0 & 0.0 & 0.0 & 4.4 \\
\hline$P K_{m s q}$ & 3.4 & 0.0 & 0.0 & 6.9 & 0.0 & 21.4 & 0.0 & 0.0 & 0.0 & 2.9 \\
\hline Nyblom & 10.3 & 0.0 & 10.3 & 3.4 & 15.4 & 14.3 & 10.0 & 14.8 & 0.0 & 9.3 \\
\hline robust-N & 6.9 & 6.9 & 0.0 & 3.4 & 11.5 & 7.1 & 0.0 & 7.4 & 0.0 & 5.4 \\
\hline QLR & 37.9 & 10.3 & 24.1 & 17.2 & 34.6 & 42.9 & 35.0 & 44.4 & 0.0 & 29.4 \\
\hline robust-QLR & 7.7 & 7.7 & 3.8 & 3.8 & 12.5 & 25.0 & 0.0 & 18.5 & 0.0 & 9.1 \\
\hline MW & 24.1 & 13.8 & 17.2 & 13.8 & 30.8 & 14.3 & 20.0 & 22.2 & 0.0 & 19.6 \\
\hline robust-MW & 15.4 & 15.4 & 3.8 & 3.8 & 16.7 & 16.7 & 5.3 & 18.5 & 0.0 & 11.8 \\
\hline APW & 37.9 & 10.3 & 24.1 & 17.2 & 34.6 & 35.7 & 35.0 & 44.4 & 0.0 & 28.9 \\
\hline robust-APW & V 7.7 & 15.4 & 3.8 & 3.8 & 16.7 & 25.0 & 0.0 & 18.5 & 0.0 & 10.7 \\
\hline
\end{tabular}

Note: The table reports the percentages of rejections of the null of parameter constancy per variable across the country-specific models at the 5 percent nominal level.

heteroskedastic-robust versions. Table 3.8 shows the test results, where for each variable the percentage of rejections at the 5 percent nominal level is reported. The last column shows the total number of rejections by each test. When we consider the $\mathrm{PK}_{\text {sup }}$ and $\mathrm{PK}_{m s q}$ test the total rejection rate of parameter stability is 4.4 percent and 2.9 percent, respectively. This implies that we reject coefficient stability only for a small number of variables. The Nyblom test shows similar results, both versions show rejection rates lower than 10 percent and based on these results there seems to be little concern about parameter stability.

Interestingly, the tests do not always reject stability for the same variables. The PK tests never reject stability for stock market prices, whereas the Nyblom tests show relatively high rejection rates. A similar story applies to short-term interest rates. The QLR, MW and APW tests show very high rejection rates across all variables. Both the QLR and APW tests show rejection rates of over 30 percent for stock prices, housing prices, short-term and long-term interest rates. The QLR rejects stability for 60 out of 204 variables and the results for MW and APW show similar rejection rates. However, the rejection rates are much lower when we take heteroskedasticity into account in these tests. Accounting for heteroskedasticity is especially important for variables such as stock and housing prices. In this situation all tests show rejection rates close to 10 percent. Notice that the drop is especially strong for those variables which had high rejection rates before accounting for heteroskedasticity.

These findings imply that the main reason of rejection by the tests appears to be breaks in error variances and not changes in the parameter coefficients. So, most of the structural parameters in our model seem to be relatively stable and concerns for structural breaks are further mitigated, also against the background of the findings in Candelon and Lütkepohl (2001). We account for heteroskedasticity by 
Table 3.9: Correlation coefficients of country-specific foreign variables using constant and time-varying trade weights

\begin{tabular}{|c|c|c|c|c|c|c|c|c|c|c|c|c|}
\hline Country/region & $r y^{*}$ & $r c^{*}$ & $r s^{*}$ & $r h^{*}$ & $r^{l *}$ & $r^{s *}$ & $\Delta r y^{*}$ & $\Delta r c^{*}$ & $\Delta r s^{*}$ & $\Delta r h^{*}$ & $\Delta r^{l *}$ & $\Delta r^{s *}$ \\
\hline United States & 1.00 & 1.00 & 0.99 & 1.00 & 1.00 & 0.95 & 0.76 & 0.90 & 0.98 & 0.99 & 0.99 & 0.96 \\
\hline China & 1.00 & 1.00 & 0.99 & 1.00 & 0.99 & 0.99 & 0.75 & 0.75 & 0.99 & 0.90 & 0.97 & 0.98 \\
\hline India & 0.99 & 1.00 & 1.00 & 1.00 & 1.00 & 0.95 & 0.75 & 0.69 & 0.99 & 0.98 & 0.98 & 0.93 \\
\hline Japan & 0.99 & 1.00 & 1.00 & 1.00 & 1.00 & 0.98 & 0.57 & 0.77 & 0.99 & 0.92 & 0.98 & 0.96 \\
\hline \multicolumn{13}{|l|}{ Europe } \\
\hline Austria & 1.00 & 1.00 & 1.00 & 1.00 & 1.00 & 1.00 & 0.98 & 0.99 & 1.00 & 0.99 & 1.00 & 1.00 \\
\hline Belgium & 1.00 & 1.00 & 1.00 & 1.00 & 1.00 & 1.00 & 0.94 & 0.98 & 1.00 & 0.99 & 1.00 & 0.99 \\
\hline Denmark & 1.00 & 1.00 & 1.00 & 1.00 & 1.00 & 1.00 & 0.95 & 0.98 & 1.00 & 0.99 & 1.00 & 1.00 \\
\hline Finland & 1.00 & 1.00 & 1.00 & 1.00 & 1.00 & 0.99 & 0.88 & 0.94 & 1.00 & 0.99 & 0.99 & 0.99 \\
\hline France & 1.00 & 1.00 & 1.00 & 1.00 & 1.00 & 0.99 & 0.91 & 0.96 & 1.00 & 0.99 & 0.99 & 0.99 \\
\hline Germany & 1.00 & 1.00 & 1.00 & 1.00 & 1.00 & 0.99 & 0.89 & 0.95 & 1.00 & 0.99 & 0.99 & 0.98 \\
\hline Italy & 1.00 & 1.00 & 1.00 & 1.00 & 1.00 & 0.99 & 0.90 & 0.93 & 1.00 & 0.99 & 0.99 & 0.99 \\
\hline Luxembourg & 1.00 & 1.00 & 1.00 & 1.00 & 1.00 & 0.99 & 0.81 & 0.93 & 1.00 & 0.99 & 1.00 & 0.99 \\
\hline Netherlands & 1.00 & 1.00 & 1.00 & 1.00 & 1.00 & 0.99 & 0.87 & 0.95 & 1.00 & 0.99 & 1.00 & 0.98 \\
\hline Norway & 1.00 & 1.00 & 1.00 & 1.00 & 1.00 & 1.00 & 0.95 & 0.95 & 1.00 & 0.97 & 0.99 & 0.98 \\
\hline Spain & 1.00 & 1.00 & 1.00 & 1.00 & 0.99 & 0.97 & 0.87 & 0.83 & 0.99 & 0.98 & 0.99 & 0.95 \\
\hline Sweden & 1.00 & 1.00 & 1.00 & 1.00 & 1.00 & 1.00 & 0.95 & 0.97 & 1.00 & 0.99 & 1.00 & 0.99 \\
\hline Switzerland & 1.00 & 1.00 & 1.00 & 1.00 & 1.00 & 1.00 & 0.98 & 0.98 & 1.00 & 0.99 & 1.00 & 1.00 \\
\hline United Kingdom & 1.00 & 1.00 & 1.00 & 1.00 & 1.00 & 1.00 & 0.92 & 0.97 & 1.00 & 0.99 & 1.00 & 0.99 \\
\hline \multicolumn{13}{|l|}{ Other OECD } \\
\hline Australia & 0.99 & 1.00 & 1.00 & 1.00 & 0.99 & 0.97 & 0.73 & 0.78 & 0.99 & 0.98 & 0.97 & 0.96 \\
\hline Canada & 1.00 & 1.00 & 1.00 & 1.00 & 1.00 & 1.00 & 0.94 & 0.98 & 1.00 & 1.00 & 1.00 & 1.00 \\
\hline Mexico & 1.00 & 1.00 & 1.00 & 0.99 & 1.00 & 1.00 & 0.94 & 0.97 & 0.99 & 0.96 & 1.00 & 0.99 \\
\hline New Zealand & 1.00 & 1.00 & 1.00 & 1.00 & 1.00 & 0.99 & 0.83 & 0.86 & 0.99 & 0.98 & 0.99 & 0.98 \\
\hline \multicolumn{13}{|c|}{ South-East Asia } \\
\hline Indonesia & 0.99 & 1.00 & 0.98 & 0.99 & 0.98 & 0.98 & 0.61 & 0.78 & 0.98 & 0.94 & 0.97 & 0.96 \\
\hline Korea & 0.99 & 1.00 & 1.00 & 1.00 & 1.00 & 0.93 & 0.72 & 0.68 & 0.99 & 0.99 & 1.00 & 0.93 \\
\hline Malaysia & 1.00 & 1.00 & 1.00 & 1.00 & 1.00 & 0.99 & 0.76 & 0.91 & 0.99 & 0.88 & 0.99 & 0.98 \\
\hline Phillipines & 0.99 & 1.00 & 0.99 & 1.00 & 1.00 & 0.99 & 0.52 & 0.53 & 0.98 & 0.95 & 0.98 & 0.97 \\
\hline Singapore & 1.00 & 1.00 & 1.00 & 1.00 & 0.99 & 0.98 & 0.73 & 0.78 & 0.99 & 0.96 & 0.98 & 0.96 \\
\hline Thailand & 1.00 & 1.00 & 1.00 & 1.00 & 1.00 & 0.98 & 0.71 & 0.80 & 0.99 & 0.91 & 0.99 & 0.97 \\
\hline \multicolumn{13}{|l|}{$\overline{\text { Oil }}$} \\
\hline Saudi Arabia & 0.99 & 1.00 & 0.98 & 1.00 & 0.98 & 0.98 & 0.58 & 0.78 & 0.96 & 0.86 & 0.97 & 0.96 \\
\hline
\end{tabular}

Note: The table reports the correlation coefficients of country-specific foreign variables using constant and time-varying trade weights.

using robust bootstrapped standard errors for the determination of the confidence bounds of the GIRFs. Moreover we account for the uncertainty surrounding the parameter stability by taking a conservative stance on the width of the confidence bounds - a 90 percent confidence bound is considered.

Finally, we address the implications of using time-varying trade-weights on the starred variables and the number of cointegrating relationships. Table 3.9 displays the correlation coefficients of country-specific foreign variables using constant and time-varying trade weights. Since the country-specific foreign variables are determined as the product of trade weights and the respective economic variables, 
they will follow the trend of the relevant variables in the other country models.

The results show a very strong relationship between the starred variables using fixed or varying trade weights. The correlation coefficient is close to one. However, part of this strong relationship may be reflected by a common time trend. Therefore, Table 3.9 considers also the correlation between the first difference starred variables. Correlations are again very high, especially for financial data (stock market prices, housing prices and interest rates) where virtually all correlations are above 0.9 .

Most developed countries show very high correlations for GDP and consumption as well, whereas correlations are slightly lower for most developing countries, at around 0.7 .

The number of cointegrating vectors changes slightly for a number of countries when employing time-varying weights. There are several countries for which the trace test selects one cointegrating vector less: Finland, Philippines, Saudi-Arabia, Sweden, Thailand and the United Kingdom. Others will get one more: Australia, Denmark, France, Singapore and the United States. Overall, this sensitivity is similar to Dees et al. (2007) for their GVAR model when they employ time-varying instead of fixed trade-weights. A full exposition of the results using time-varying trade-weights can be provided upon request.

\subsection{Conclusion}

In this paper we empirically test the link between real stock and housing prices, consumption and the trade balance. Against the background of an established theoretical and empirical literature that links asset prices to consumption through the domestic wealth effect, we argue that the current surge of real and financial integration provokes an international perspective. Hence, we hypothesize that movements in real stock and housing prices are transmitted also into the trade balance. We refer to this link as the international wealth channel and test if it is a potential alternative to exchange rate changes using the recent GVAR methodology of PSW. The GVAR methodology is particularly suited for our study since it explicitly accounts for the complex interdependencies that exist across countries. It proceeds in two steps. First, we estimate individual VECMs for 29 countries over the period 1981Q1-2006Q4. Second, we combine these country individual models into a global VAR representation using information on bilateral trade patterns.

The global VAR model allows conducting generalized impulse response studies and forecast error variance decompositions that provide evidence in favour of the existence of the international wealth channel for the US, UK and France. In these countries, exposing real stock prices to a one standard deviation negative 
shock results in a statistically significant improvement of the trade balance. In addition, we observe a simultaneous significant decrease in consumption, showing that stock price changes have an effect on the trade balance through consumption. We also observe that the trade balances of the same countries improve following a negative shock to real housing prices. This housing shock is not transmitted through consumption and we conjecture that business and private expenditures on investments are the likely transmission mechanisms. We also test if the international wealth channel exists for Germany and Japan, but do not find any statistically significant results.

To determine the relative importance of real stock and housing prices for consumption and the trade balance, we also consider the real effective exchange rate in our studies and find compelling evidence that asset prices are at least as important drivers of international trade balances as real effective exchange rates. This finding is a crucial impetus in the debate on global current account imbalances. In this context, we also find that movements in the real effective exchange rate exert a considerable influence on US real consumption and the trade balance. This influence is not paralleled by any other country and points at the prominent role that the foreign sector plays for the US.

\subsection{Appendix: Data sources}

- Trade data for all countries are from the IMF Direction of Trade Statistics at the quarterly frequency and in US\$. The trade balance is constructed as the log of exports over imports and seasonally adjusted in EViews using the X12 method of the US Census Bureau.

- Nominal consumption, nominal output and inflation data are from the IMF International Financial Statistics at the quarterly frequency an in domestic currency. For China, India, Indonesia, Malaysia, New Zealand, Saudi Arabia and Thailand annual data are interpolated to a quarterly frequency in some cases. We interpolate the data by first taking logs and assuming a constant growth rate between two annual observations. Real consumption and real output are seasonally adjusted in EViews using the X12 method of the US Census Bureau.

- Real effective exchange rate data are taken from the IMF International Financial Statistics at the quarterly frequency.

- Stock price data are from Global Financial Data using a large domestic stock market index. Stock market index prices are denominated in local currencies and at the quarterly frequency. 
- United States (S\&P 500 Composite Price Index), Japan (Nikkei 225 Stock Average) and India (Bombay SE Sensitive Index)

- European countries: Austria (Wiener Boersekammer Share Index), Belgium (Brussels All-Share Price Index), Denmark (OMX Copenhagen All-Share Price Index), Finland (OMX Helsinki All-Share Price Index), France (SBF-250 Index), Germany (CDAX Composite Index), Italy (Banca Commerciale Italiana Index), Luxembourg (LuXX Index), Netherlands (All-Share Price Index), Norway (Oslo SE All-Share Index), Spain (Madrid SE General Index), Sweden (Affarsvarlden General Index) and United Kingdom (FTSE All-Share Index)

- Other OECD: Australia (ASX All-Ordinaries), Canada (S\&P/TSX 300 Composite), Mexico (SE Indice de Precios y Cotizaciones) and New Zealand (SE Share Capital All Index)

- South-East Asia: Korea (SE Stock Price Index KOSPI), Malaysia (KLSE Composite), Philippines (Manila SE Composite Index), Singapore (FTSE All-Share Index) and Thailand (SET General Index)

- Housing price data are from the Bank of International Settlements at quarterly frequency.

- Both short term and long term interest rates are from the IMF International Financial Statistics at the quarterly frequency.

- The oil price is the price in US\$ of one barrel Brent crude and retrieved through Datastream. 


\section{4 \\ CAUSES OF US EXTERNAL DEFICITS: \\ AN INTERNATIONAL \\ PORTFOLIO-BALANCE MODELING PERSPECTIVE}

\subsection{Introduction}

International financial integration manifests itself in three stylized facts: (1) an unprecedented expansion of private international asset trade, (2) growing country heterogeneity of international balance sheets and (3) valuation gains that dominate the evolution of the net international investment position (NIIP) of countries. Empirically, these stylized facts are well-documented in the literature (Lane and Milesi-Ferretti, 2001, 2003, 2005, 2007). What remains relatively unexplored is the modeling of the international adjustment process in a globalized world. What forces are in place and how do they interact to bring a country with an initial current account deficit back to long-term national solvency? What is the relative role of asset prices and exchange rates and do they have the potential to mitigate the necessary current account adjustments of a debtor country on its path to external balance? Any model that seeks to answer these questions needs to combine the complex interplay between asset price and exchange rate movements, valuation effects on NIIPs and current account (im)balances with the stylized facts that characterize today's integrated financial markets.

This is the first contribution of the present paper. We develop a portfoliobalance model that builds on the contributions of Branson (1979), Henderson and Rogoff (1982) and Kouri (1983) and advances the more recent work of Blanchard et al. (2005) - hereinafter BGS - in a number of ways. The second contribution is to calibrate the model to the US and to evaluate two common arguments for the emergence of US current account deficits: the savings glut hypothesis and US economic policies and developments. 
The early versions of portfolio-balance theory incorporate net cross-country investment positions, but neglect the valuation channel of exchange rate adjustments and asset price movements. Thus they fail to account for all three stylized facts of financial integration. BGS take a first step in modifying the portfoliobalance theory to better cope with financially integrated markets. They consider US external imbalances and develop a model where changes in the NIIP of the US and the rest of the world (RW) are the sum of the current account and exchange-rate induced capital gains. In the spirit of earlier portfolio-balance models, exchange rate changes remain the unique equilibrating force, although they have been assigned a dual role in the external adjustment process. This is a clear limitation of the BGS model. It omits the vital role asset prices play in the external adjustment process, and thus partly fails to account for Stylized Fact 3. Moreover, BGS consider US and RW asset markets in their aggregate form without discriminating the risk-return characteristics of different asset classes. Rey (2005) rightly points out in her discussion of the BGS paper that reality looks different. US foreign assets are tilted towards risky equity investments, while US liabilities are dominated by low-yielding Treasury bonds. As a consequence, BGS ignore that the external adjustment process depends on relative return differentials as implied by Stylized Fact 2.

This chapter develops an advanced version of the BGS model and calibrates it to match the external imbalances of the US. One of the main improvements of our portfolio-balance model on the BGS model is the split of US and RW asset markets into equity and bond markets. It allows us to model explicitly the dynamics of exchange rates and relative asset prices as required for Stylized Fact 3 and enables us to account for the international balance sheet asymmetries of Stylized Fact 2.

Another, related and innovative, feature of our model is the inclusion of wealth dynamics. Bernanke (2005) emphasizes in his discussion of the BGS model that the exogenous treatment of asset values is the most important omission of the BGS model since it precludes any endogenous evolution of wealth due to changes in asset prices as a source of current account dynamics. In contrast, we include relative asset prices and ensuing wealth and consumption dynamics as an integral part of the model and introduce them as an alternative channel to moderate the US external deficit.

We argue that our model is better equipped to discuss all aspects of the debate on the causes of the huge US current account deficits. In particular, we take up two lines of arguments in the literature. A number of authors argue that economic policies and developments within the US have contributed to the emergence of its current account deficits (e.g. Bems et al., 2007), while others emphasize that a global perspective is warranted, in particular considering the global appetite for US assets (e.g. Bernanke, 2006, 2007). We model both considerations, separately 
and jointly, to shed further light on these arguments and find that the combination of both seems to fit empirical findings best. Despite exchange rate and asset price induced valuation gains, the US experienced a tremendous accumulation of net foreign debt with only moderate depreciation of the real effective exchange rate. Between 1990 and 2006 the US net foreign debt position worsened in the range of US-\$ 2 trillion, while the real effective exchange rate depreciated by about 3.5 percent.

Our model addresses many relevant issues of financially integrated markets. However we stress from the outset that the model is not capable of providing a complete description of the world. Rather it is our intention to deliver a partial, but concise, framework within which to analyze the joint dynamics of the current account, the exchange rate and relative asset prices and to produce results that are consistent with recent empirical trends. As such our model stands as an alternative to the more comprehensive class of open-economy dynamic general equilibrium models. Research into this class of models has been initiated by Obstfeld and Rogoff (1995), who provide a two-country framework that integrates exchange rate dynamics and the current account. Their model and those that followed embody the main elements of the intertemporal approach to the current account along with nominal rigidities and market imperfections. For a survey of these models, see Lane (2001). More recently and in light of proceeding financial integration, a growing literature on dynamic general equilibrium models has directed attention to the question of how investors make asset allocation decisions across countries and currencies. See the survey by Obstfeld (2007) and references therein for attempts at general-equilibrium models of portfolios in a world economy. Despite these interesting attempts, we believe that partial theories have their own virtue e.g. they do not need to rely on linearization methods to render complex non-linearities of the model tractable (see also Krugman, 2000; Buiter, 2009). We acknowledge the limits of a partial-equilibrium framework whenever a more comprehensive treatment would be desirable. That is the case for instance in the next chapter, where we consider the sustainability of global imbalances.

The rest of the chapter is organized as follows. Section 4.2 revisits the empirical stylized facts and integrates our portfolio-balance model in the literature. That is the literature on the external adjustment process and on the causes of US current account deficits. In Section 4.3, we introduce relevant concepts, the derivation of the model and its behavior in the steady state and along the transitory path. Section 4.4 calibrates the model to the situation of the US and undertakes a number of simulation studies to put evidence on the model's ability to reproduce recent empirical findings. In particular we model two common arguments for the US current account deficits, namely the savings glut hypothesis and US economic policies and developments. Section 4.5 concludes. 


\subsection{Stylized facts and literature review}

The need to advance portfolio-balance modeling is brought about by proceeding integration of international financial markets. In this respect we discuss three stylized facts that are essential for our model. Moreover we contribute to at least two strands of the literature. First, by providing model-induced explanations we contribute to the literature that empirically investigates the adjustment process of country's external positions. Second, the application of the portfolio-balance model allows evaluating the causes of the external position of the US. We will shortly review the stylized facts and the literature in turn.

\subsubsection{Stylized facts of international financial integration}

Figure 1 summarizes three stylized facts of international financial integration that we seek to capture by our portfolio-balance model. ${ }^{1}$

1. The past two decades have witnessed an unprecedented growth in private international asset trade. As a consequence, cross-border holdings of financial assets are reaching all-time highs. Figure 4.1a shows that between 1980 and 2006, aggregate gross foreign assets and liabilities (scaled by GDP) have increased almost sixfold for OECD countries, sevenfold for Euro area countries and more than fivefold for Asian countries. ${ }^{2}$ These numbers are evidence that portfolio diversification has become the main motive for international asset flows. Investors increasingly seek foreign asset markets to diversify investment risk. Intertemporal lending and borrowing play a subordinated role.

2. The composition of gross foreign assets and liabilities in terms of equity and bonds, geographical allocation and currency denomination is more heterogeneous than ever before. Figure $4.1 \mathrm{~b}$ demonstrates the heterogeneity of the international balance sheet by splitting foreign assets and liabilities into equity and bond holdings. We find, for instance, that in 2006, the US is short in bond and long in equity holdings, while most Asian and oil-exporting countries hold considerable amounts of net foreign bonds.

\footnotetext{
${ }^{1}$ The data are taken from Lane and Milesi-Ferretti (2007) and the correlation coefficient is the trend component of the series using the Hodrick-Prescott filter with $\lambda=6.25$.

${ }^{2}$ OECD countries consist of Australia, Austria, Belgium, Canada, Denmark, Finland, France, Germany, Ireland, Italy, Japan, Mexico, Netherlands, New Zealand, Norway, Spain, Sweden, UK and the US. Euro area countries consist of Austria, Belgium, Finland, France, Germany, Ireland, Italy, Netherlands and Spain. Asian countries consist of China, Indonesia, Japan, Korea, Singapore, Taiwan and Thailand.
} 
Figure 4.1: Stylized facts of international financial integration, 1980-2006

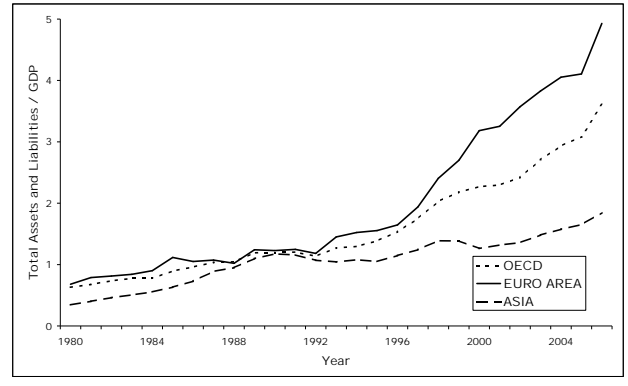

(a) Cross-border asset trade

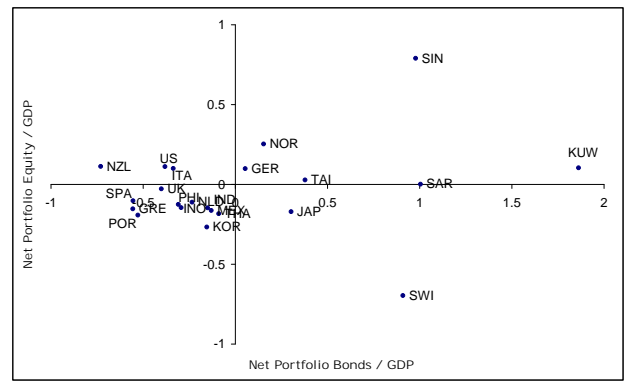

(b) Heterogeneous international balance sheet composition

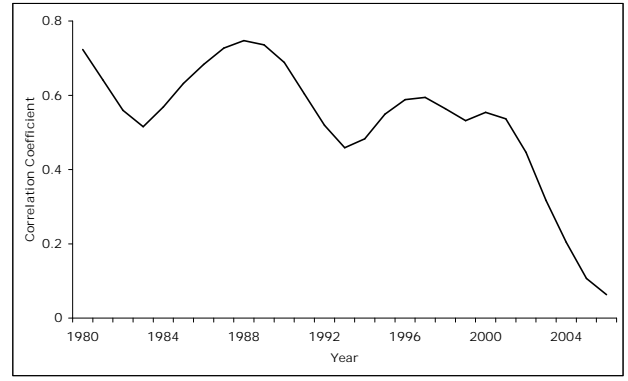

(c) Disconnect of the current account and changes in NIIP 
3. We observe an apparent disconnect between the current account and changes in the net international investment position (NIIP) of a country. Before the onset of financial globalization, changes in a country's NIIP were primarily determined by capital flows stemming from current account imbalances. Countries that were running persistent current account surpluses improved their NIIP, while countries with persistent current account deficits worsened their NIIP vis-à-vis RW. In a financially integrated world, however, exchange rate and asset price dynamics generate revaluations of existing stocks of foreign assets that are as important as current account imbalances in shaping a country's NIIP. In light of Stylized Fact 1, the impact of the valuation channels of exchange rate adjustment and asset price fluctuation has been considerably leveraged in the last two decades. Figure 4.1c illustrates the disconnect using year-by-year correlation coefficients between current accounts and changes in NIIPs. It is apparent that the current account is no longer the number one determinant of changes in a country's NIIP. The correlation is vanishing, particularly in recent years.

\subsubsection{Literature on the external adjustment process}

Two aspects of the empirical work on the external adjustment process are relevant for our paper: (1) valuation effects of exchange rate and asset price movements and (2) the wealth effect on the trade balance. Empirical studies on exchange-rateand asset-price-induced valuation gains remain largely confined to a small set of countries for which detailed statistical data on valuation components are available, e.g. the US (Gourinchas and Rey, 2007, 2008; Lane and Milesi-Ferretti, 2005; Tille, 2003) or Australia (Gourinchas, 2008). For other countries, overall valuation gains need to be estimated indirectly by combining both stock and flow data and its decomposition into exchange rate and relative asset price effects approximated by a portfolio-weighted basket of exchange rates and equity-market indices, e.g. Switzerland (Stoffels and Tille, 2007). Most important for our model of the external adjustment process is that all of these studies find conclusive evidence that valuation gains are not randomly at work. Gourinchas and Rey (2008) employ the intertemporal approach to the current account which suggests that any movement in NIIP must predict either future portfolio returns or future net export growth. For the US, they find that the valuation channel is stabilizing in nature and contributes around 30 percent of the cyclical (deviation from slow moving trends) process of international adjustment. Their findings have asset-pricing implications: external imbalances forecast net foreign portfolio returns one quarter to two years ahead. Similarly, Lane and Milesi-Ferretti (2005) establish considerable empirical support for stabilizing patterns of exchange rate and asset price movements. While 
the US net foreign asset position deteriorates, US foreign assets earn consistently higher rates of return than paid out on foreign liabilities. The rate of return differentials are asset price and exchange rate induced. The opposite pattern emerges for Switzerland. As a small and highly integrated economy, Switzerland stands out as a sizable creditor country with persistent current account surpluses that averaged 12 percent of GDP since 1999. Yet, their NIIP marginally narrowed from 128 percent of GDP in 1999 to 114 percent of GDP in 2005. Stoffels and Tille (2007) first construct estimates for valuation gains and then find that the apparent discrepancy can be (partly) attributed to exchange rate and asset price valuation losses over the observed time horizon. For Australia the picture is less clear cut. Although Gourinchas (2008) shows that exchange rate and asset price valuation are equally important for the external adjustment process of Australia, no stable and convincing pattern evolves in the data.

Having established in the empirical literature that US investors earn excess rates of return on their foreign assets, Gourinchas and Rey (2007) disaggregate these excess returns into two components: a return discount within each asset class and a composition effect due to international balance sheet asymmetries. They find that between a quarter and a third of current excess returns can be explained by the composition effect, the remainder by the return discount. Their study substantiates the need to properly include Stylized Fact 2 in our model. Curcuru et al. (2008) dispute these findings and introduce a third effect to the discussion, the timing of reshuffling across different asset classes, which they regard as a measure of investment skills. Their study confirms a positive composition effect that derives from the risk-seeking structure of the US external positions. However they claim that it is neutralized by a superior performance of US asset markets vis-à-vis the RW. Moreover, the return foreigners earn in the US would have been even higher (by about 0.70 percent per year) if not for their inferior timing and investment skills.

The second aspect concerns the wealth effect on the trade balance. While its empirical treatment is scarce in the literature, two studies provide insightful results and advocate the inclusion of the wealth effect in our model. Fratzscher et al. (2007) investigate the relative importance of asset prices (as a proxy for US financial wealth) for the US current account. Using Bayesian estimation techniques, they show that asset prices account for up to 32 percent of movements in the US current account. In contrast, real exchange rates account for only around 7 percent. In Chapter 3 we extend the study to a sample of 29 countries and cast the analysis into a global macroeconometric model. There we also establish the relevance of the international wealth channel for the external adjustment process of the US and many other countries. We include the wealth effect in our analysis, following the discussion of the BGS model by Bernanke (2005). 


\subsubsection{Literature on the causes of US current account deficits}

As regards causes of US current account deficits two complementary views can be found in the academic literature: a focus on economic policies and developments within the US and a global perspective.

Three domestic US factors are largely held responsible for the deterioration of the trade balance. First, accelerated productivity growth (relative to the rest of the world) has arguably influenced the US current account through its impact on the real exchange rate and investment demand. For instance, Hunt and Rebucci (2005) partly attribute the deterioration of the US current account in the second half of the 1990s to this factor, while Bems et al. (2007) find a greater role of technology shocks since 2000. The second domestic factor concerns the burgeoning US fiscal budget deficits and the twin deficit hypothesis. Erceg et al. (2005) find that fiscal deficits have a relatively small effect on the US trade balance. A rise in the fiscal deficit of 1 percentage point of GDP induces a trade balance deterioration of less than 0.2 percentage points of GDP. However, Bems et al. (2007) find that loose fiscal policy, in particular since 2000, contributed considerably to US current account deficits in the same way as loose monetary policy did - the third US domestic factor that is frequently put forward in the literature. We will account for these arguments in our simulation studies by exposing our model to a negative US trade balance shock.

The second view on the deterioration of US current accounts takes a global perspective and has been initiated by a speech of Bernanke (2006). It is known as the savings glut argument. The argument can be broken down into two components: the emergence of a global savings surplus and the channeling of these excess savings to the US. Bernanke $(2006,2007)$ argue that the savings glut is the result of a number of developments: (1) aging populations in developed markets, (2) developing countries that chose to become net exporter of capital in the aftermath of the Asian financial crisis, (3) central banks in developing countries that accumulate foreign reserves as a buffer against potential capital outflow and (4) to promote export-led growth and (5) sharp increases in revenues of oil exporting countries. Particularly interesting for our paper are the arguments why international financial markets have channeled these excess savings to the US. Caballero et al. (2008) argue that deep and sophisticated financial markets in combination with low political risk and strong property rights made the US an attractive destination for international investments. Gourinchas and Rey (2007) added that the US enjoys an exorbitant privilege pointing at the unique position of the US dollar in the international monetary order. Other arguments emphasize that declining foreign home bias and a lack of supply of assets elsewhere play an important role for the observed US capital inflow (Greenspan, 2004; Caballero, 
2006). In our simulation studies we will account for these arguments by considering a shock to the portfolio structure of foreign investors. In particular we model increases in foreign appetite for US assets.

\subsection{Modeling the external adjustment}

In this section, we develop our portfolio-balance model that meets the stylized facts shown in Figure 4.1. Our model advances the work of BGS, and whenever deemed necessary we shall point out both models' similarities and differences. The building assumption of the BGS analysis is that of imperfect substitutability between assets. For simplicity, we will focus on the case where the degree of substitutability is zero. ${ }^{3}$ The model is cast in discrete time, but for notational convenience, we will suppress the time index, $t$, when there is no confusion. Similar to BGS, the model can be summarized in two equilibrium relationships. The first relationship concerns equilibrium in our four asset markets, US bond and equity markets and RW bond and equity markets, and provides the equilibrium set of relative prices, $e, P$ and $P^{*}$, conditional on the net foreign debt position. We refer to it as the portfolio balance relationship. The second relationship accounts for the dynamic feedback of these relative prices on the accumulation of net foreign debt. We refer to it as the current account balance relationship and elaborate both relationships below.

\subsubsection{Introduction of relevant concepts}

Think of two countries, domestic and foreign, or the US and RW, which both have bond and equity markets. We denote the outstanding stock of US bonds and equity by $B$ and $E$, respectively, and the outstanding stock of RW bonds and equity by $B^{*}$ and $E^{*}$, respectively. ${ }^{4}$ All assets are denominated in local currency. Moreover, $P$ is the price of equity relative to bonds in the US, and $P^{*}$ the corresponding relative price in the RW. The exchange rate, $e$, is defined as the price of foreign currency in terms of the US dollar (such that an increase in the exchange rate denotes a depreciation of the US dollar). Note that this leaves us with three relative prices, $P, P^{*}$ and $e$, to uniquely identify the price system of all

\footnotetext{
${ }^{3}$ The case of rational expectations and non-zero imperfect asset substitutability has been considered in an earlier working paper version of this chapter. We refer the interested reader to METEOR Research Memorandum 09/033.

${ }^{4}$ Note that, for reasons of analytical tractability, we exclude currencies as asset classes. They are of minor relevance in the current context. This is in contrast to the early work on portfoliobalance models by Branson (1979), Henderson and Rogoff (1982) and Kouri (1983), but in line with BGS.
} 
four assets. We use subscripts to show which party holds the asset:

$$
\begin{aligned}
& B=B_{U S}+B_{R W} \\
& B^{*}=B_{U S}^{*}+B_{R W}^{*} \\
& P E=P E_{U S}+P E_{R W} \\
& P^{*} E^{*}=P^{*} E_{U S}^{*}+P^{*} E_{R W}^{*} .
\end{aligned}
$$

We can think of (4.1-4.4) as equilibrium in our four financial markets. The lefthand side constitutes the supply of assets in each market and the right-hand side the corresponding demand for these assets by both US and foreign investors.

Let $W$ denote the financial wealth of US investors, measured in units of US goods, and $W^{*}$ that of RW investors, measured in units of foreign goods, and define financial wealth as the sum of all asset holdings:

$$
\begin{aligned}
W & =B_{U S}+P E_{U S}+e\left[B_{U S}^{*}+P^{*} E_{U S}^{*}\right] \\
W^{*} & =B_{R W}^{*}+P^{*} E_{R W}^{*}+\left[B_{R W}+P E_{R W}\right] / e .
\end{aligned}
$$

Assume further that US and foreign investors want to allocate their wealth between the individual markets according to a given set of asset preferences, which are labeled with $\alpha$-shares for US investors and $\beta$-shares for RW investors. These preferences

$$
\begin{array}{cl}
B_{U S}=\alpha_{B} W, & P E_{U S}=\alpha_{E} W, \\
B_{U S}^{*}=\alpha_{B^{*}} W / e, & P^{*} E_{U S}^{*}=\alpha_{E^{*}} W / e, \\
B_{R W}^{*}=\beta_{B^{*}} W^{*}, & P^{*} E_{R W}^{*}=\beta_{E^{*}} W^{*}, \\
B_{R W}=\beta_{B} W^{*} e, & P E_{R W}=\beta_{E} W^{*} e .
\end{array}
$$

are postulated in (4.7-4.8) for US investors and in (4.9-4.10) for RW investors. Total US and RW wealth is allocated over the four asset classes such that the $\alpha$ and $\beta$-shares add up to unity. An important point to note is that we assume that these asset preferences lead to home bias in US and RW portfolios. More precisely, asset home bias implies that the wealth shares allocated to own-country assets is greater than one, $\left(\alpha_{E}+\alpha_{B}\right)+\left(\beta_{E^{*}}+\beta_{B^{*}}\right)>1$.

Additionally, we introduce in (4.7-4.10) the zero substitutability assumption to the model. We abstain from modeling the wealth shares as a function of expected return differentials, but assume that every marginal unit of wealth is invested in the same way as the average unit according to investors' asset preferences. This assumption is innocuous to the steady state behavior of our model, but affects the 
transitory path between two steady states.

Substituting (4.7-4.8) in (4.5), and (4.9-4.10) in (4.6) allows expressing US and foreign wealth and relative equity prices as functions of the exchange rate $e$ (conditional on the outstanding stocks of US and RW equity and bonds, $B, E, B^{*}$ and $\left.E^{*}\right)$. Hence we obtain

$$
\begin{aligned}
& W=\left(\beta_{B^{*}} B-\beta_{B} B^{*} e\right) / \Omega, \\
& W^{*}=\left(\alpha_{B} B^{*}-\alpha_{B^{*}} B / e\right) / \Omega,
\end{aligned}
$$

and

$$
\begin{aligned}
& P=(1 / E)\left[\left(\alpha_{E} \beta_{B^{*}}-\alpha_{B^{*}} \beta_{E}\right) B+\left(\alpha_{B} \beta_{E}-\alpha_{E} \beta_{B}\right) B^{*} e\right] / \Omega, \\
& P^{*}=\left(1 / E^{*}\right)\left[\left(\alpha_{E^{*}} \beta_{B^{*}}-\alpha_{B^{*}} \beta_{E^{*}}\right) B / e+\left(\alpha_{B} \beta_{E^{*}}-\alpha_{E^{*}} \beta_{B}\right) B^{*}\right] / \Omega,
\end{aligned}
$$

with $\Omega=\alpha_{B} \beta_{B^{*}}-\alpha_{B^{*}} \beta_{B}$. We refer to $\Omega$ as net bond home bias - the difference between the products of home $\left(\alpha_{B} \beta_{B^{*}}\right)$ and foreign $\left(\alpha_{B^{*}} \beta_{B}\right)$ demands for bonds. Note that due to portfolio home bias $\alpha_{B}>\alpha_{B^{*}}$ and $\beta_{B^{*}}>\beta_{B}$, we have $\Omega>0$. From (4.13) and (4.14), it becomes immediately apparent that in both countries relative equity prices are negative functions of outstanding equity stocks. Moreover, for reasonable asset preferences, e.g. those that we find in the data below, relative equity prices are positive functions of outstanding domestic bond stocks. Another interesting observation is that the sign of the covariances between the exchange rate, $e$, and relative equity prices, $P$ and $P^{*}$, is ambiguous. Signs depend on the preference parameters, the signs of $\left(\alpha_{B} \beta_{E}-\alpha_{E} \beta_{B}\right)$ and $\left(\alpha_{E^{*}} \beta_{B^{*}}-\alpha_{B^{*}} \beta_{E^{*}}\right)$.

We are now able to develop a portfolio-balance model that allows studying the joint dynamics of the exchange rate, relative asset prices and the current account.

\subsubsection{Portfolio balance}

Equilibrium in our four asset markets can be easily derived from the concepts introduced above. Financial markets clear at all times. In case of any disturbance, for instance, caused by cross-border wealth transfers, the relative prices, $e, P$ and $P^{*}$, move to yield short-run equilibrium in all four markets simultaneously. Since we are interested in how the external adjustment process impacts equilibrium in financial markets, we need to link the short-run equilibrium exchange rate, $e$, with the net foreign debt position of the US, $F$. The relative equity prices, $P$ and $P^{*}$, follow as functions of the exchange rate according to (4.13) and (4.14). In our analysis the net foreign debt position of the US is given as the difference between 
US foreign liabilities and foreign assets at market value:

$$
F=B_{R W}+P E_{R W}-e\left(B_{U S}^{*}+P^{*} E_{U S}^{*}\right) .
$$

Using $F=B+P E-W$, we can derive the portfolio balance relationship between net foreign debt $F$ and the exchange rate $e$ as

$$
F=\left\{\left[\left(1-\alpha_{E}\right) \beta_{B}+\beta_{E} \alpha_{B}\right] B^{*} e-\left[\left(1-\alpha_{E}-\alpha_{B}\right) \beta_{B^{*}}+\left(\beta_{E}+\beta_{B}\right) \alpha_{B^{*}}\right] B\right\} / \Omega .
$$

The portfolio balance relationship, together with (4.13) and (4.14), provides the set of relative prices, $e, P$ and $P^{*}$, that yield equilibrium in financial markets for given levels of US net foreign debt. This is the analogon to the portfolio balance curve in the analysis of BGS, but we have endogenized the shifts in the curve that happen in the BGS model due to exogenous changes in asset values. That is, our portfolio balance relationship recognizes asset price valuation effects. The slope of the relationship between the exchange rate and net foreign debt becomes:

$$
\frac{d e}{d F}=\frac{\Omega}{\left[\left(1-\alpha_{E}\right) \beta_{B}+\beta_{E} \alpha_{B}\right] B^{*}} .
$$

The slope is positive whenever $\Omega>0$, which coincides with the presence of net bond home bias. ${ }^{5}$ Under this condition, an increase in net foreign debt is associated with a depreciation of the exchange rate. The increase in net foreign debt constitutes a wealth transfer from the US to the rest of the world. Portfolio home bias implies that the wealth transfer leads to a decline in the US demand for US equity and bonds that exceeds the concomitant increase in the foreign demand for these assets. As a consequence, there is excess supply of US equity and bonds at the initial exchange rate. To restore equilibrium on all four asset markets, the relative price of US equity and bonds needs to fall, hence the exchange rate needs to depreciate. To summarize, the accumulation of net foreign debt causes changes in relative asset prices according to (4.13), (4.14) and (4.17), which are caused by both, wealth effects, as $W$ and $W^{*}$ change, and substitution effects, as US and foreign investors reshuffle their investment positions to achieve portfolio balance.

To complete the portfolio-balance model, we need a second relationship that accounts for the dynamic feedback of these relative prices on the accumulation of net foreign debt. We refer to it as the current account balance relationship and elaborate it now.

\footnotetext{
${ }^{5}$ Note the analogy with BGS from (4.17). Assuming only one asset class in the US and RW and accordingly only preferences over domestic and foreign assets, we can set $\alpha_{E}=\alpha_{B}=\alpha$, $\alpha_{E^{*}}=\alpha_{B^{*}}=(1-\alpha), \beta_{E^{*}}=\beta_{B^{*}}=\beta$ and $\beta_{E}=\beta_{B}=(1-\beta)$ to obtain the same slope for the portfolio balance relationship as in BGS.
} 


\subsubsection{Current account balance}

The second equilibrium condition defines how the relative prices, $e, P$ and $P^{*}$, feed back on the accumulation of net foreign debt. Simplifying, the accumulation of net foreign debt consists of three components: the trade deficit $(T D)$, net factor payments $(r F)$ and valuation gains $(V G)$ on the existing stock of gross foreign assets and liabilities:

$$
F_{+1}-F=T D_{+1}+r F_{+1}-V G_{+1} .
$$

First, we need to define the US trade deficit

$$
T D\left(e, W(e), W^{*}(e), s\right)
$$

with $T D_{e}<0, T D_{W}>0, T D_{W^{*}}<0$ and $T D_{s}>0$ as a function of the exchange rate, US and foreign wealth and a shift parameter, $s$. In particular, we assume that exchange rate depreciation and an increase in foreign wealth reduce the US trade deficit, while an increase in US wealth increases the own trade deficit. Important to note is that (4.11) and (4.12) define US and foreign wealth as functions of the exchange rate and we find that $W_{e}<0$ and $W_{e}^{*}>0$ hold. Thus in the presence of wealth effects, an exchange rate depreciation narrows the trade deficit directly through the common expenditure switching mechanism, but also indirectly through its impact on domestic and foreign wealth. The importance of the wealth effect is stressed in recent empirical work as we mentioned above and recognized in our model. The shift parameter, $s$, captures all exogenous influences on the trade deficit, i.e. changes in relative productivity or the taste for goods. Substituting the trade deficit in the current account balance relationship (4.18), we now are in a position to elaborate on the returns on assets and the valuation gains. Therefore the current account balance relationship is elaborated as follows:

$$
\begin{aligned}
F_{+1}-F & =r_{B} B_{R W}+\left[\left(1+r_{E}\right)\left(P_{+1} / P\right)-1\right] P E_{R W} \\
& -\left[\left(1+r_{B^{*}}\right)\left(e_{+1} / e\right)-1\right] e B_{U S}^{*} \\
& -\left[\left(1+r_{E^{*}}\right)\left(e_{+1} / e\right)\left(P_{+1}^{*} / P^{*}\right)-1\right] e P^{*} E_{U S}^{*} \\
& +T D\left(e_{+1}, W_{+1}, W_{+1}^{*}, s_{+1}\right) .
\end{aligned}
$$

(4.20) shows that the change in net foreign debt derives from asset price and exchange rate induced revaluations of the existing stocks of gross foreign liabilities (first and second terms) and gross foreign assets (third and fourth terms) and the trade balance deficit. $r_{E}, r_{B}, r_{E^{*}}$ and $r_{B^{*}}$ are best understood as the rates of return on US equity and bonds and RW equity and bonds that prevail in the 
steady state. This is not to be confused with the endogenized total return on US and RW equity, which is the sum of these steady state returns and relative equity price changes, $\left[\left(1+r_{E}\right)\left(P_{+1} / P\right)-1\right]$ and $\left[\left(1+r_{E^{*}}\right)\left(P_{+1}^{*} / P^{*}\right)-1\right]$, respectively.

The current account balance relationship captures many of the earlier introduced innovations that set our model apart from the work of BGS. First, it clearly shows that valuation gains on accumulated existing stocks of foreign assets and liabilities have three sources, changes in $e, P$ and $P^{*}$. Second, it allows for international balance sheet heterogeneity and related risk-return characteristics to exert its influence on the accumulation of net foreign debt, and third, it includes the wealth effect as a determinant of the trade deficit. In the steady state, relative prices, $e, P$ and $P^{*}$ settle at their equilibrium values, valuation gains are absent and we can obtain the steady state current account balance relationship from (4.20) as

$$
\begin{aligned}
-r F & =\left[\left(r^{\prime}-r\right) \alpha_{B}+\left(r^{*}-r\right) \beta_{B} / \Omega\right] B^{*} e \\
& -\left[\left(r^{\prime}-r\right) \alpha_{B^{*}}+\left(r^{*}-r\right) \beta_{B^{*}} / \Omega\right] B+T D\left(e, W, W^{*}, s\right)
\end{aligned}
$$

with an internal rate of return $r$ and

$$
\begin{gathered}
\left(r^{\prime}-r\right)=\left[\left(r_{B}-r\right) \beta_{B}+\left(r_{E}-r\right) \beta_{E}\right], \\
\left(r^{*}-r\right)=\left[\left(r_{B^{*}}-r\right) \alpha_{B^{*}}+\left(r_{E^{*}}-r\right) \alpha_{E^{*}}\right] .
\end{gathered}
$$

(4.21) is comparable to the current account balance relationship of BGS, when all rates of return, $r_{E}, r_{B}, r_{E^{*}}$ and $r_{B^{*}}$, are equal to the internal rate of return $r .^{6}$ Under this condition, (4.21) simplifies to the standard steady state equation for the current account

$$
-r F=T D\left(e, W, W^{*}, s\right)
$$

with slope

$$
\frac{d e}{d F}=-\frac{r}{T D_{e}}
$$

Our current account balance relationship is upward sloping since $T D_{e}<0$ and flatter than the one of BGS due to the inclusion of the wealth effects. In the steady state, the trade balance exactly offsets the interest payments on net foreign debt and valuation effects disappear. Thus, while valuation effects govern an economy

\footnotetext{
${ }^{6}$ The internal rate of return is introduced to reduce the notational burden. It is best understood as the weighted average of individual rates of return, $r_{E}, r_{B}, r_{E^{*}}$ and $r_{B^{*}}$.
} 
from one steady state to another, it is the trade balance channel of the exchange rate and its expenditure switching/reducing mechanism that ultimately balances the current account.

\subsubsection{Steady states and transitory dynamics}

Figure 4.2 plots the portfolio and current account balance relationships, $P B$ and $C A B$, respectively. Both relationships are upward sloping, where, for reasonable parameter values, we find that the current account balance relationship is flatter than the portfolio balance relationship:

$$
\frac{\Omega}{\left[\left(1-\alpha_{E}\right) \beta_{B}^{*}+\beta_{E^{*}} \alpha_{B}\right] B^{*}}>-\frac{r}{T D_{e}} .
$$

Condition (4.24) also ensures that the equilibrium of our dynamic system is saddle point stable. The condition is important when rational expectations and non-zero imperfect asset substitutability are introduced. BGS provide an intuitive interpretation. An increase in US net foreign debt has two effects on the current account balance: it increases net factor income payments, thus fueling the accumulation of foreign debt, but it also leads, through the portfolio balance relationship, to more depreciated exchange rates, thus improving the trade balance and slowing down the accumulation of foreign debt. Condition (4.24) says that the second effect dominates to yield saddle point stability. The initial steady state is found at the intersection of the two relationships in Point A. It defines the exchange rate and net foreign debt position of the US as prevailing in equilibrium. Using (4.11-4.14), we find the associated relative equity prices, $P$ and $P^{*}$, and wealth positions, $W$ and $W^{*}$ in equilibrium.

To demonstrate the operation of our model, we consider two shocks, first separately and then jointly: (1) the impact of an increased taste of the US for foreign goods and (2) the impact of an increased taste of the RW for US bonds. These arguments are often put forward as explanations for the widening US current account deficit. Our model easily accommodates such external shocks and allows studying the dynamic responses.

For the first scenario we disturb the initial equilibrium through an unexpected and permanent change in the shift parameter, $s$, that, all else equal, worsens the US trade balance. How does the dynamic system respond to the current account balance shock? While the portfolio balance equation remains unchanged in response to a change in $s$, the current account balance relationship shifts upward in Figure 4.2. For a given level of net foreign debt and concomitant net factor income payments, the value of the US currency has to depreciate to compensate the increased taste for foreign goods, and thus to keep the current account in 
Figure 4.2: Current account and portfolio balance relationships

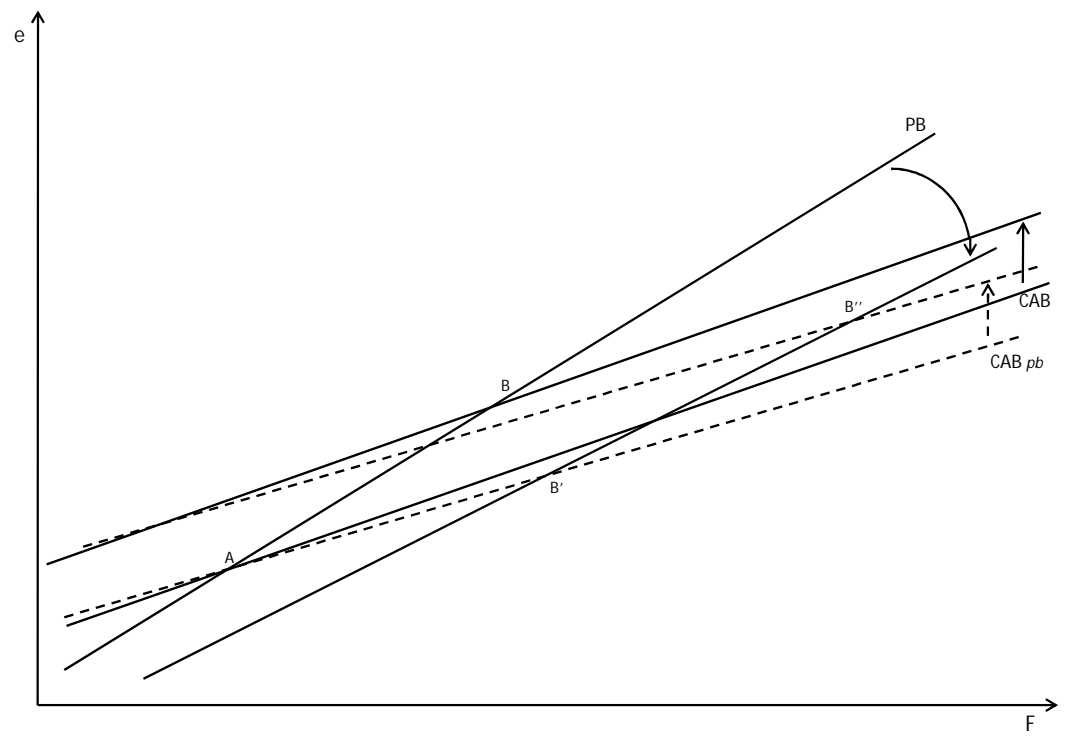

balance. The transitory behavior is determined by our assumption of zero asset substitutability. We do not observe a jump at the initiation of the shock, but the beginning of a smooth convergence process along the portfolio balance curve towards the new long run equilibrium in Point B. On the transitory path, asset markets clear at all times and the exchange rate and relative equity prices move to ensure portfolio balance. The US current account, however, turns into deficit on impact and recovers only gradually over time as the US dollar loses value. Once the two economies reach the new equilibrium in Point B, the current account balance is restored and the accumulation of foreign debt comes to a halt. Since the US has accumulated additional foreign debt in the new equilibrium, the final value of the exchange rate is more depreciated to yield a trade balance that exactly offsets the net factor income payments on the now higher level of foreign debt.

For the second scenario we disturb the initial equilibrium through unexpected and permanent changes in the asset preference parameters of RW investors. More precisely we assume an increase in $\beta_{B}$ which is compensated by decreasing $\beta_{E}$, $\beta_{B^{*}}$ and $\beta_{E^{*}}$ in proportion. In response to such a portfolio balance shock the corresponding relationship shifts downward and becomes less tilted. Both can be explained intuitively. For a given level of net foreign debt, asset-market clearing 
requires an appreciated exchange rate to offset the increased demand of foreign investors for US bonds. Also, an increased taste of RW investors for US bonds lowers the excess home demand for bonds, $\Omega$, which is the prime determinant of the slope of the portfolio balance relationship in (4.17). Less net bond home bias mitigates the need for exchange rate adjustments following a cross-border transfer of wealth. Regarding the current account balance equation, a change in asset preferences impacts the slope of the relationship through the inclusion of the wealth effect. Here it becomes less tilted. This is represented by the dashed line, $C A B_{p b}$. In contrast to the first scenario the transitory dynamics include a jump from the initial equilibrium in Point A to the new portfolio balance relationship. Subsequently the dynamic system converges towards the new equilibrium in Point $\mathrm{B}^{\prime}$. Along the trajectory we observe exchange rate depreciation and net foreign debt accumulation in both scenarios, but to different degrees compared to the first scenario.

Finally we consider shocks to current account and portfolio balance jointly and find that the system settles at the new equilibrium in Point $\mathrm{B}^{\prime \prime}$. Interesting to note is that the joint equilibrium entails a considerably larger net foreign debt position than in either scenario with only marginally more exchange rate depreciation than in the first scenario. This seems to come closest to the empirical reality of the US which has accumulated a considerable net foreign debt position over the past decade alongside moderate exchange rate movements. Note from Figure 4.2 that the relationship between net foreign debt and exchange rate changes is the same irrespective of whether a current account balance shock is added to the portfolio balance shock or not. In both scenarios the trajectory is the new PB schedule. In Section 4.4, we analyze the consequences of the two shocks as displayed in Figure 4.2 in more detail.

\subsection{Simulating the external adjustment}

We distinguish between two shocks and three scenarios when simulating the external adjustment process of the US:

Scenario $I(A \Rightarrow B)$ considers the external adjustment process following a negative shock to the US trade balance. The scenario captures those explanations that seek to attribute causes for current account deficits to US domestic policies and developments. In the corresponding simulation study we optionally consider the scenario excluding the wealth effect. Without wealth effect the scenario comes closest to the simulations of BGS.

Scenario II $\left(A \Rightarrow B^{\prime}\right)$ considers the external adjustment process following a shock 
to the portfolio preference structure of RW investors. The scenario builds on the discussion in the literature that US current account deficits are driven by foreign demand for US assets, in particular US bonds. Thus it capitalizes on the model's ability to recognize and manipulate the structure of the international balance sheet. Again we present a simulation study that discriminates the inclusion of the wealth effect.

Scenario III $\left(A \Rightarrow B^{\prime \prime}\right)$ combines the first two scenarios and thus acknowledges the reciprocity of the current account and financial account in the balance of payment. That is we reciprocate an increased taste of the US for RW goods by an increased taste of the RW for US bonds.

In preparation for the simulation analysis, we first consider the data. More specifically, we will calibrate the model to capture the US external balance as it stands in 2006 and examine the joint dynamics of the current account, exchange rate and relative equity prices.

\subsubsection{A first glance at the data}

Table 4.1: Market capitalization and allocation in 2006, USD trillions

\begin{tabular}{ccccc}
\hline \hline \multirow{2}{*}{ Market Capitalization } & \multicolumn{2}{c}{ Allocation } \\
\cline { 3 - 4 } US & Equity & 14.54 & UW \\
\cline { 3 - 4 } RW & 11.75 & 2.79 \\
& Bonds & 27.29 & 17.05 & 10.24 \\
& Equity & 24.09 & 4.33 & 19.76 \\
& Bonds & 42.09 & 5.19 & 36.90 \\
\hline \multicolumn{2}{c}{ Financial Wealth } & 38.32 & 69.69 \\
\hline \hline
\end{tabular}

The information that we need to define the model parameters are summarized in Table 4.1. In 2006, the US had outstanding US-\$14.54 trillion of equity and US-\$27.29 trillion of bonds, whereas the RW had outstanding US- $\$ 24.09$ trillion of equity and US- $\$ 42.09$ trillion of bonds. These numbers highlight the outstanding position of US financial markets. They account for about 40 percent of worldwide equity and bond capitalization. The allocation of these assets reveals a considerable degree of portfolio home bias. US investors allocate 31 and 44 percent, respectively, of their financial wealth to home equity and bond markets, but only 11 and 14 percent, respectively, to international equity and bond markets. 
For foreign investors we find a similar degree of portfolio home bias with 28 and 53 percent, respectively, of financial wealth being invested in home equity and bond markets and only 4 and 15 percent, respectively, in US equity and bond markets. Next to portfolio home bias, the asset allocation of Table 4.1 confirms international balance sheet asymmetries discussed earlier (Figure 4.1b). The US invests a relatively greater share of financial wealth in domestic and foreign equity, a total of 42 percent, in contrast to the rest of the world with a total of 32 percent. We take these percentages to define investors' asset preferences as in (4.7-4.10). Finally, one can easily derive from Table 1, that the US net foreign debt position stood at US-\$3.51 trillion in 2006 , resulting from a US-\$1.54 trillion long position in equity investments and a US- $\$ 5.05$ trillion short position in bond investments.

Another important parameter is the trade balance responsiveness to exchange rate movements. The views on the responsiveness of the US trade balance to changes in the exchange rate differ widely and depend on a number of considerations. Goldberg and Tille (2006) state that for an exchange rate change to alter the trade balance, it must first affect the border prices of imported and exported goods, these prices need to be passed on to prices paid by consumers, and finally consumers must alter their consumption behavior - substitute away from imports if they have become relatively more expensive or increase import demand if they have become relatively cheap. Goldberg and Tille (2006) find an asymmetric effect of exchange rates across the US and its trading partners that they attribute to the special role of the US dollar as a vehicle currency. Exchange rate movements are mainly influencing the trade balance via exports, leaving US expenditure on imports, by and large, unchanged. Similarly, Gust and Sheets (2006) use simulation studies to argue that a 10 percent US dollar depreciation increases US real exports by about 9 percent. Together with a 12 percent export share of US GDP, this yields a 1 percent reduction of the US trade deficit relative to GDP. We adopt these numbers in our simulations and assume that every 10 percent depreciation in the exchange rate closes the US trade balance deficit by 1 percent of GDP. The chosen value is obviously important in assessing the necessary adjustments of the variables in absolute terms.

\subsubsection{Scenario I - Current account balance shock}

In this scenario we consider a negative shock to the US current account deficit. The first simulation disregards the wealth effect (solid-line curves in Figure 4.3), whereas in the second simulation wealth dynamics become an integral part of the dynamic system (dashed-line curves in Figure 4.3). In presenting both sets of simulation results, we follow Bernanke (2005) and show the potential capacity of the wealth effect as an alternative channel to moderate the US external deficit. 
For simplicity we assume the same rate of return for all four assets, $r_{E}, r_{B}, r_{E^{*}}$ and $r_{B^{*}}$, and set it equal to 3 percent.

Obviously, the internal rate of return equals 3 percent as well and the current account balance relationship in the steady state simplifies to (4.22). Figure 4.3 shows the simulation results for an unexpected and permanent shock to the US current account balance that equals 1 percent of GDP. On impact the current account turns into deficit and triggers an equally-sized wealth transfer from the US to the RW. The wealth transfer pushes the four asset markets out of equilibrium and the earlier described mechanisms are set in motion. Portfolio home bias implies

Figure 4.3: Current account balance shock
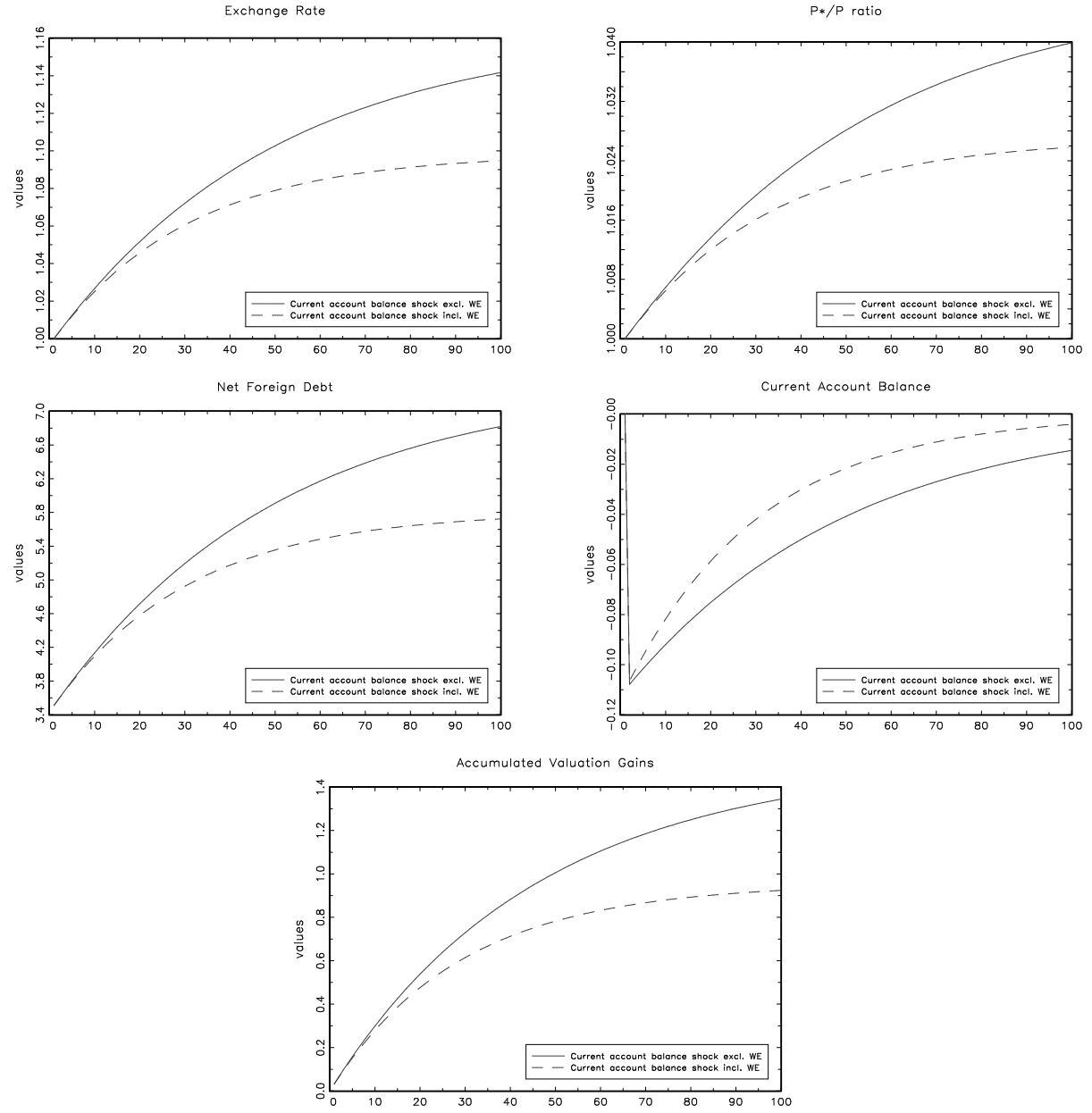
that the wealth transfer from the US to the rest of the world leads to a decrease in US demand for US assets that is less than offset by the concomitant increase in foreign demand for these assets. Excess supply of US assets results and the dollar exchange rate depreciates to restore equilibrium. A similar mechanism is at work for the relative equity prices, $P$ and $P^{*}$. Given that foreign investors have a relatively lower preference for equity investment than their US counterparts, we see that $P$ has to fall relative to $P^{*}$ (or $P^{*} / P$ to rise) in order to restore equilibrium in all asset markets. The new short run equilibrium set of relative prices, $e, P$ and $P^{*}$, leads to changes in the US foreign debt position through revaluations of inherited stocks of foreign assets and liabilities and changes in the trade balance deficit - see (4.20). The change in net foreign debt feeds back into the asset markets and the process starts over again until the new steady state is eventually reached.

Our model produces results that are consistent with recent empirical findings. While the US is running current account deficits, we find stabilizing patterns of exchange rate and asset price movements. A depreciating exchange rate and a rising ratio of relative equity prices, $P^{*} / P$, imply that the US is generating valuation gains. That is, they earn more on their foreign assets than they pay out on their foreign liabilities. This is summarized in the last graph of Figure 3 which shows that these exchange rate and asset price induced valuation gains are sizable. Hypothetically, in the absence of valuation gains, the accumulation of US net foreign debt equals the sum of the current account deficits and would be greater by about one-third - a number that is broadly in line with the findings of Gourinchas and Rey (2008).

The quantitative specification of the wealth channel is not an easy task as empirical evidence is scarce. While both, Fratzscher et al. (2007) and our own study in Chapter 3 confirm the impact of financial household wealth on the current account, they need to rely on empirical proxies for financial household wealth in the absence of directly observable data. Usually data on stock market capitalization and asset prices are employed. To obtain the dashed-lined curves in Figure 4.3, we assume that one percent of the change in US and RW wealth is consumed on foreign goods and hence translates into the trade balance. For instance, a decrease in US wealth or increase in RW wealth improves the US trade balance since US consumers cut their expenditure on US imports and RW consumers increase their expenditure on US exports by one percent of the respective change in their wealth. We believe that the chosen value is in the more conservative range of plausible estimates for the wealth effect. Before turning to the simulation results, we can already analyze the inclusion of the wealth effect from (4.19). According to (4.11) and (4.12) US wealth is a negative and RW wealth a positive function of the exchange rate. Thus the inclusion of wealth dynamics opens an additional channel 
that assists the exchange rate in closing the US current account deficit. Hence, all else equal, less exchange rate depreciation and foreign debt accumulation can be expected following the initial shock. These are exactly the results that we find in Figure 4.3. The current account closes faster, the accumulation of US foreign debt is slowed down and less exchange rate and relative equity price adjustments are necessary to clear the asset markets. As suggested by Figure 4.2, we see that all variables converge smoothly to the new long run equilibrium. Moreover, the transitory path is stable for the chosen parameter values - condition (4.24) is fulfilled. Although judging the magnitude of the wealth effect is obviously conditional on the chosen value for the responsiveness of the trade balance to changes in US and RW wealth, our results indicate that it is a potent channel to reduce current account imbalances.

\subsubsection{Scenario II - Portfolio balance shock}

The second scenario considers the external adjustment process following a shock to the portfolio preference parameters of RW investors. More precisely we assume that foreign investors want to reshuffle their portfolios as to increase US bond holding by 10 percent, while reducing US equity and RW bond and equity holdings according to their relative portfolio weights. The $\beta$-shares change in an unexpected and permanent fashion. All other parameters are copied from the first scenario to maintain comparability. We also continue presenting the scenario excluding and including the wealth effect. Figure 4.4 summarizes the simulation results for the portfolio balance shock. Since our four asset markets clear at all times, we observe an immediate exchange rate appreciation in response to the increased demand for US assets. At the same time, the movement in the exchange rate induces relative equity price changes according to (4.13) and (4.14) and both together impact the net foreign debt position through the valuation and trade balance channels in (4.20). An appreciated exchange rate implies valuation losses of US foreign bond and equity holdings (that are partly mitigated by equity price induced valuation gains) and pushes the trade balance into deficit. These responses are shown in Figure 4.2 as a jump from the initial to the new portfolio balance schedule along which the dynamic system subsequently converges to the new long-run equilibrium in $\mathrm{B}^{\prime}$. Interesting to find is that the initial exchange rate appreciation and valuation losses are gradually offset during the convergence process and completely reversed by the time the dynamic system settles in the new steady state.

Comparing the first two scenarios, namely shocks to the current account and portfolio balances, we observe a considerable resemblance of the trajectories of both external adjustment processes. Both shocks initiate dynamic responses 
Figure 4.4: Portfolio balance shock
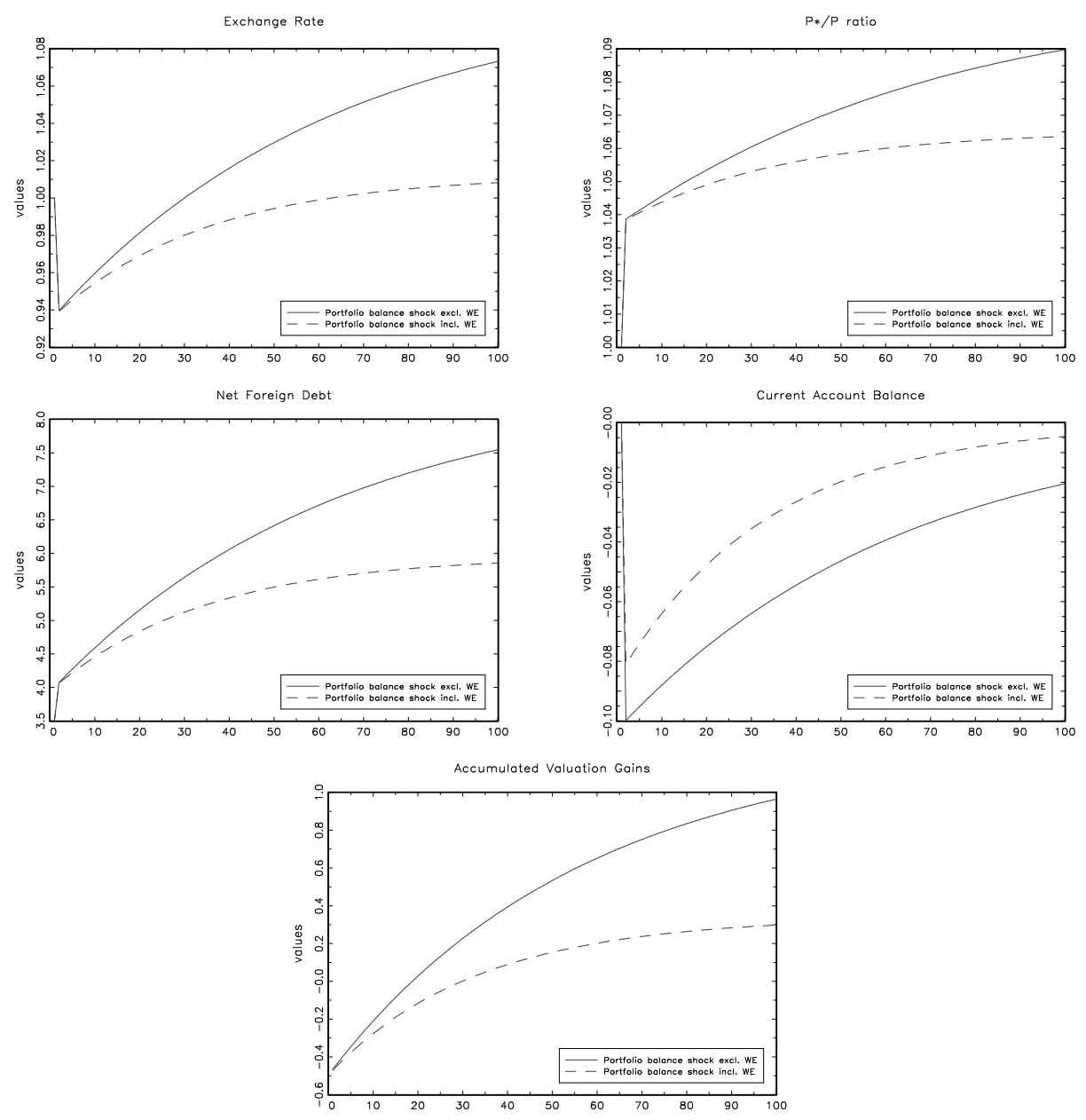

that fit the empirical findings in the literature; namely a US that is running current account deficits which, as a result of exchange rate and asset price induced valuation gains, do not translate into a tantamount accumulation of net foreign debt. The noticeable difference between both scenarios is the response of the systems on impact. While a shock to the current account sets a smooth convergence process in motion, the convergence process is similar but preceded by an initial jump in case of a shock to the portfolio balance. Hence, in order to evaluate the two views in the literature, the simulations of our portfolio-balance model show that domestic US factors and the savings glut argument are equally 
capable of reproducing the current situation of the US, but the latter requires an initial phase of US dollar appreciation. The interpretation of the simulation results regarding the wealth effect is the same as in the first scenario. As a logical extension we will consider both shocks jointly in the next scenario.

\subsubsection{Scenario III - Current account and portfolio balance shocks}

From a balance of payment accounting perspective it is evident that a country's current account and financial account are two sides of the same coin. That is, the US can only run current account deficits if its trading partners accept holding US financial claims. In our portfolio-balance model the exchange rate and asset price mechanisms ensure that RW investors willingly hold US assets up to an amount that is in accordance with the evolution of US current account deficits. Thus the exchange rate and asset price consequences of a negative shock to the US trade balance are mitigated if at the same time foreign investors show an increased appetite for US assets. This is the subject of the third scenario. Figure 4.5 shows the simulation results for the joint inclusion of shocks to the current account and portfolio balances. We adopt the exact same parameter settings as in the previous two scenarios and again provide simulation results for the optional exclusion of the wealth effect. Already in Figure 4.2 we can observe the mitigating effect. Comparing the new long-run equilibrium of the current account balance shock, B, with the one that emerges after the joint inclusion of shocks to the current account and portfolio balances, $\mathrm{B}^{\prime \prime}$, we find that the latter involves considerably more foreign debt accumulation, but only marginally more exchange rate depreciation. The change in the portfolio structure compensates for the need of foreign investors that willingly hold US assets in the presence of US current account deficits. Hence less exchange rate movements are necessary to equilibrate financial markets. Apart from this observation we find that the simulation results inherit many characteristics of the previous two scenarios. On impact the jump of the dynamic system to the new portfolio balance schedule includes again exchange rate appreciation and a worsening of the US net foreign debt position. Along the trajectory exchange rate depreciation and equity price movements generate valuation gains that stabilize the accumulation of foreign debt. An important difference to the previous two scenarios is that the initially balanced current account is hit twice - through the appreciation of the exchange rate and the exogenous change in the taste parameter. All in all, the three scenarios provide exchange rate, asset price and net foreign debt dynamics that are consistent with recent empirical findings. However the joint consideration of shocks to current account and portfolio balances seems to fit empirical reality 
best. It allows modeling a major accumulation of US net foreign debt with only moderate exchange rate depreciation. In addition, it provides for valuation dynamics that come closest to those experienced by the US. In the joint scenario US valuation gains are largest and more evenly induced by exchange rate and asset price movements than in either separate scenario.

Figure 4.5: Current account balance and portfolio balance shocks
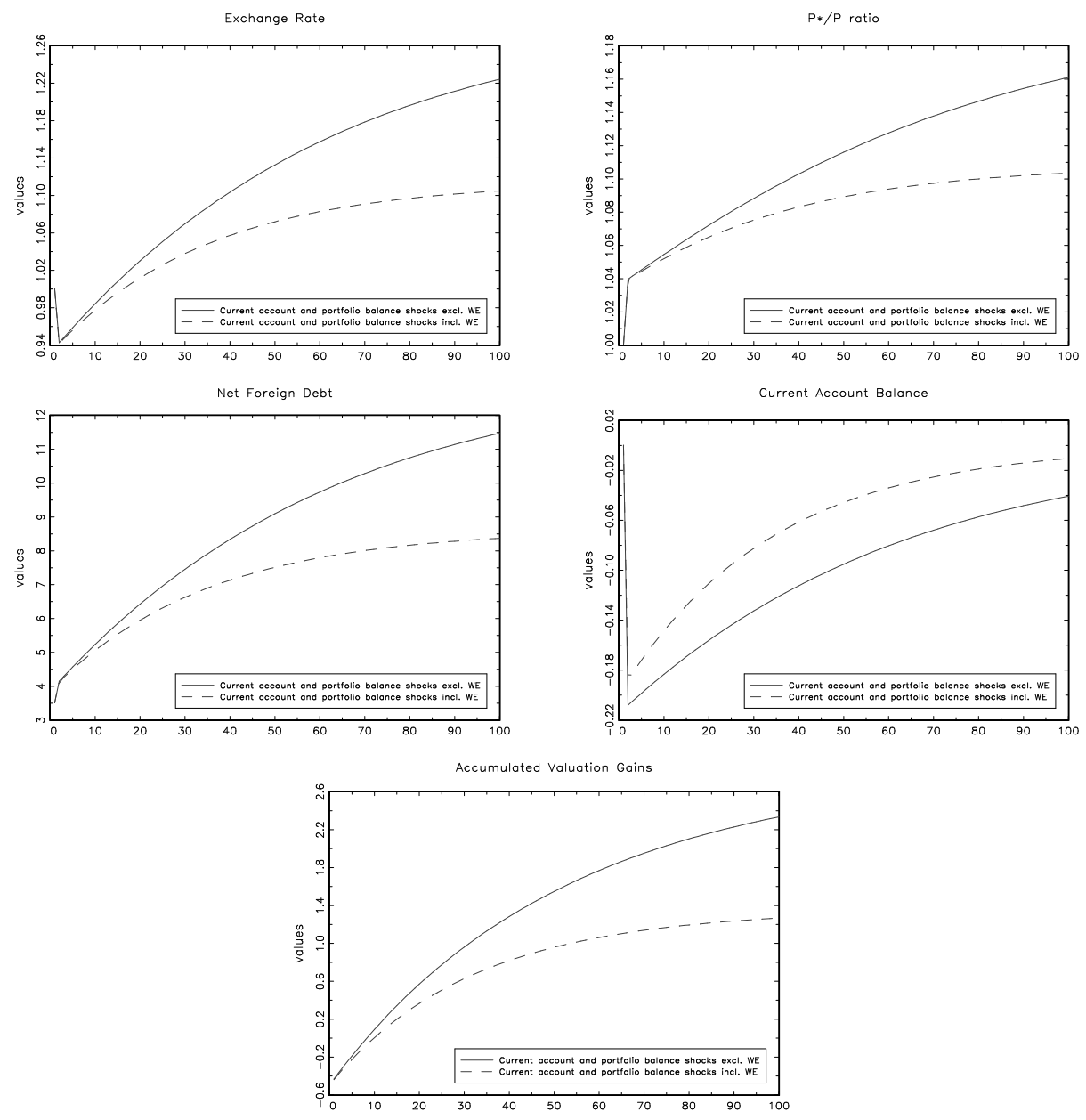


\subsection{Conclusion}

International portfolio-balance models provide useful guidance in thinking about the joint dynamics of external asset positions, exchange rates and asset prices, particularly nowadays with integrated capital markets. Building on the early contributions of Branson (1979), Henderson and Rogoff (1982) and Kouri (1983) and the more recent work of BGS, we have developed a portfolio-balance model that derives its relevance in light of stylized facts of international financial integration. In contrast to BGS, our model recognizes the tremendous increase in cross-border asset holdings, allows for the heterogeneous composition of these asset holdings and reproduces the disconnect of the current account and changes in the NIIP that has been found in the data. Calibrating the model to the external position of the US in 2006, we show the relevance of these stylized facts for the external adjustment process. To this end we implement two complementary views on the causes of US current account deficits - a negative shock to the US current account balance and an exogenous increase in the rest of the world's appetite for US bonds. Considering these shocks separately and jointly, our model confirms that the valuation channels of exchange rate and relative asset price adjustment are stabilizing the external adjustment process and that these valuation gains are sizable. The simulations provide suggestive evidence that the joint consideration of shocks to current account and portfolio balances comes closest to the empirical reality of the US. It yields a considerable accumulation of net foreign debt with only moderate exchange rate depreciation. In the corresponding adjustment process valuation gains are more pronounced and equally induced by exchange rate and asset price movements. 


\section{SUSTAINABILITY OF US EXTERNAL IMBALANCES: AN INTERNATIONAL PORTFOLIO-BALANCE MODELING PERSPECTIVE}

\subsection{Introduction}

We continue our study of global external imbalances. In the previous chapter, we focused on the build-up phase of the significant US external debt position, the long and growing string of US current account deficits, and the partly compensating valuation effects of exchange rate and asset price movements. We employed our portfolio-balance model to gain a better understanding of the triggers of growing external imbalances and found these in the interaction of global demand for US assets and US domestic economic policies and developments.

The present chapter examines the sustainability issues of widening external imbalances. The concept of sustainability is notoriously difficult to assess and remains largely an unsettled issue in a growing literature (see, for instance, Gruber and Kamin, 2007; Higgins and Klitgaard, 2007; Krugman, 2007; Cooper, 2008; Faruqee and Lee, 2008; Feldstein, 2008; Kool, 2009). Important parameters in this discussion are the underlying equilibrium models, assumptions about the macroeconomic environment and the time horizons considered.

Three possible developments of future global imbalances can be identified in the literature. The first strand of the literature expects an unwinding of imbalances that is matched with financial and economic disruptions. In recent studies, Blanchard and Milesi-Ferretti (2009) and Darvas and Pisani-Ferry (2010) discuss how global imbalances have contributed to the financial crisis and in turn how the fallout of the crisis has initiated the adjustment process of global imbalances. The second strand of the literature expects that the adjustments will be in an 
orderly and gradual fashion as central banks in Asia reverse their accumulation of US dollar reserves and investors start diversifying their portfolios. And lastly, it is argued in the literature that the current situation constitutes a temporary equilibrium in which creditor countries willingly hold US dollar claims. Under this scenario global imbalances continue to persist.

Our contribution to the literature is in providing model-induced answers to the question of what happens if foreign investors are no longer willing to accumulate low-interest-bearing US Treasury bonds and start reshuffling their international portfolio investments. Our portfolio-balance model is well equipped to address this question. We distinguish two scenarios: first rest of the world (RW) investors have their fill of US bonds, and, second, RW investors lower their tolerance for US foreign indebtedness. Both scenarios have in common that RW investors shift wealth out of US bonds into other asset classes, but differ in respect of timing. The first scenario considers a permanent change in the asset preference structure, while the second is of temporary nature and links asset preferences to the net foreign bond position.

The model is calibrated to the external position of the US in 2006, just before the financial crisis evolved. This is a deliberate choice as we want to stay away from short- and medium-run influences of the crisis and maintain focus on long-term prospects of correcting global imbalances.

The rest of the chapter is organized as follows. Section 5.2 briefly elaborates on the link between the nature of global imbalances and its sustainability. The relevant literature is reviewed. In Section 5.3 we augment the portfolio-balance model to capture the shift in RW asset preferences under the two scenarios. We present the corresponding simulation results in Section 5.4. Section 5.5 concludes.

\subsection{Sustainability issues of global external imbal- ances}

To put the sustainability discussion of global external imbalances in perspective, it is interesting to note that the present situation of current account balance dispersion is not exceptional by historical standards. Since the Gold Standard in the early nineteenth century the world economy has witnessed several episodes of global imbalances. Bracke et al. (2008) provide a survey of these episodes and detect a substantial degree of diversity in terms of debtor and creditor regions and modes of subsequent external adjustments. ${ }^{1}$ Despite the historical perspective, there are at least two factors that set the current situation of global imbalances

\footnotetext{
${ }^{1}$ See studies by Meissner and Taylor (2006) and Brendner and Pisani (2007) for an elaborate historical account of global imbalances.
} 
Figure 5.1: Current account balances, USD billions

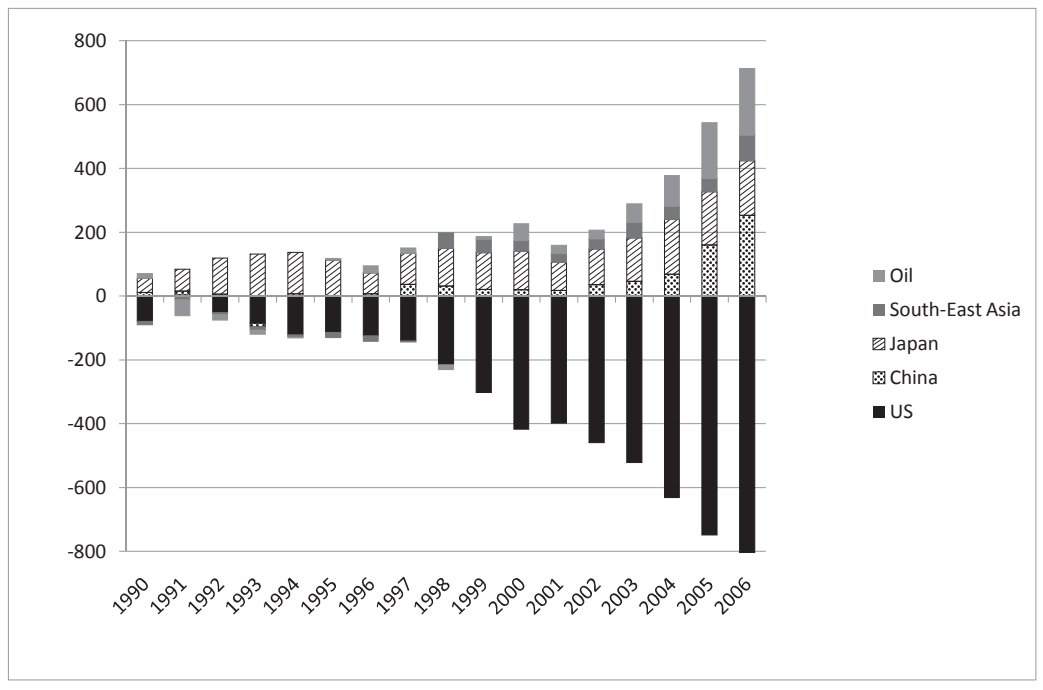

apart and warrant a closer analysis. The first factor concerns the emergence of new global players as creditor countries, and, the second concerns the role of international financial integration in the build-up of large debtor and creditor positions. Both factors can be illustrated with Figure 5.1.

Before the onset of financial globalization in the late 1990s international trade and financial market activities were largely confined to three actors: the US, Japan and Europe. Figure 5.1 shows that Japan consistently runs current account surpluses over the time period 1990 to 2006, while the US, with a minor exception in 1991, is a notorious debtor country. ${ }^{2}$ In addition, with the introduction of trade and financial market liberalization, other market economies emerged on the international landscape - foremost, China and India, but also South-East Asian and oil exporting countries. Again Figure 1 produces evidence by showing that these emerging market economies became the main trading partners of the US. Together with Japan they are generating the current account surpluses that match the sizeable deficit positions of the US. Capital has to flow in the opposite direction to close the balance of payments - hence from emerging market economies to the

\footnotetext{
${ }^{2}$ Note that Europe is omitted in Figure 5.1. Although Europe is important for international trade and financial market activities, it does not constitute a major counterpart to US deficits as a region. Its overall curent account is largely balanced.
} 
advanced US - which is in conflict with predictions of neoclassical theory. In the previous chapter we discussed arguments for this to happen.

How does all this relate to the parallel process of international financial integration? International financial integration, as witnessed in an unprecedented growth in financial wealth and cross-border asset holdings, has undoubtedly spurred the global current account pattern that we observe in Figure 5.1. First, it has enabled emerging market economies to participate in international capital markets and thus to finance the current account deficits of the US. Before, they belonged at best to the periphery of international capital markets and did not hold major portions of international capital on their balance sheets. Second, deep, liquid and sophisticated financial markets in the US have facilitated the concentration of global current account deficits in a single country, the US. For the same reason we observe that the current account surpluses of China, South-East Asia and oilexporting countries are persistently growing. The high persistence of the present current account pattern is also noted by Cooper (2008). Third, changes in the valuation of financial asset wealth affect consumption and investment behavior and thus the trade balance. The international wealth effect is discussed in Chapter 3 .

All these aspects necessitate a close monitoring of global imbalances in general and the question of sustainablity in particular. As part of the external adjustment process, nothing less than the external value of the US dollar is at stake. Despite the significance of the issue and length of the debate no consensus exists in the literature about the ultimate solution for the US current account deterioration and the required depreciation of the US dollar in correcting these imbalances. We briefly review those strands of the literature that are relevant for our simulation study. $^{3}$

According to Krugman (2007) the decisive question is when, not if, the US dollar will decline. Market forces alone will cause the US trade deficit to close as the world will no longer provide enormous gifts - exports in exchange for a promise to be repaid in the future - to the US year after year. Key in this process is the future decline in the US dollar, brought about by foreign investors, both public and private, who become less willing to keep adding US bonds to their international portfolios. The main reasons why foreign investors will reduce their demand for US bonds are (1) the low return on US bonds increases the relative attractiveness of other investment projects, e.g. domestic infrastructure investments, (2) the overall demand for portfolio diversification and (3) the expectation that the US dollar must eventually decline as part of the external adjustment process.

Krugman (2007) takes up the latter point. Assuming that the US dollar must

\footnotetext{
${ }^{3} \mathrm{~A}$ more comprehensive review of the literature on current account sustainability is provided in Edwards (2005).
} 
fall, he studies whether the fall is gradual or abrupt and links the question to the expectation formation of international investors. According to him data suggest investor myopia which makes a US dollar plunge the more likely scenario. In this case investors fail to factor the long-run need for US dollar depreciation into their portfolios. At the time they recognize their mistake, they shift out of US bonds and trigger an abrupt exchange rate adjustment. ${ }^{4}$ Krugman calls the point in time when investors realize that the value of the US dollar is not supported, the Wile E. Coyote moment. ${ }^{5}$ We model this moment in our simulation exercise below.

How long US asset accumulation might continue before the above scenario materializes is discussed in Higgins and Klitgaard (2007) and Cooper (2008). Cooper argues that the decrease in asset home bias, as part of the globalization process, is far from complete. Until then, there is no reason to expect that foreign investors are about to become saturated with US assets and suspicious about future US dollar developments. Thus the financing of large US trade deficits remains possible. Higgins and Klitgaard argue along the same lines, but distinguish between different asset classes. In general they find that international financial integration has increased the worldwide capacity for US asset holdings and that the US havs not received a disproportionate share of global crossborder investments. This holds true for foreign direct investment, portfolio equity investment and banking and other investments, but, interestingly, not for portfolio debt investment. Foreign investment in US bonds exceeds a GDP-implied neutral benchmark. We include this stylized fact in our simulation exercise below. That is, we are simulating two different scenarios of the Wile E. Coyote moment in which RW investors realize their excessive exposure to US bond holdings and begin to reshuffle their portfolios. But before, we introduce the necessary augmentation of our portfolio-balance model.

\subsection{Augmenting the portfolio-balance model}

We continue working with the portfolio-balance model that we have developed in the previous chapter. The model consists of two core equations. The first is the portfolio-balance equation, which equilibrates our four asset markets, US bond and equity markets and RW bond and equity markets, and provides the set of relative prices, $e, P$ and $P^{*}$, for a given net foreign debt position of the

\footnotetext{
${ }^{4}$ The adjustment dynamics will be very different if investors take expectations of future US dollar depreciation properly into account. BGS consider this scenario with rational expectation formation, resulting in a smooth US dollar descent towards its long-run sustainable level. Also Gruber and Kamin (2007) argue for a gradual transition process.

${ }^{5}$ We adopt the terminology of Krugman (2007). Wile E. Coyote is the main character in a cartoon series where he often would run off a cliff, take several steps on thin air, then look down - and only after realizing that there was nothing under him, would he plunge.
} 
US. The second, the current account balance equation, describes US net foreign debt dynamics as determined by the evolution of relative prices, $e, P$ and $P^{*}{ }^{6}$ Importantly, net foreign debt dynamics derive from asset price and exchange rate induced revaluations of the existing stocks of gross foreign liabilities and gross foreign assets and the trade balance deficit. It allows studying the contribution of valuation effects to the process of restoring external balances. This aspect has been largely ignored in the literature on redressing global imbalances, which has almost exclusively focused on the role of the current account in this context. Valuation considerations figure more prominently in the discussion of the build-up of external imbalances as shown in the literature review of the previous chapter.

In general all parts of the portfolio-balance model remain operational for the present simulation study. In addition we elaborate the asset preferences of RW investors to take two innovations on board: the Wile E. Coyote moment and the degree of US net foreign bond indebtedness.

We do not introduce rational expectations in the formation of asset preferences as we consider the case of myopic investors along the lines of Krugman (2007) and Higgins and Klitgaard (2007). That also implies that asset preferences in our portfolio-balance model are not subject to expectations of excess asset price and exchange rate returns. This is backed by a comprehensive literature that finds at best mixed results for portfolio-balance effects of return differentials (see, Frankel, 1984; Faust et al., 2003; Hau and Rey, 2004). Also Hallwood and MacDonald (2000) conclude that "empirical studies on the portfolio balance approach are not particularly supportive". Instead, we augment the original model and allow the asset preference parameters of RW investors to depend on the net foreign bond position of the US.

Asset preferences of US investors are retained from Table 4.1 in the previous chapter. They are reproduced in the lower panel of Table 5.1 below. We leave them unchanged as the discussion of the sustainability of US external imbalances largely pertains to the willingness of non-US investors to keep on financing the latter. We adopt this view, but could easily extend our model in this respect.

Asset preferences of RW investors become,

$$
\begin{aligned}
& \beta_{B}(N F B)=\mu_{\beta_{B}} \beta_{B}^{\prime}+\gamma_{\beta_{B}}\left[\frac{N F B-N F B^{\prime}}{N F B^{\prime}}\right] \\
& \beta_{E}(N F B)=\mu_{\beta_{E}} \beta_{E}^{\prime}+\gamma_{\beta_{E}}\left[\frac{N F B-N F B^{\prime}}{N F B^{\prime}}\right]
\end{aligned}
$$

\footnotetext{
${ }^{6}$ We do not replicate the derivation of the portfolio-balance model here, but refer the interested reader to the previous chapter. The portfolio-balance equation and current account balance equation are shown in (4.16) and (4.21), respectively.
} 


$$
\begin{aligned}
& \beta_{B^{*}}(N F B)=\mu_{\beta_{B^{*}}} \beta_{B^{*}}^{\prime}+\gamma_{\beta_{B^{*}}}\left[\frac{N F B-N F B^{\prime}}{N F B^{\prime}}\right] \\
& \beta_{E^{*}}(N F B)=\mu_{\beta_{E^{*}}} \beta_{E^{*}}^{\prime}+\gamma_{\beta_{E^{*}}}\left[\frac{N F B-N F B^{\prime}}{N F B^{\prime}}\right]
\end{aligned}
$$

where $\beta_{(\cdot)}^{\prime}$ are the equilibrium asset preferences of RW investors as derived from Table 4.1 in the previous chapter and $\mu_{(\cdot)}$ and $\gamma_{(\cdot)}$ are adjustment parameters. $N F B$ is the US net foreign bond position defined as the difference between gross foreign bond liabilities and assets of the US, $\left(B_{R W}-e B_{U S}^{*}\right)$. NFB' is the corresponding threshold value that is tolerated by international asset markets. Any deviation from this tolerance threshold will initially induce an adjustment in the asset preference structure of RW investors. Note that the choice of $\mu_{(\cdot)}$ and $\gamma_{(\cdot)}$ are restrained to ensure that the total stock of RW wealth is allocated over the four asset classes, hence that $\beta_{(\cdot)}(N F B)$ add up to unity. Moreover setting $\mu_{(\cdot)}=1$ and $\gamma_{(\cdot)}=0$ in (5.1-5.4), we have the asset preference structure of RW investors of the previous chapter.

With the augmented portfolio-balance model at hand, we are prepared to answer the question of what happens if foreign investors recognize the disproportionately large position of low-interest-bearing US bonds in their international portfolio and start diversifying. For this exercise we need to determine a reasonable anchor of what RW investors consider a proportionate position, and hence to what extent they wish to reshuffle their portfolios. We believe that the state of affairs in 2000 can serve as a good proxy for such an anchor as we elaborate below. To this end we reproduce the information of Table 4.1 of the previous chapter for the years 2000 and 2006. This is shown in Table 5.1.

Comparing both tables we immediately observe the immense increase of financial wealth over the years 2000 to 2006. It has increased for the US by US- $\$ 10.43$ trillion, or about 37 percent, and for the RW even by US- $\$ 31.26$ trillion, or about 81 percent. Most of the rise can be attributed to newly issued bonds. Taken together bond market capitalization of the US and RW has nearly doubled from US- $\$ 35.05$ trillion in 2000 to US- $\$ 69.38$ trillion in 2006 , while equity market capitalization has only risen by relatively modest 24 percent over the same time period. Although these changes would certainly deserve further scrutiny, in particular the question of to what extent the newly issued bond capitalization constitutes financial wealth, it falls outside the scope of this chapter. Instead it is more instructive for the calibration of our modeling exercise to note that the current account deficit and net foreign debt position of the US have roughly doubled over these years. That is most of the deterioration in both variables stems from the more recent period, as can be seen from Figure 5.1 for the former and 
Table 5.1 for the latter. Moreover it is interesting to observe that the increase in the net foreign debt position, $F$, from US- $\$ 1.55$ trillion in 2000 to US- $\$ 3.51$ trillion in 2006 is dwarfed by the increase in the net foreign bond position, $N F B$, of the US. It has risen from US-\$1.76 trillion to US-\$5.05 trillion over the same time period. This implies that the net exposure of the RW to US bonds has increased almost three times. Also when expressed relative to financial wealth, which itself has risen tremendously, we can document the increased exposure of the RW to US bonds. Assuming that the years 2000 and 2006 constitute steady state situations from which portfolio preferences can be derived, we observe that the corresponding preference parameter, $\beta_{B}$, has increased by roughly 3 percentage points from 0.117 in 2000 to 0.147 in 2006 . Taken together we argue for our modeling exercise that the accumulation of US net foreign debt and the US bond exposure of RW investors have become disproportionate or excessive only after 2000. Thus the state of affairs in 2000 serves as a reasonable proxy for a common situation. We are now prepared to consider two scenarios for our simulation study:

Scenario I models the Wile E. Coyote moment in which RW investors recognize that the share of US bonds in their international portfolios is excessive and they abruptly shift wealth out of US bonds into other asset classes - US equity and RW bonds and equity. The change in the structure of asset preferences is permanent and independent of the tolerated threshold value for US net foreign bond positions. We assume that RW investors seek to reduce their exposure of financial wealth to

Table 5.1: Market capitalization and allocation in 2000 and 2006, USD trillions

\begin{tabular}{|c|c|c|c|c|c|}
\hline \multirow[t]{2}{*}{2000} & & & & \multicolumn{2}{|c|}{ Allocation } \\
\hline & \multicolumn{3}{|c|}{ Market Capitalization } & US & RW \\
\hline & \multirow[t]{2}{*}{ US } & Equity & 14.40 & 12.76 & 1.64 \\
\hline & & Bonds & 15.04 & 10.53 & 4.51 \\
\hline & \multirow[t]{2}{*}{ RW } & Equity & 16.87 & 1.85 & 15.02 \\
\hline & & Bonds & 20.01 & 2.75 & 17.26 \\
\hline & \multicolumn{3}{|c|}{ Financial Wealth } & 27.89 & 38.43 \\
\hline \multirow[t]{7}{*}{2006} & \multirow{2}{*}{\multicolumn{3}{|c|}{ Market Capitalization }} & \multicolumn{2}{|c|}{ Allocation } \\
\hline & & & & US & RW \\
\hline & \multirow[t]{2}{*}{$\overline{\mathrm{US}}$} & Equity & 14.54 & 11.75 & 2.79 \\
\hline & & Bonds & 27.29 & 17.05 & 10.24 \\
\hline & \multirow[t]{2}{*}{ RW } & Equity & 24.09 & 4.33 & 19.76 \\
\hline & & Bonds & 42.09 & 5.19 & 36.90 \\
\hline & \multicolumn{3}{|c|}{ Financial Wealth } & 38.32 & 69.69 \\
\hline
\end{tabular}

Source: International Financial Statistics \& BIS (2006) 
US bonds by roughly three percentage points. Thus they wish to return to the level in 2000. This translates into a reduction of their current US bond holdings by 20 percent. The proceeds are reinvested in the other asset classes according to their relative preferences in 2006. In terms of (5.1-5.4), we have

$$
\mu_{\beta_{B}}=0.80 \quad \text { and } \quad \mu_{\beta_{B^{*}}}=\mu_{\beta_{E}}=\mu_{\beta_{E^{*}}}=\left[\frac{10.24 \times 0.10}{2.79+19.76+36.90}+1\right] .
$$

As in this scenario the preference shares do not respond to the evolution of the US net foreign bond position, $N F B$, we set $\gamma_{(\cdot)}=0$. All other parameters are adopted from the previous simulation studies. In particular the wealth effect enters the trade balance.

Scenario II models the Wile E. Coyote moment in which RW investors' tolerance for US foreign indebtedness reaches its limits and they reevaluate the threshold of an acceptable US net foreign bond position. While initially the tolerated threshold value of the US net foreign bond position equals the one that we can derive from the data in Table 4.1 of the previous chapter, corresponding to the situation in 2006, it is reduced after the reevaluation to the one implied by Table 5.1, corresponding to the situation in 2000. Hence in the Wile E. Coyote moment, $N F B^{\prime}$ drops from currently US-\$5.05 trillion to US-\$1.76 trillion in (5.1-5.4). Similar to the previous scenario we assume as a response to the reevaluation that RW investors want to divest US bonds and in exchange increase their portfolio holding in US equity and RW equity and bonds according to their relative preferences. In contrast to the previous scenario the change in the asset preference structure is not permanent but depends on the evolution of the US net foreign bond position and, in particular, its deviation from the tolerated threshold. The strength of this link is defined by $\gamma_{(\cdot)}$. The determination is difficult since the empirical literature does not provide reliable estimates for this parameter. To overcome this issue we proceed with an hypothetical exercise and calibrate $\gamma_{\beta_{B}}$ as to trigger the exact same exchange rate reaction as in the first scenario. It will allow for a direct comparison of both scenarios later on. The sensitivity parameters $\gamma_{\beta_{B^{*}}}, \gamma_{\beta_{E}}, \gamma_{\beta_{E^{*}}}$ follow according to their relative importance in the investment portfolio of foreign investors. We obtain that

$$
\begin{gathered}
\gamma_{\beta_{B}}=-0.03 \\
\gamma_{\beta_{B^{*}}}=-\gamma_{\beta_{B}} \times \frac{36.90}{59.45}, \quad \gamma_{\beta_{E}}=-\gamma_{\beta_{B}} \times \frac{2.79}{59.45}, \quad \gamma_{\beta_{E^{*}}}=-\gamma_{\beta_{B}} \times \frac{19.76}{59.45} .
\end{gathered}
$$

Moreover we assume that whenever the actual US net foreign bond position coincides with the threshold value, RW investors choose to invest according to Table 4.1 in the previous chapter. That implies $\mu_{(\cdot)}=1$. Again all other 
parameters are adopted from the previous simulation studies. In particular the wealth effect enters the trade balance. We can now turn to the simulation results.

\subsection{Simulating the Wile E. Coyote moment}

In our simulation studies we are considering the case of abrupt exchange rate and current account balance adjustments in response to ever-growing global imbalances. The plunge is brought about by formerly myopic investors who upon realizing the unsustainability of international investment positions abruptly seek to rebalance their international portfolios. Two forms of this Wile E. Coyote moment are discussed. The corresponding simulation results are summarized as Scenario I and Scenario II in Figure 5.2. To focus on the short to medium run dynamics following the shock in the Wile E. Coyote moment we present the simulation results for the first 20 periods only.

\subsubsection{RW investors realize excess US bond holdings}

In the first scenario we are considering a permanent change in the asset preference structure of RW investors who seek to reinvest 20 percent of their US bond holdings in other asset classes following their relative preferences for them.

In terms of the portfolio balance and current account balance schedules, see previous chapter, we observe that the former shifts upwards and becomes steeper, while the later rotates counterclockwise around the initial steady state. We do not replicate the schedules at this point, since we are considering the exact opposite behavior from the one discussed in the portfolio balance shock scenario of the previous chapter. The intuition follows accordingly. The new portfolio balance schedule yields a more depreciated US dollar for a given level of net foreign debt to accommodate the decreased relative demand for US bonds. Also the change in the asset preference structure increases the excess home demand for bonds, $\Omega$, which causes the steeper slope of the schedule. As before, the impact on the slope of the current account balance equation is due to the inclusion of the wealth effect. We can already analyze the behavior of the dynamic system with the help of these schedules. At the initiation of the shock we observe a jump from the initial equilibrium to the new portfolio balance relations - the US dollar depreciates and net foreign debt is reduced. Subsequently the dynamic system converges along the schedule towards the new equilibrium, bringing about exchange rate appreciation and a further rebalancing of the net foreign debt position.

The solid lines in Figure 5.2 show that on impact the exchange rate depreciates to equilibrate the four financial markets in response to falling demand for US bonds. The plunge in the US dollar improves the current account through the 
Figure 5.2: Simulation results for both scenarios
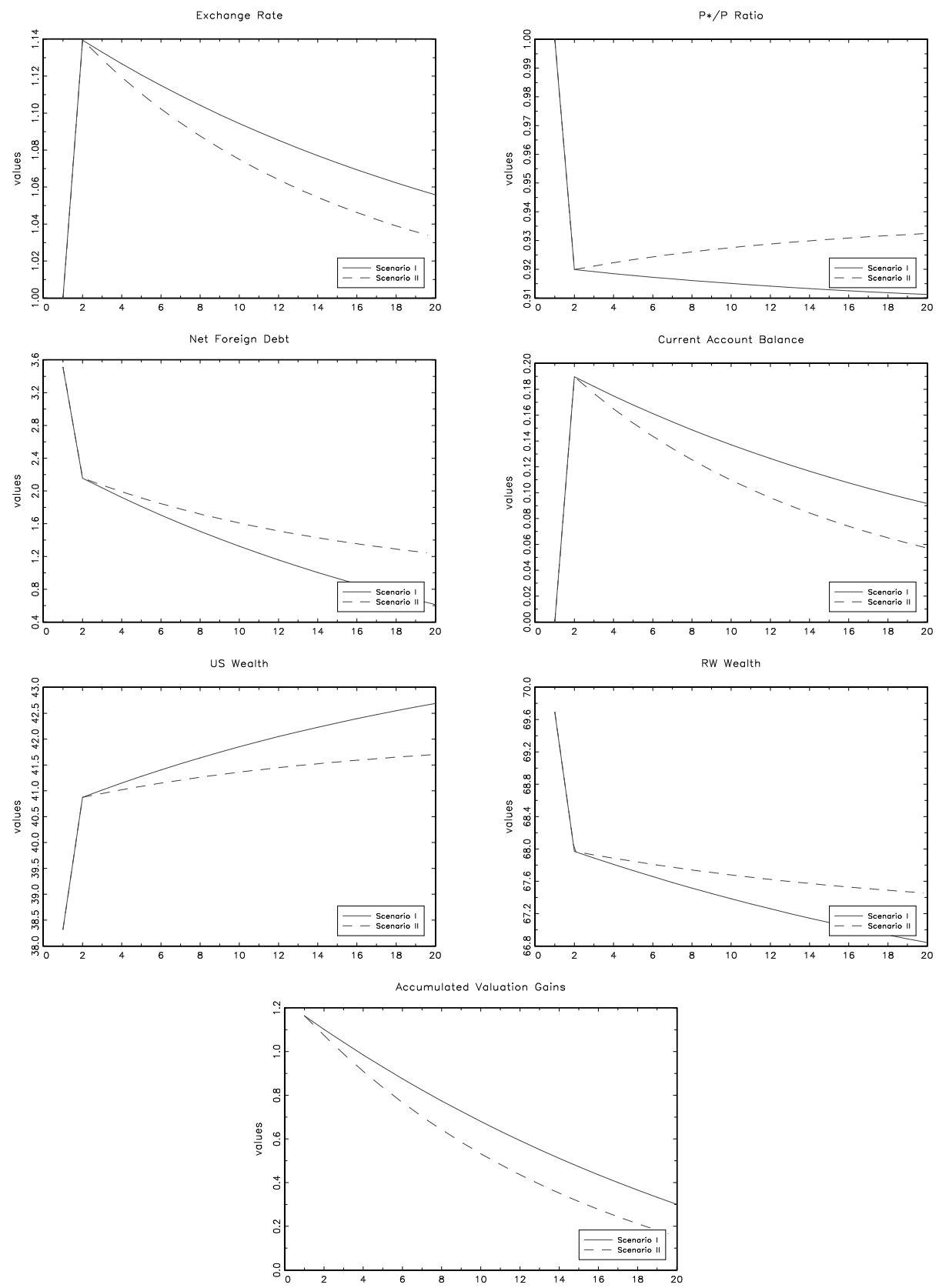
expenditure switching/reducing mechanism and induces valuation gains. Both help in redressing the US net foreign debt position substantially. The ratio of relative equity prices drops since US investors have relatively greater appetite for equity investments than RW investors. Thus with a wealth transfer from the RW to the US, demand for US equity increases relative to RW equity. As a consequence, $P$ rises relative to $P^{*}$ to restore equilibrium in financial markets. The evolution of relative equity prices acts as a drag on the rebalancing of the US net foreign debt position. A falling $P^{*}$ to $P$ ratio implies a valuation loss on the stock of US gross foreign equity assets relative to the corresponding liability position. In general it is important to note that, except for the first period, exchange rate and equity price induced valuation losses slow down the global rebalancing process. Accumulated valuation gains, the difference between changes in the net foreign debt position and accumulated CA balances, turn negative eventually. Along the trajectory to the new steady state, the wealth transfer from the RW to the US continues, although at a diminishing rate, triggering the exchange rate to appreciate and the current account surplus to close again. This brings us to another interesting simulation result - the observed change in US and RW financial wealth following the diversification of RW investment portfolios. A common argument for the observed reluctance of RW investors to diversify out of US assets is the anticipated valuation loss of their financial wealth. This argument is particularly often put forward for Asian central banks that accumulated vast amounts of US bonds in the past and allegedly have a self-interest in continuing this process into the future. This concern could add to myopia and postponement of the Wile E. Coyote moment. Our simulation result substantiates the concern to some extent. We observe that RW financial wealth declines by US- $\$ 1.7$ trillion, or 2.5 percent, on impact and further by US- $\$ 4$ trillion, or 6 percent, in the new steady state. Exchange rates and equity prices evolve however as to stabilize the financial wealth position of the RW and thus prevent a greater plunge.

What can be concluded about the order of magnitude and the speed of the adjustment process? Although both hinge crucially on the trade balance responsiveness to exchange rate movements, a number of observations stand out. $^{7}$ First, the reshuffling of 20 percent of US bonds triggers a substantial depreciation of the exchange rate of 14 percent. Second, it triggers on impact a sizeable reduction of the net foreign debt position by almost 40 percent that would eventually turn even into a net foreign asset position. Such a change is probably accompanied by further repercussions that we have to leave unmodeled. Third, valuation effects play an important role in redressing global balances. On impact it supports the process through the depreciation of the US dollar, subsequently

\footnotetext{
${ }^{7}$ We continue to assume from the previous chapter that every 10 percent depreciation in the exchange rate closes the US trade balance by 1 percent of GDP.
} 
it hinders the adjustment process as exchange rates start appreciating again and relative equity prices deteriorate further. In sum, the accumulated valuation effect turns slightly negative as we approach the new steady state. That implies valuation effects exert a significant influence on the adjustment speed along the trajectory. Fourth, opposite to the impact of exchange rate and equity price movements on the accumulated valuation effect of the US, we find that they stabilize the financial wealth position of the RW in the process and prevent a further deterioration.

The dynamics of the valuation effect and financial wealth positions are remarkable as they have been largely neglected in the literature on rebalancing external positions. Our results indicate their potential role in financially integrated markets and warrant a greater focus in future research.

\subsubsection{RW investors reevaluate US net foreign bonds}

In the second scenario we assume that RW investors realize in a Wile E. Coyote moment that the US net foreign bond indebtedness is not sustainable. In reaction, they revise their tolerance level of net foreign bond holdings to US- $\$ 1.76$ trillion, the level that prevailed in 2000, and start reducing their US bond holdings accordingly. The degree to which RW investment portfolios are diversified out of US assets is calibrated to match the portfolio shock of the previous scenario. This approach allows a direct comparison of both scenarios and sidesteps the problem of a lack of reliable empirical estimates for the sensitivity parameter, $\gamma_{(\cdot)}$. The second scenario is depicted by dashed lines in Figure 5.2.

Illustrating the ensuing dynamics with the help of the portfolio balance and current account balance schedules is more complex. Initially we observe the exact same behavior as in the previous scenario - both portfolio shocks are calibrated to be the same. Afterwards however the dynamics differ. In the present scenario asset preferences, and hence both schedules, are dependent on the realization of US net foreign bonds. That implies that asset preferences converge back to their initial values and so do the portfolio balance and current account balance schedules as the gap between actual and tolerated net foreign bonds closes. Note that this process comes to a halt before the initial locations of both schedules are reached again, hence before the tolerated level of net foreign bond holdings is actually realized. There is no constraint in (5.1-5.4) that restricts $N F B$ to settle at $N F B^{\prime}$ in the new steady state. Hence, as RW investors choose for a new threshold value, $N F B^{\prime}$, in the Wile E. Coyote moment, the dynamics of the system do not ensure that it is reached eventually. We believe that this modeling omission is less relevant for the short to medium run dynamics that we consider as it only materializes in the long run. The simulation results of the asset preferences in Figure 5.3 provide further clarification in this respect. 
Important to note is also that the dynamic system continuously jumps to new portfolio balance schedules instead of converging along a single one towards the new steady state.

The simulation results in Figure 5.2 confirm that the US dollar depreciates, the current account turns into surplus and the net foreign debt position of the US improves correspondingly on impact.

Subsequently however some interesting differences emerge. The exchange rate adjustments are more pronounced in the second scenario. The US dollar appreciation is not only spurred by the wealth transfer from the RW to the US, but, in addition, by the gradual return of US bonds in RW investment portfolios. As the US net foreign bond position converges to its new tolerance threshold, RW investors return to previous asset preferences which further fuels the appreciation of the US dollar. The observed exchange rate behavior has its bearing on the current account and the evolution of the US net foreign debt position. The former returns faster to balance and the latter experiences a lesser degree of external rebalancing. The net foreign debt position of the US is reduced to US- $\$ 1.2$ trillion after 20 periods, compared to US- $\$ 0.6$ trillion in Scenario I. Also the accumulated valuation gains deteriorate faster as an immediate response to the exchange rate behavior. A noticeable difference to the first scenario is that relative equity prices marginally improve. They induce valuation gains that are however outweighted by exchange rate induced valuation losses. Again, valuation effects govern the external adjustment process. At the Wile E. Coyote moment the valuation channel works to rebalance the US net foreign debt position, thereafter it slows the process down. Interesting to observe is again the behavior of US and RW financial wealth positions. Following the initial shock changes are more benign than in Scenario I. RW financial wealth drops only by US- $\$ 2.5$ trillion, or 3.6 percent in the new steady state. Hence the concerns of RW investors that their portfolio reshuffling will lead to major financial wealth losses can be mitigated by our simulation results. We take from it that if RW investors follow a less crude investment strategy than described in the first scenario, but instead consider adapting their international portfolio to an improving US external situation, they can manage or limit the loss in financial wealth following the initial shock.

In summary, we find that, depending on how RW investors continue to manage their portfolios following the Wile E. Coyote moment, pronounced differences between both scenarios can be observed. These materialize already in the short to medium run.

Figure 5.3 shows how the share of US bonds in the international portfolio of RW investors, $\beta_{B}$, changes over time. As discussed before RW seek to reduce their exposure to US bonds in the Wile E. Coyote moment by 3 percentage points as to return to the state of affairs in 2000. Therafter, as the gap between the 
Figure 5.3: RW exposure to US bonds, $\beta_{B}$

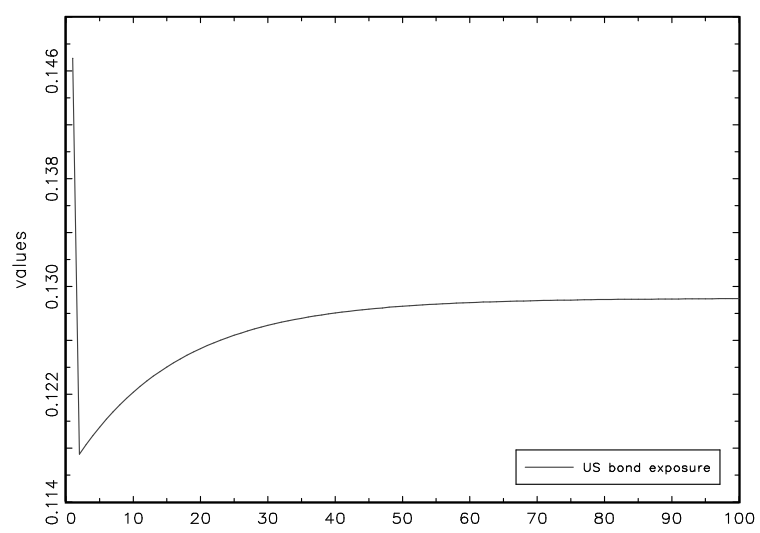

US net foreign bond position and the tolerated level thereof closes, RW investors start investing greater shares of financial wealth in US bonds again. The dynamic system settles before the initial preference parameter is reached, but only in the long run after more than 50 periods. In the short to medium run we observe a considerable return to US bonds in RW investors' portfolios. The dynamics of the other preference parameters, $\beta_{E}, \beta_{B^{*}}$ and $\beta_{E^{*}}$, follow accordingly.

\subsection{Conclusion}

In this chapter we continue the study of global external imbalances, but shift our focus to the sustainability of the US net foreign bond position. The literature on this issue is diverse and draws three possible scenarios: (1) an unwinding of imbalances that results in financial and economic disruptions, (2) a smooth and orderly adjustment as Asian central banks review their US dollar portfolios, and (3) a temporary equilibrium in which creditor countries willingly continue holding US dollar claims. This chapter does not aim at explaining the first scenario. It is a deliberate choice to stay away from the financial crisis and to calibrate the model to the situation of the US prior to the crisis. Hence we do not mean to discuss the question of whether or to what extent global imbalances have contributed to the financial and economic crisis, for a discussion of this link see Blanchard and MilesiFerretti (2009) and Darvas and Pisani-Ferry (2010). To model the redressing of global imbalances during times of crisis the more comprehensive class of general equilibrium models seems to be better equipped. This class of models can properly account for the interaction between exchange rate movements, inflation, interest 
rates and real economic activity. The partial-equilibrium model that we have devised reaches its limits in modeling the first scenario, but is well equipped to provide model-induced answers for the second scenario.

We employ our portfolio-balance model to answer the question of what happens if RW investors recognize the unsustainability of the current situation and start diversifying their portfolios, hence the second scenario. In this context we adopt the view of Krugman (2007) and the notion of the Wile E. Coyote moment therein. Two different modes of elaborating asset preferences of RW investors are considered which either allow for a permanent shift out of US bonds or a temporary shift that is linked to the evolution of US net foreign bond holdings. We show how a modest change in RW asset preferences can trigger a substantial reduction in global external imbalances. This process is influenced by the valuation channel of exchange rates and asset prices. On impact valuation effects fuel the rebalancing process, later they act as a drag on it. This is an important finding as the valuation channel is largely overlooked in the literature which assigns the current account the main role in redressing global balances. Another important finding is that the reduction of RW financial wealth turns out to be relatively modest depending on the investment behavior of RW investors following the shock in the Wile E. Coyote moment. It can be in the range of 3.6 percent of total financial wealth. If RW investors follow a more subtle investment strategy that allows for gradual adjustments, our model does not confirm the common concern in the academic literature and among policy makers that a diversification out of US bonds by Asian central banks triggers a prohibitively detrimental revaluation of their foreign exchange reserves. Exchange rate and asset price valuation changes work here to stabilize the financial wealth position of the US.

This brings us to the third scenario, the assertion in the literature that the current situation constitutes a temporary equilibrium in which foreign investors, mainly Asian central banks, willingly hold US bonds. We do not explictly model this scenario. Our portfolio-balance model does not provide for a temporary equilibrium. Rather it views an equilibrium as a situation that is sustainable over the long term, in which the current account is balanced and the accumulation of net foreign assets comes to a halt. Hence the sort of temporary equilibrium in which US current account imbalances are financed through concomitant capital account surpluses does not meet our conception of sustainability. 


\section{ORIGINS OF PERSISTENT MACROECONOMIC IMBALANCES IN THE EURO AREA}

\subsection{Introduction}

The broad fiscal consolidation among member countries of the European Economic and Monetary Union (EMU) since the adoption of the Euro in 1999 changed dramatically with the unfolding of the current financial and economic crisis in 2008. Not only are all member countries now in breach with the self-imposed budgetary constraints of the Treaty of Maastricht, some are even on the verge of a sovereign debt crisis. International capital markets reacted by demanding risk premiums for continuing to hold public debt of Spain, Portugal and Ireland. Greece even faces such unsustainable terms on international capital markets that it effectively can no longer access these markets and the group of Euro area countries together with the International Monetary Fund had to step in as lenders of last resort in May 2010. ${ }^{1}$

The situation on Greece has also turned the spot light on the alarming indebtedness of some other Euro Area countries, in particular Portugal, Spain and Ireland. Without doubt, the debt levels of these countries and the corresponding responses of international investors must be evaluated in light of the current economic environment. However, in order to understand the situation in a comprehensive way and to define appropriate policy responses one should look beyond the current economic crisis and the focus on government debt. We argue in this chapter that there has been a structural economic divergence process among Euro area countries that seems to have started already with the introduction of

\footnotetext{
${ }^{1}$ Greece, with a budget deficit of 13.6 percent of GDP and an expected government debt burden of about 150 percent of GDP over the medium-term, faced in April 2010 a yield spread of up to 10 percentage points over comparable German debt instruments.
} 
the common currency in 1999 and cannot be confined to the public sector only. We elaborate both points below.

To facilitate our analysis, we distinguish between two clusters of Euro area countries, ${ }^{2}$ North consisting of Austria, Finland, Germany and the Netherlands and South consisting of Greece, Ireland, Portugal and Spain, and two sub-periods 1992 to 1998 and 1999 to 2007. The first sub-period spans the run-up to EMU between the signing of the Treaty of Maastricht and the introduction of the Euro, while the second can be characterized as a time period of moderate and stable economic expansion between the introduction of the Euro and the recent economic crisis. Providing first a comprehensive and consistent review of savings and investment behaviour and current account imbalances, we show that Northern countries can be characterized as prudent net savers, consuming moderately and providing for their future. This holds for their public and private sectors alike and is reflected in stable and high private saving rates, balanced government savings and persistent current account surpluses. The net foreign asset positions of these countries are almost balanced on average. On the other hand we observe that the private and public sectors of Southern countries continuously consume in excess of their resources and consequently these countries show negative balances on all three accounts. Moreover the servicing of high net foreign debt positions constitutes a considerable burden for these countries. Thus we observe growing external and internal imbalances across the Euro area and an increasing indebtedness of the South to the North.

We next evaluate the disparate situation between Northern and Southern Europe in light of the literature. The standard argument is that imbalances can be attributed to intertemporal maximization and thus to underlying fundamentals of a European convergence process (Blanchard and Giavazzi, 2002; Ahearne et al., 2007; Artis and Hoffmann, 2008). Countries with lower per-capita income and lower productivity attract foreign capital investment. In the same adjustment process, relative inflation is likely to rise, leading to real exchange rate appreciation and a loss of international competitiveness. As a result, current account deficits arise that match the surpluses on the capital accounts. These adjustments are all the more credible in the presence of integrated real and financial markets. Thus cross-country imbalances may well be perceived as a success of and not a threat to the Euro.

We beg to differ on three grounds. First, the Euro area divergence of consumption and spending behavior is unprecedented and implies an unsustainable transfer of wealth from the North to the South. A complication is that most of the divergence occurs in the private sector where economic policy coordination

\footnotetext{
${ }^{2}$ We elaborate this clustering below. Our analysis would not change fundamentally when we include Belgium, Luxembourg and France under North and Italy under South.
} 
is largely lacking. The Treaty of Maastricht is not competent in this respect. Second, the Euro area countries form a common currency area that abolished nominal interest and exchange rate mechanisms and seeks to achieve low and common inflation rates. Third, we show that data do not provide evidence for a strong convergence process.

Based on our empirical analysis two promising avenues for future research come to our mind. Both look into causes for the observed dispersion in current account balances that go beyond the economic convergence hypothesis. First, we believe that country heterogeneity in particular cross-country differences in spending habits, planning horizons and levels of risk aversion are a promising research avenue. Placing behavioral considerations on par with economic fundamentals also provides a suitable framework for deriving policy implications. Second, it is interesting to analyze the observed dispersions against the background of an optimal currency area and to pursue the question if they are the inevitable consequence of a Stability and Growth Pact that insufficiently recognizes the diversity of the EMU member countries.

The rest of the chapter is organized as follows. Section 6.2 provides a systematic review of internal and external imbalances in the Euro area by distinguishing the private and public sectors and their respective savings and investment behavior. In addition we disaggregate Euro area current accounts into trade balances, net factor income and net current transfers. In Section 6.3 we review the corresponding literature and analyze the common argument that Euro area imbalances are part of an overall convergence process. Section 6.4 concludes with a brief outline of the broader perspective and policy implications and provides an outlook for future research.

\subsection{Savings behavior and current account imbal- ances}

In our empirical analysis we largely employ data taken from the AMECO database of the European Commission which allows for a detailed and consistent breakdown of all relevant variables. The country groups are obtained using the k-means clustering methodology based on data for current accounts and private saving rates, both in levels and first differences. The two country groups that are always clustered together independent of the choice of variable or taking levels or differences are Austria, Finland, Germany and the Netherlands, which we call North, and Greece, Ireland, Portugal and Spain, called South. ${ }^{3}$ Belgium, France,

\footnotetext{
${ }^{3}$ Gros (2010) discusses current differences between those countries that we cluster as South. Our analysis focuses on a longer time period during which they form a more homogeneous set of
} 
Figure 6.1: Current account (\% of GDP), 1992-2007

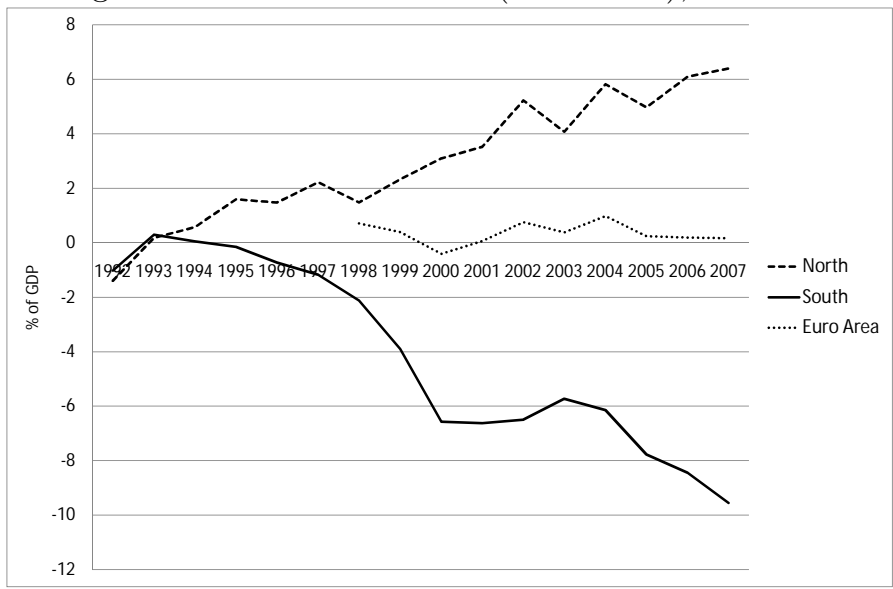

Italy and Luxembourg are clustered differently depending on whether data are employed in levels or first differences, but this is independent of the choice of variable. They are grouped to North based on data in levels and belong to South if the cluster analysis is conducted with data in first differences. In our analysis, we will concentrate on the polar clusters and leave Belgium, France, Italy and Luxembourg aside. However, our conclusions remain roughly the same when we include Belgium, France and Luxembourg under North and Italy under South.

From an economic accounting perspective current account imbalances occur if the demand of a country by households, firms and the government falls short of its output or vice versa. Thus as a general rule current account imbalances should not give rise to concerns as long as they are temporary in nature, e.g. in the event of adverse shocks countries are able to retain stable consumption paths. The situation in the Euro area is different however with current account imbalances that are growing persistently.

Figure 6.1 provides evidence for persistently rising current account imbalances between the two country groups of the Euro area that we have defined above. Since the inception of the EMU process the average current account balance of Northern countries has been continuously growing from a small deficit in 1992 to more than 6 percent of GDP in 2007, while at the same time current accounts of Southern countries deteriorated from close to zero in the early 1990s to a tremendous deficit of almost 10 percent of GDP in $2007 .{ }^{4}$ In comparison, the current account deficits

\footnotetext{
countries.

${ }^{4}$ Note that throughout the paper we employ unweighted averages for the two country clusters to avoid that Germany dominates the Northern countries group and Spain the Southern countries
} 
Table 6.1: Disaggregation of average current accounts in the Euro area

\begin{tabular}{|c|c|c|c|c|c|c|}
\hline & \multicolumn{2}{|c|}{ Current Account } & \multicolumn{2}{|c|}{$\begin{array}{c}\text { Public } \\
\text { Net Savings }\end{array}$} & \multicolumn{2}{|c|}{$\begin{array}{c}\text { Private } \\
\text { Net Savings }\end{array}$} \\
\hline & $1992-1998$ & $1999-2007$ & 1992-1998 & $1999-2007$ & $1992-1998$ & 1999-2007 \\
\hline South & -0.7 & -6.8 & -5.7 & -2.1 & 5.0 & -4.7 \\
\hline North & 0.9 & 4.6 & -3.3 & -0.2 & 4.2 & 4.8 \\
\hline
\end{tabular}

Source: AMECO database

of the US in the ongoing discussion of global imbalances peaked at a level of about 6 percent of GDP.

Most of the current account divergence can be attributed to the second subperiod and hence corresponds to the introduction of the Euro as a common currency. The first column of Table 6.1 confirms that in the run-up to EMU, 19921998, current account differences were relatively minor with an average deficit for Southern countries of 0.7 percent of GDP compared to an average surplus for Northern countries of 0.9 percent of GDP. Since the introduction of the Euro, current accounts drifted apart by more than 11 percent of GDP and distinct groups of creditor and debtor countries emerged. Finally it is interesting to observe from Figure 6.1 that despite underlying dispersions, the aggregate current account of the Euro area (EU-16) is hovering around zero at all times. This suggests the interpretation that Northern countries are essentially financing the current account deficits of Southern countries with their surpluses - either directly through capital flows from North to South or indirectly with non-Euro area countries acting as intermediaries.

To further explore the current account balances in the Euro area we proceed along two lines. First we view the contributions of saving $(S)$ and investment $(I)$ decisions of households and firms as the private sector and the government as the public sector to the evolution of current account balances

$$
C A=S_{\text {public }}-I_{\text {public }}+S_{\text {private }}-I_{\text {private }}
$$

and second, we consider the different components of the current account balance from an accounting perspective

$$
C A=T B+N F I+N C T
$$

with trade balance $(T B)$, net factor income $(N F I)$ and net current transfers $(N C T)$. Both approaches are revealing.

group, respectively. The conclusions do hardly change when we use GDP weighted figures. The corresponding figures are available from the authors upon request. 
Figure 6.2: Public net savings (\% of GDP), 1992-2007

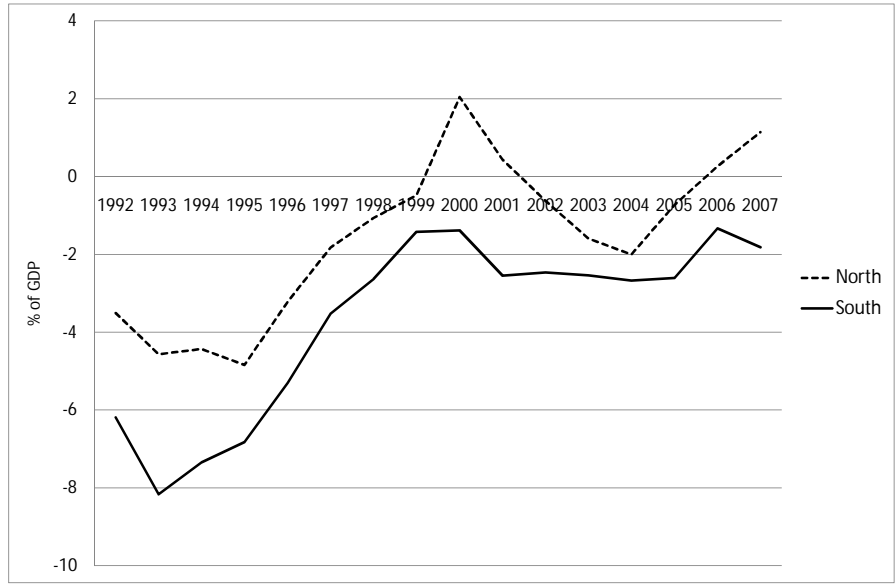

Figure 6.3: Private net savings (\% of GDP), 1992-2007

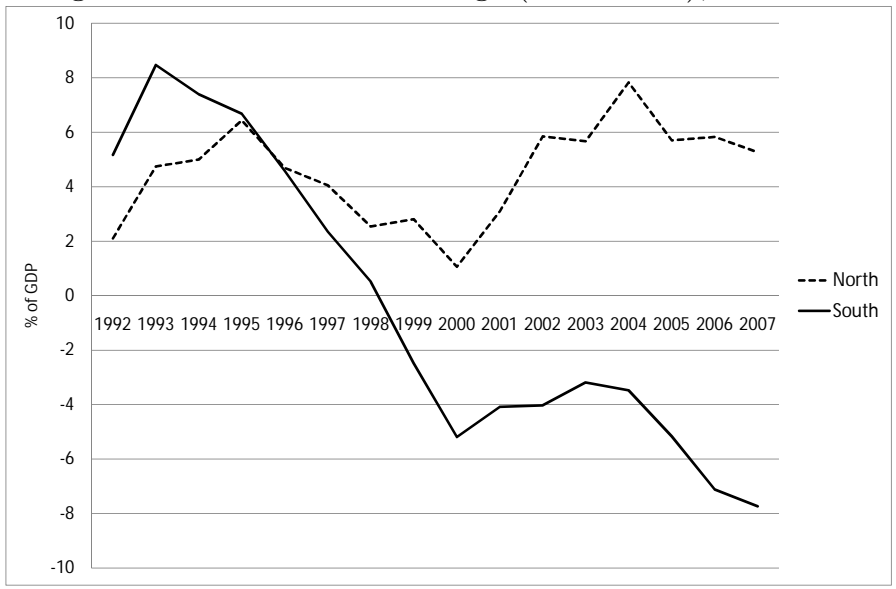

\subsubsection{Public versus private net saving rates}

We distinguish between the public sector consisting of the government and the private sector consisting of households and firms. Both contribute through saving and investment decisions to the evolution of a country's current account. Figures 6.2 and 6.3 show net savings of Northern and Southern countries as they emerge from their public and private sectors, respectively. In addition, columns 2 and 3 of Table 6.1 present the time averages for the two subperiods that we consider. A number of interesting facts are notable. Considering the contributions of the public 
sectors to the current account balances we find that notwithstanding a common upward trend for both country groups, Southern countries are persistently lagging behind by about 2 percent of GDP. In particular during the run-up to EMU, all governments managed to improve their initial deficit positions: Southern countries on average by 3.6 percent of GDP and Northern countries on average by 3.1 percent of GDP, respectively. Thereafter, since the introduction of the Euro, the public net savings of both country groups are fairly stable with an average deficit of 0.2 percent of GDP for North and an average deficit of 2.1 percent of GDP for South. In summary, we can see from the data that public net savings seem to obey the criteria of the Treaty of Maastricht. However we note that the period of fiscal consolidation coincides with the upward phase of the business cycle and one could argue that, in particular South, should have done even more to weather the storm ahead.

To explain the current account divergence that we observe in Figure 6.1, we have to shift our attention to the private sectors, depicted in Figure 6.3. For Northern countries we find relatively steady private net savings that vary within a three-percent margin around 5 percent of GDP. No trend is detectable, neither in the run-up to EMU nor in the time period thereafter. For Southern countries however we observe a tremendous deterioration of private net savings exceeding 16 percent of GDP: from a surplus of 8 percent of GDP in the early 1990s to a deficit of the same magnitude in 2007. Also from column 3 of Table 6.1 we can see that private net savings of Southern countries were positive with 5 percent of GDP in the first subperiod, but turned negative with 4.7 percent of GDP in the second subperiod. Particularly interesting to observe is that in the South the net saving rates of the public and private sectors are almost one-to-one mirror images. That is during the run-up to EMU when we observed the most pronounced improvements of net savings in the public sector, we also observe the most distinct deteriorations of net savings in the private sector. For Southern countries, it seems as if the adjustment burden of the fiscal policy measures that are stipulated in the Treaty of Maastricht have a strong compensatory influence on the private sector.

The joint conclusion of both figures is that the current account divergence in the Euro area can be explained by the interaction of the public and private sectors. While the public sectors in all countries reacted largely in the same way to the fiscal convergence criteria imposed on them, we find that the private sectors were differently prepared to cope with it. The private sectors of Northern countries could insulate themselves and showed no reaction to the current account improvements of their public sectors. In contrast, the private sectors of Southern countries more than set off the improvements of the public net savings with the result of an overall current account deterioration as shown in Figure 6.1.

To further shed light on what happened to private net savings in the Euro 
Figure 6.4: Private savings (\% of GDP), 1992-2007

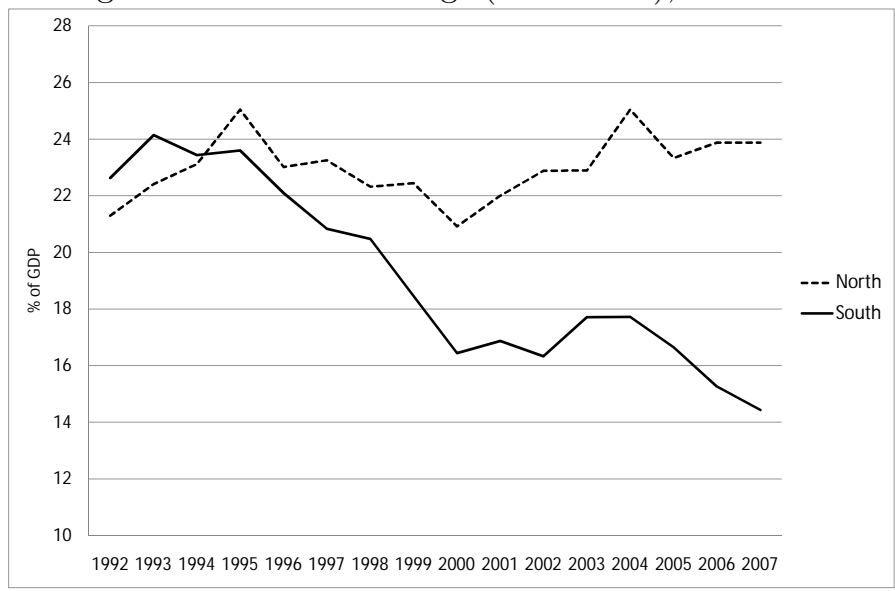

Figure 6.5: Private investment (\% of GDP), 1992-2007

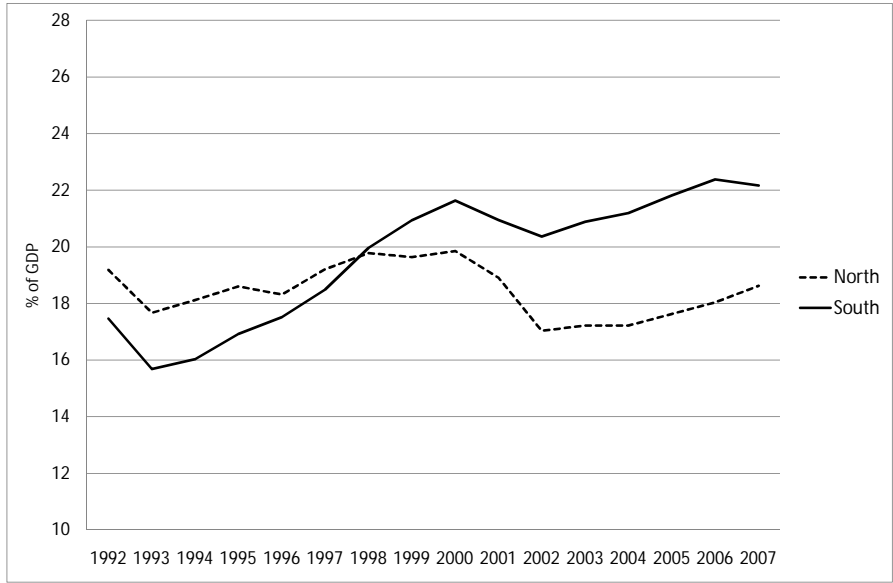

area, we proceed with their disaggregation into private savings and investments, in Figures 6.4 and 6.5, respectively. In addition we also present the corresponding time averages for the two subperiods in Table 6.2. In line with private net savings, we find that private saving and investment rates of Northern countries remained largely unchanged over the past one and a half decades. While private savings fluctuate closely around 23 percent of GDP, private investment rates are 18.5 percent of GDP on average. This in itself is an interesting result: neither the preparation for, nor the introduction of a common currency (with all its far- 
Table 6.2: Disaggregation of average private net saving rates in the Euro area

\begin{tabular}{c|cccccc}
\hline \hline \multirow{2}{*}{} & \multicolumn{2}{|c}{$\begin{array}{c}\text { Private } \\
\text { Net Savings }\end{array}$} & \multicolumn{2}{c}{$\begin{array}{c}\text { Private } \\
\text { Savings }\end{array}$} & \multicolumn{2}{c}{$\begin{array}{c}\text { Private } \\
\text { Investment }\end{array}$} \\
\cline { 2 - 7 } & $1992-1998$ & $1999-2007$ & $1992-1998$ & $1999-2007$ & $1992-1998$ & $1999-2007$ \\
\cline { 2 - 7 } South & 5.0 & -4.7 & 22.4 & 16.7 & 17.4 & 21.4 \\
North & 4.2 & 4.8 & 22.9 & 23.0 & 18.7 & 18.2 \\
\hline \hline
\end{tabular}

Source: AMECO database

reaching consequences) seem to have implications for the savings and investment behavior of households and firms in Northern countries. For Southern countries the situation is fundamentally different. From Figure 6.4 we can see that the tremendous deterioration of private net saving rates can be primarily attributed to the saving behavior of the private sector. The private saving rates per GDP dropped from a high of 24 percent in 1993 to almost 14 percent in 2007. This is also confirmed by Table 6.2. During the run-up to EMU both country groups displayed almost the same average private saving rates of about 22.5 percent of GDP, however with the introduction of the Euro it declined to an average of 16.7 percent of GDP in Southern countries, while it remained by and large unchanged in Northern countries. Concomitant to falling private saving rates, we observe private investment growth in Southern countries that also contributed to the deterioration of their current accounts. The growth in private investment rates is largely confined to the time period of the run-up to EMU and might be triggered by the output growth prospects of the common currency area. From Table 6.2 we find that the average private investment rate for Southern countries is 17.4 percent of GDP prior to the introduction of the Euro and 21.4 percent of GDP thereafter.

Having established that private sectors are prime drivers of current account imbalances we proceed with taking an accounting perspective and disaggregate these imbalances into their components.

\subsubsection{Components of the current account}

Reviewing external and internal imbalances in the Euro area, we ultimately seek to answer the question of how sustainable these imbalances are, in particular for a common currency area that can no longer rely on nominal exchange rates and interest rates adjustments. In this respect, viewing the individual components of current accounts - trade balances, net factor income and net current transfers - is particularly informative as the mix of these components reveals how past external imbalances transmit into present and future years. In the absence of valuation gains, current account deficits in the past lead inevitably to the accumulation of 
Figure 6.6: Net foreign assets (\% of GDP), 1992-2007

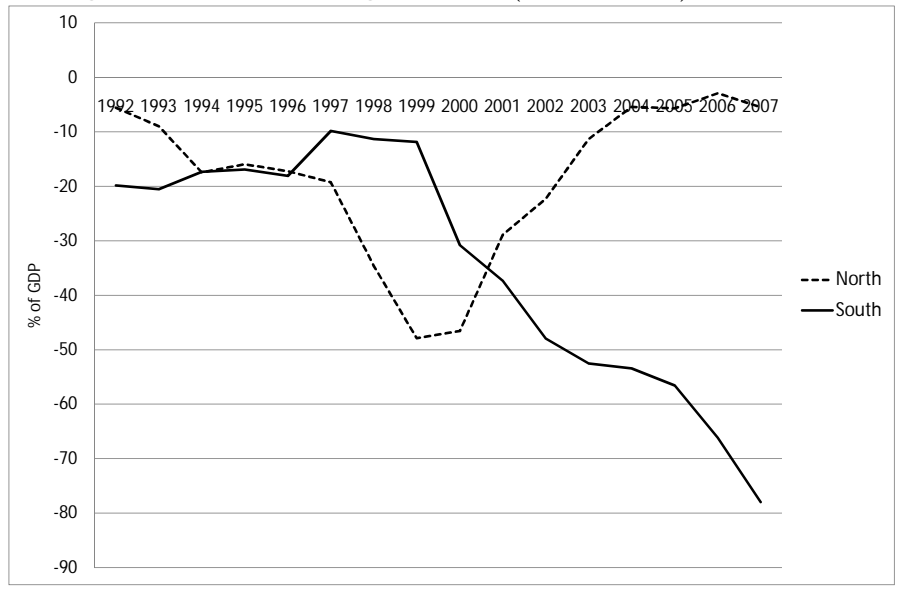

net foreign debt positions that need to be serviced out of current income. ${ }^{5}$ As such the situation of external imbalances in the Euro area will stretch into the future and accelerate the current divergences process.

Figure 6.6 shows the evolution of net foreign asset positions as a percentage of GDP over the time period 1992 to 2007. In accordance with the current account patterns in Figure 6.1 we find that Northern and Southern countries are holding similar net foreign debt positions of about 10 to 20 percent of GDP during the run-up to EMU. Since 2000 however differences in current account patterns begin to materialize in net foreign asset positions. Northern countries with average current account surpluses of 4.6 percent of GDP continuously reduced their foreign indebtedness to close to zero. For Southern countries mounting current account deficits took their toll. In 2007 they face a level of foreign indebtedness of close to 80 percent of GDP with concomitant consequences that are alarming. Figure 6.7 shows how the divergence of net foreign asset positions induces net foreign income payments that reinforce current trends. Following the deterioration of their net foreign asset positions, Southern countries have to pay an increasingly larger share of GDP to service their foreign creditors. In 2007 almost 6 percent of GDP has to be spent on net factor income payments. Northern countries on the other hand are net recipients of factor income in the range of 0.5 to 1 percent of GDP in the latest years. Figure 6.8 presents whether trade balances as differences of exports and imports of goods and services react to the evolution of net factor income payments by restraining or expanding net imports.

\footnotetext{
${ }^{5}$ For an empirical and theoretical discussion of valuation effects in the external adjustment process see, among other studies, Chapter 4.
} 
Figure 6.7: Net factor income (\% of GDP), 1992-2007

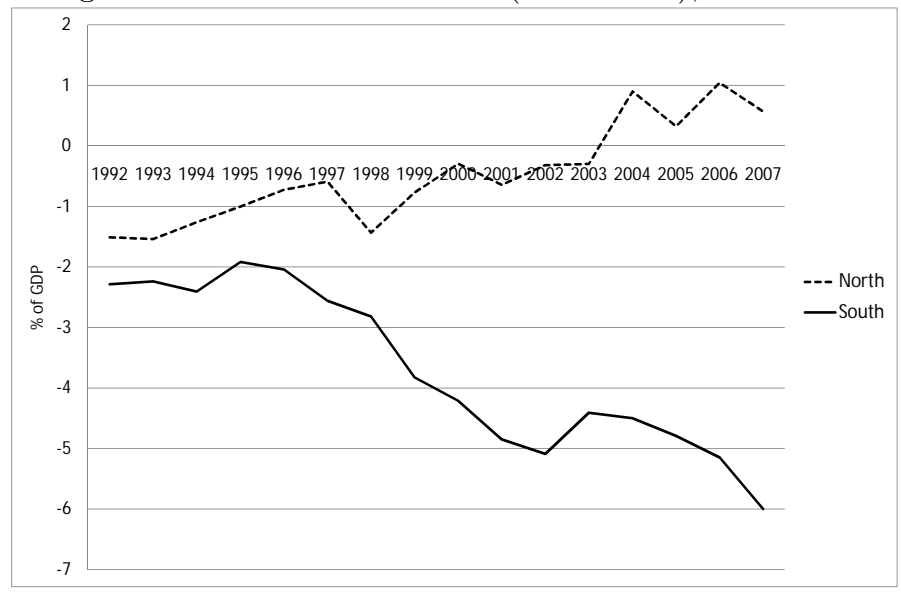

Figure 6.8: Trade balance (\% of GDP), 1992-2007

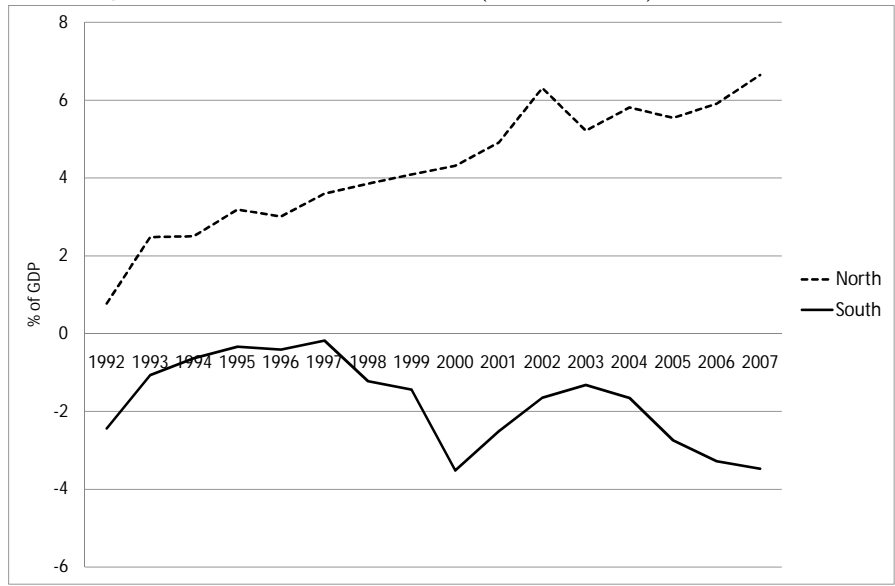

Northern countries persistently improved their trade balances from about 1 percent of GDP in 1992 to more than 6 percent of GDP in 1992. There is no evidence that they adapted their behavior and consumed the extra income they earned on their net foreign asset positions. The same holds true for Southern countries, but with reversed signs. The trade balances of Southern countries decreased around the time of the introduction of the Euro from an average deficit of about 1 percent of GDP before to an average deficit of 2.5 percent of GDP thereafter. The relatively stable trade balance deficits since 2000 are remarkable 
Figure 6.9: Net current transfers (\% of GDP), 1992-2007

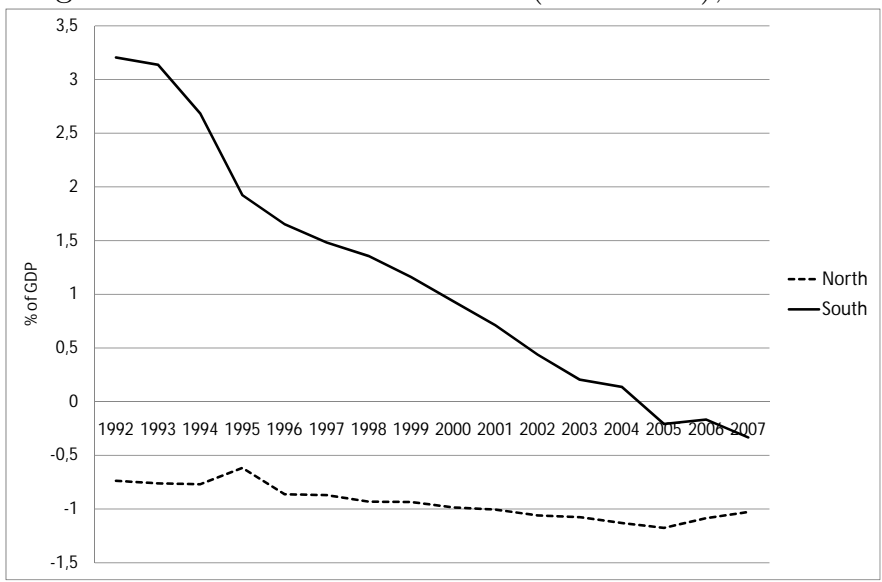

as they show no sign of restriction in net imports to compensate the tremendously increasing net factor income payments. This implies that the latter are directly passed on to the current account from where they feed back to the further accumulation of foreign debt. This process is unsustainable and will eventually lead to exploding foreign debt levels. To halt the accumulation of foreign debt, Southern countries will have to adapt their consumption behavior in a way as to offset the payments to foreign creditors.

The final component of the current account, net current transfers, is particularly prevalent in Europe as it captures, among others, payments related to current international cooperation (AMECO, 2010). Figure 6.9 summarizes the evolution of net current transfers for both country groups over the time period 1992 to 2007. Three observations stand out. First, Northern countries are continuously transferring an average of 1 percent of GDP over the entire time period, while Southern countries are net recipients of current transfers for most of the time. Initially their net current transfers amount to more than 3 percent of GDP, but are steadily decreased to marginally below zero in 2007. Second, the magnitude of net current transfers is remarkable and allowed Southern countries to finance their trade balance deficits and net factor payments during the run-up to the EMU to a considerable extent by the receipt of net current transfers. During this time period the average sum of the trade balance deficit and net factor payments amounted to 3.2 percent of GDP while the average net current transfers are 2.2 percent of GDP. Third, in the same way as net factor income payments, the decline in net current transfers is transmitted to the current account. We do not observe any compensatory adjustments in the trade balances of Southern countries. 
Considering the different components of the current account we can summarize that continuously growing current account surpluses of Northern countries are largely attributable to improving trade balances and net factor income receipts, whereas for Southern countries growing net factor income payments and declining net current transfers are primarily responsible for the deterioration of their current account balances. We have also shown that diverging net foreign asset positions and induced net factor income payments further fuel internal and external imbalances in the Euro area.

In the next section we review the argument that the observed current account patterns are part of a catching-up process of countries in the South with their neighbors in the North.

\subsection{All a matter of economic convergence?}

Only very few papers recognize the evolution of external and internal imbalances across Euro area countries since the early 1990s. Those that do, generally seek to attribute the observed pattern of current account differentials to the European economic convergence process (Blanchard and Giavazzi, 2002; Ahearne et al., 2007; Arghyrou and Chortareas, 2008).

The theory of intertemporal maximization suggests that diverging current accounts are the natural consequence of a convergence process among countries with different levels of economic development. In particular in the presence of integrated real and financial markets, we should expect that countries with a lower per-capita income attract domestic and foreign investment as higher productivity and economic growth rates promise extra-ordinary rates of return. The productivity of the invested capital ensures that the accumulated foreign debt can ultimately be repaid. At the same time, these countries should consume more and consequently save less in anticipation of higher income growth in the future. Thus on both accounts, higher investment and lower saving rates, the theory of intertemporal maximization suggests that Southern countries should accumulate net foreign debt, while Northern countries should act as their net foreign creditors.

In the same convergence process Southern countries will experience inflationinduced appreciation of their real exchange rates relative to Northern countries. Given a fixed nominal exchange rate, relatively higher inflation rates in Southern countries lead to an immediate real exchange rate appreciation and thus a less competitive international position. ${ }^{6}$ As a result, current account balances evolve

\footnotetext{
${ }^{6}$ Two complementary theories exist to explain the inflation-induced loss of international competitiveness during the convergence process. For a supply-side approach see Balassa (1964) and Samuelson (1964) and for a demand-side approach see Baumol and Bowen (1966).
} 
Figure 6.10: Relative real GDP per capita (average $=100$ ), 1992-2007

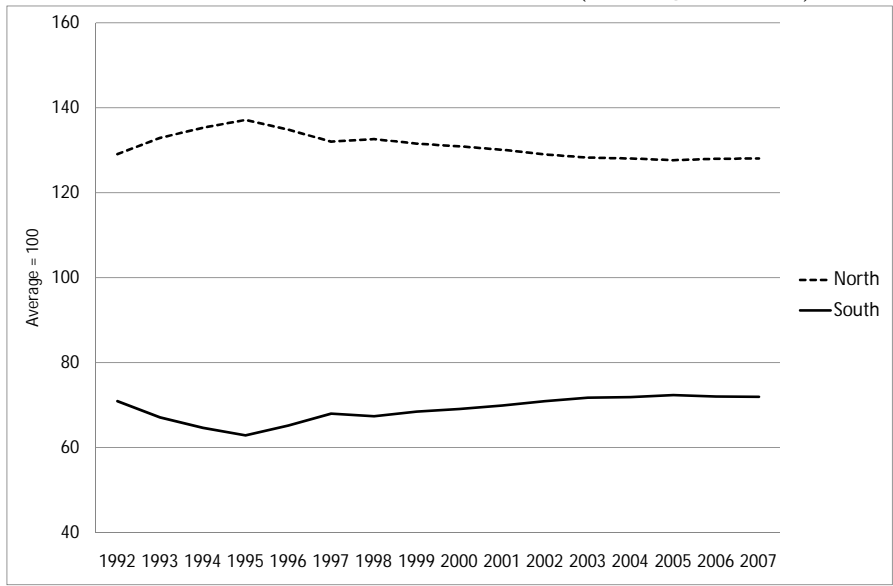

in such a way as to match the capital account surpluses of countries in the South and deficits in the North.

In principle our findings in Figure 6.4 and 6.5, namely a moderate increase in private investment and a strong decline in private savings for Southern countries, are consistent with economic convergence. Also the literature that seeks to explain external imbalances in the Euro area seems to support this line of reasoning. However when looking further at the data we find that the economic convergence hypothesis does not stand up to the empirical facts as (1) real income differentials are persistent, (2) total factor productivity remains low in the South and (3) the terms of trade data do not point at a substantial loss in international competitiveness. We discuss each empirical fact in turn.

Figure 6.10 shows relative real GDP per capita for Northern and Southern countries over the time period 1992 to 2007. We find that in real terms Northern countries have about twice as much GDP per capita as Southern countries, and more surprisingly, that the European economic and monetary integration process has triggered little convergence among those two groups of countries. The gap is relatively persistent over the time spans of the run-up to EMU and the subsequent introduction of the Euro. The cause is shown in Figure 6.11 - diverging total factor productivity of both country groups over the years 1992 to $2007 .{ }^{7}$ Ireland constitutes an exception here with a strongly increasing total factor productivity,

\footnotetext{
${ }^{7}$ AMECO data show that while relative gaps of capital and employment rates between North and South (excl. Ireland) are gradually closing, diverging total factor productivity impedes an overall economic convergence process. Using OECD data on total factor productivity yields similar results. The corresponding figures are available from the authors upon request.
} 
Figure 6.11: Relative total factor productivity (average $=100$ ), 1992-2007

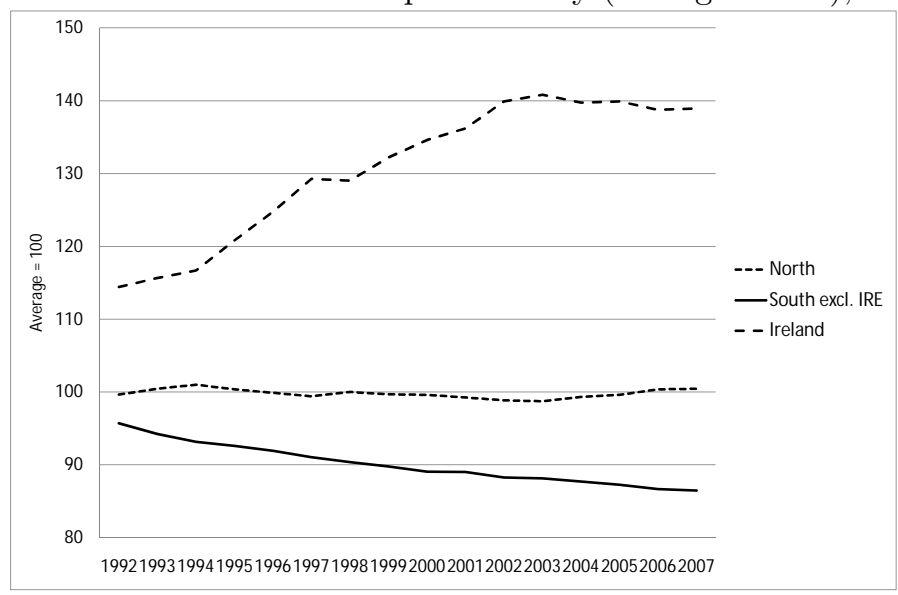

in particular during the run-up to EMU. Although the economic convergence hypothesis is framed within expectations of productivity and economic growth, the realization thereof, shown in Figures 6.10 and 6.11, is not in support. Given the persistent differences in relative income and productivity, we have either to assume that expectations of Southern countries are continuously off or they have other motives for consuming today.

Also the empirical growth literature that analyzes the success of the Euro area performance since 1992 seems to invalidate the economic convergence motive for the observed external imbalances. Roubini et al. (2007) find little evidence of per capita GDP convergence (in PPP terms), with Ireland being the only genuine example of standard of living catching up. In fact the country moved from the group of laggards to one of the leaders in the Euro area group within one ddecade. Countries such as Portugal, Greece and Spain do not show evidence of per capita incoem catching up. Similarly, Giannone and Reichlin (2006) and Giannone et al. (2009) conclude that Euro area gaps are very persistent in the last 30 years and there is no clear sign of convergence to a common level of output per capita, again with the exception of Ireland. Formal unit root tests show that there is no common trend along which these economies move.

Next we seek to contest the argument that inflation-induced appreciation of the real exchange rate and a concomitant loss of international competitiveness cause the current account deficits of the South.

At first sight the argument seems to find support in Figure 6.12 which presents producer price inflation rates for Northern and Southern countries over the time period 1992 to 2007. Inflation rates in Northern countries vary within the range of 
Figure 6.12: Producer price inflation, 1992-2007

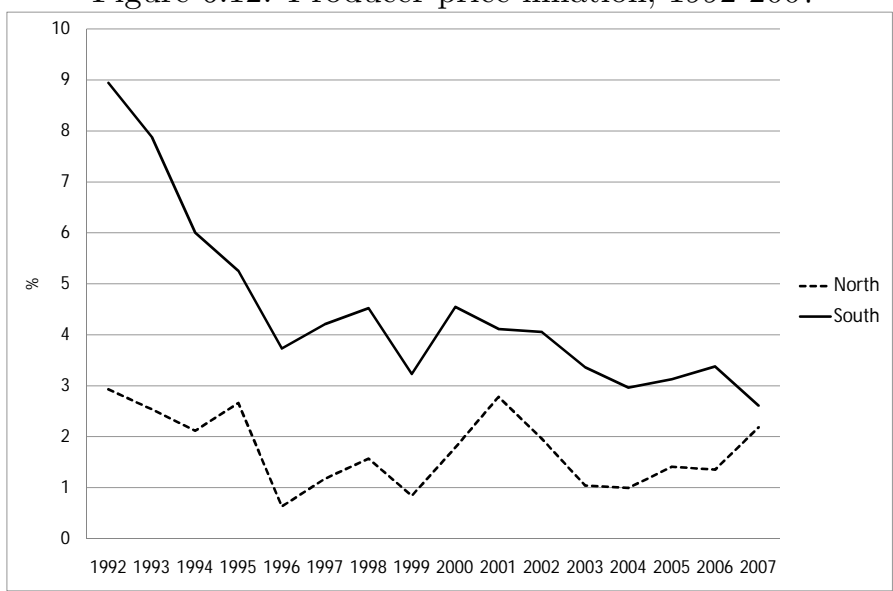

Figure 6.13: Terms of trade $(1980=100), 1992-2007$

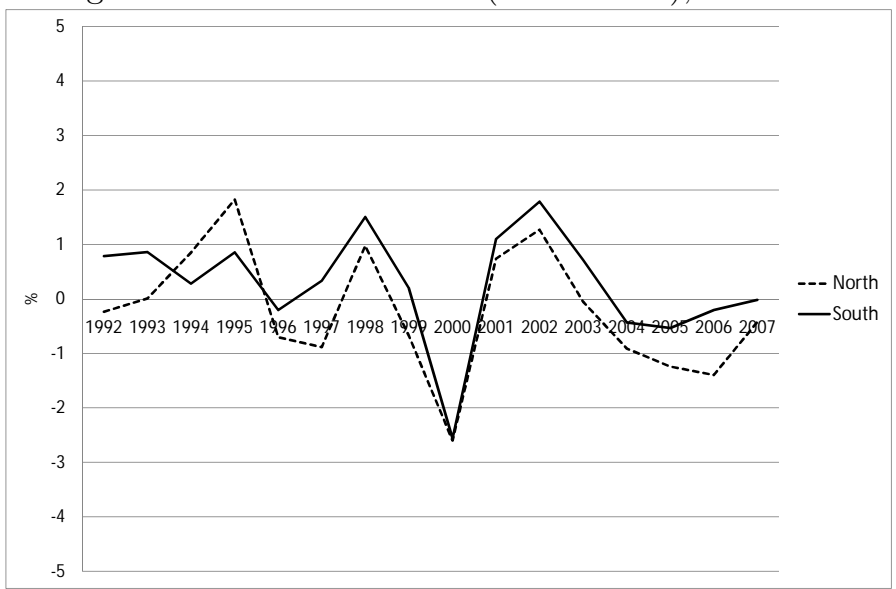

1 to 3 percent over the total period, while Southern countries exhibit inflation rates that are at least 1 to 2 percent higher. This implies an annual appreciation of the real exchange rate by 1 to 2 percentage points, preceded by a considerably higher amount during the run-up to EMU. However we disagree with the use of inflation rates as a measure for external price competitiveness. Producer price inflation rates combine price information on tradable and non-tradable goods, although both are subject to distinct sets of determinants, in particular for countries with different stages of economic development.

A better measure to determine a country's external price competitiveness is 
its terms of trade, the ratio of export over import prices which exclude the nontradable sector. Figure 6.13 shows the percentage change in the terms of trade for Northern and Southern countries over the time period 1992 to 2007. We find that the relative loss of international competitiveness of Southern countries is far less pronounced than inflation differentials suggest. This shows that the observed correlation between real exchange rate movements and current account dispersion in the Euro area is at least partially spurious as the underlying mechanism of a relative loss in international competitiveness is not equally given. ${ }^{8}$ Moreover we have seen in the foregoing analysis that in particular for Southern countries net factor income and net current transfers play a much greater role in shaping the current account than the trade balance.

Taken together, it becomes obvious that arguments of economic convergence can be at best part of an explanation for growing internal and external imbalances. Financial markets seem to have recognized that two important adjustment devices are missing to redress these imbalances, since North and South have common nominal interest rates and exchange rates. In our view other economic adjustment mechanisms are either ineffective or carry substantial risk. First, Southern countries could restore international price competitiveness and thus their external balances through a prolonged period of disinflation. Such a process goes along with a painful period of economic contraction and will only be effective over the medium to long run. Second, lower inflation in the South results in higher real interest rates which could encourage higher savings and less investment. The emergence of risk premiums in financial markets potentially works in the same way, but involves the substantial risk that debtor countries are pushed to the brink of insolvency. The situation of Greece is an alarming example. Third, wealth effects could act as important transmission channels. However our analysis has shown that - at least in the past - Southern countries did not adapt their consumption and savings behavior in the face of mounting external debt positions.

The apparent failure of these adjustment mechanisms and the associated risk justifies European economic policy coordination. We believe that the success of such policy coordination will largely hinge on a better understanding of country heterogeneity. As such we regard the descriptive analysis in this chapter as a starting point for future theoretical and empirical research into this direction.

In the conclusion we will point out two directions for future research that derive from the empirical background of this chapter.

\footnotetext{
${ }^{8} \mathrm{~A}$ possible transmission channel is that higher inflation in the South lowers the real interest rate and thereby induces consumption and investment.
} 


\subsection{Conclusion and future research directions}

In this chapter we provide a systematic analysis of current internal and external imbalances in the Euro area that emerged with the introduction of the Euro as a common currency. This is an issue that has obtained scant attention in the past, but gained significance with the unfolding of Greek solvency problems. During the time period 1999 to 2007 we identify two groups of Euro area countries that were running an average current account surplus and deficit of 4.6 and 6.8 percent of GDP, respectively. The main drivers of the current account dispersion are the private sectors - households and firms - as the fiscal constraints of the Treaty of Maastricht have proved reasonably effective on the public sectors. For the private sectors we find that a tremendous decrease in savings of Southern countries from about 24 percent of GDP in the beginning of the 1990s to about 14 percent of GDP in 2007 , reflected by a corresponding increase in consumption and to a lesser extent investment, is mainly responsible for the deterioration of their current accounts.

Our analysis shows that the fiscal policy measures that are stipulated in the Treaty of Maastricht have diverse consequences for the private sectors in the Euro area. While the public sectors in all countries reacted largely in the same way to the fiscal convergence criteria imposed on them, we find that the private sectors were differently prepared to cope with it. The private sectors of Northern countries could largely insulate themselves and showed no reaction to the improvements of their public sectors. In contrast, we observe strong compensatory influences on the private sectors in the South.

In our view underlying fundamental economic factors are not able to fully explain the observed imbalances in the Euro area. The common argument of economic convergence does not provide a satisfactory explanation of our observations. For that reason we suggest two avenues for future research and review them shortly.

First, future models of the EMU should be built around behavioral aspects such as cross-country differences in spending habits, planning horizons and levels of risk aversion. Theoretical and empirical research on the determinants and dynamics of the current account has been growing over the past decade. We have already dealt with one class of models, portfolio-balance models, in Chapters 4 and 5 . Another class comprises the intertemporal approach to the current account that has gained prominence as a workhorse model of open economy macroeconomics. It was initially proposed by Sachs (1981) and elaborated further by Obstfeld and Rogoff $(1995,1996)$. The standard intertemporal model includes a representative agent with an infinite life who smoothes consumption over time by borrowing and lending abroad. The approach is well adapted to consider the savings-investment behavior of agents as the driver of current accounts. Also different propensities to 
consume can easily be recognized as explanations for emerging current account patterns. However the intertemporal approach to the current account in its standard framework is less well suited to consider the impact of fiscal policies on the current account. It assumes that Ricardian equivalence holds, e.g. the representative agent adapts the own consumption plan to the fiscal stance of the government as to absorb its impact on the current account. This is certainly an undesirable feature in a world where government deficits and debt matter and twin deficits emerge, particularly in the Euro area.

In order to get a better understanding of the situation of growing external imbalances in the Euro area we need to deviate from the standard intertemporal approach to the current account. We will shortly discuss two interesting ingredients to realistically model the EMU.

First, the model of Piersanti (2002), which is inspired very much by work of Blanchard (1984, 1985) and Yaari $(1964,1965)$, could serve as a starting point. It assumes forward-looking agents who maximize utility over uncertain life-times. The uncertainty is introduced through a probability of death parameter, where the inverse can be interpreted as the planning horizon of agents. It allows us to model the shorter planning horizon of Southern countries, but also to consider the special case of infinite horizons as the probability of death goes to zero. The case of infinite horizons yields the presence of Ricardian Equivalence.

Second, to get a grip on the fiscal stance of the government and the modeling of twin deficits, the index of fiscal policy introduced by Blanchard (1985) could serve as a starting point. The index summarizes how current and expected levels of government spending and the way of financing those affect aggregate demand. Both are important considerations for the North-South divide in the Euro area. The fiscal index incorporates a debt tolerance parameter and allows for fiscal policy to have an effect on human wealth and consumption decision. The effect is brought about by the possibility to shift the burden of future tax increases to future generations, when someone currently alive will not be concerned anymore. Hence by modeling shorter planning horizons of consumers in the South, the model could generate government debt that is perceived as consumer wealth, and thus induces twin deficits.

We believe that these two ingredients are well suited as a starting point for modeling the current account pattern in the Euro area. It allows capturing differences in (1) the propensity to consume and planning horizons and (2) the debt tolerance of the public and private sectors. We have shown in our empirical analysis that both behavioral considerations are key in understanding the Euro area dispersion of savings and investment behavior. A number of worthwhile extensions come to mind. First, the model needs to be casted in a two-country setting to properly account for the interdependence of South and North in the Euro 
area. The common link will be through net foreign assets. Second, within a twocountry model, we need to allow for an adjustment mechanism that could be either the terms of trade or the interest rate The latter seems to be of particular interest as it would add a risk premium for the South to the model. The risk premium could be linked to the level of outstanding foreign debt (e.g. Benigo, 2002; Ca'Zorsi and Rubaszek, 2008). Third, we need to incorporate capital accumulation that leads to productive capital formation. Thus allow for productivity and production differentials. The derivation of the model and the suggested extensions are on our research agenda. We believe it will provide valuable insights in the function of the Euro area and form the basis for policy recommendations.

The second research avenue that we propose revisits the question to what extent the Euro area constitutes an optimal currency, given the observed dispersions. It is also interesting in this context to analyze the question to what extent the current draft of the Treaty of Maastricht failed to properly account for differences in economic structure and initial conditions of its member countries. At the time of the drafting of the fiscal rules, a considerable literature discussed "the risk of serious fiscal overkill" that the new convergence criteria would imply (Buiter, 1993). Also the widely diverging fiscal conditions at that time and the lack of experience with the long-run effects of a fiscal contraction gave rise to much concern (Buiter and Kletzer, 1991; Corsetti and Roubini, 1992; Buiter, 1993). In particular the latter point seems very relevant today as we observe the diverse influences of fiscal consolidations on the private sectors in the North and South. Now two decades into EMU and with the hindsight knowledge of our empirical observations it seems necessary to take up this discussion again. 


\section{Bibliography}

Ahearne, A., B. Schmitz, and J. von Hagen (2007). Current account imbalances in the Euro area. in A. Aslund and M.Dabrowski (eds.), Challenges of Globalization - Imbalances and Growth Peterson Institute for International Economics.

Ando, A. and F. Modigliani (1963). The life-cycle hypothesis of savings: Aggregate implications and tests. The American Economic Review 103, 55-84.

Andrews, D. and W. Ploberger (1994). Optimal tests when a nuisance parameter is present only under the alternative. Econometrica 62, 1383-1414.

Arghyrou, M. and G. Chortareas (2008). Current account imbalances and real exchange rates in the Euro area. Review of International Economics 16.

Artis, M. and M. Hoffmann (2008). Financial globalization, international business cycles, and consumption risk sharing. Scandinavian Journal of Economics 110(3), 447-471.

Asdrubali, P., B. Sørensen, and O. Yosha (1996). Channels of interstate risk sharing: United States - 1963-1990. The Quarterly Journal of Economics 111, 1081-1110.

Aviat, A. and N. Coeurdacier (2007). The geography of trade in goods and asset holdings. Journal of International Economics 71, 22-51.

Backus, D., P. Kehoe, and F. Kydland (1992). International real business cycles. The Journal of Political Economy 100, 745-775.

Balassa, B. (1961). The theory of economic integration. Allen \& Unwin, London, UK. 
Balassa, S. (1964). The purchasing-power parity doctrine. Journal of Political Economy 72, 584-596.

Baumol, W. and W. Bowen (1966). Performing Arts: The Economic Dilemma. Twentieth Century Fund.

Becker, S. and M. Hoffmann (2006). Intra- and international risk-sharing in the short run and the long run. European Economic Review 50, 777-806.

Bekaert, G. and X. Wang (2009). Home bias revisited. Columbia Business School Working paper.

Bems, R., L. Dedola, and F. Smets (2007). US imbalances: The role of technology and policy. Journal of International Money and Finance 26(4), 523-545.

Benigo, P. (2002). Price stability with imperfect financial integration. CEPR Discussion Paper 2854 .

Bergvall, A. (2004). What determines real exchange rates? The nordic countries. Scandinavian Journal of Economics 106(2), 315-337.

Bernanke, B. (2005). Discussion: International investors, the U.S. current account, and the dollar. Brookings Paper on Economic Activity 1.

Bernanke, B. (2006). Remarks by Governor Ben. S. Bernanke at the Sandridge Lecture, Virginia Association of Economics. Richmond, Virginia.

Bernanke, B. (2007). Global Imbalances: Recent Developments and Prospects. Speech by Ben S. Bernanke at the Bundesbank Lecture. Berlin, Germany.

Bhagwati, J. (1998). The capital myth. The difference between trade in widgets and dollars. Foreign Affairs 7(3), 7-12.

Black, A., P. Hoesli, and M. Fraser (2006). House prices, fundamentals and bubbles. Journal of Business Finance \& Accounting 33, 1535-1555.

Blanchard, O. (1984). Current and anticipated deficits, interest rates and economic activity. European Economic Review 25, 7-27.

Blanchard, O. (1985). Debt, deficits, and finite horizons. Journal of Political Economy 93(2).

Blanchard, O. and F. Giavazzi (2002). Current account deficits in the Euro area. The end of the Feldstein-Horioka puzzle? Brookings Papers on Economic Activity 2. 
Blanchard, O., F. Giavazzi, and F. Sa (2005). International investors, the U.S. current account, and the dollar. Brookings Paper on Economic Activity 1.

Blanchard, O. and G. Milesi-Ferretti (2009). Global imbalances: In midstream? IMF Staff Position Note 1009/29.

Bordo, M. and B. Eichengreen (2001). The rise and fall of a barbarous relic: The role of gold in the international monetary system. in G.A. Calvo, R. Dornbusch, and M. Obstfeld (eds.), Money, Capital Mobility, and Trade: Essays in Honor of Robert Mundell MIT Press, Cambridge, US.

Bracke, T., M. Bussiere, M. Fidora, and R. Straub (2008). A framework for assessing global imbalances. ECB Occasional Paper Series 938.

Bracke, T. and M. Schmitz (2007). Channels of international risk-sharing: Capital gains versus income flows. ECB Working Paper Series 938.

Branson, D. (1979). Exchange Rate Dynamics and Monetary Policy. Inflation and Employment in Open Economies. North-Holland Publishing Company.

Brendner, A. and F. Pisani (2007). Global imbalances: Is the world economy at risk? DEXIA.

Bruinshoofd, A. (2009). Securitization and everything after. Maastricht University lecture, 22 February, 2009.

Buiter, W. (1993). Maastricht's fiscal rules. Economic Policy 8(16), 57-100.

Buiter, W. (2009). The unfortunate uselessness of most 'state of the art' academic monetary economics. Financial Times Blog, March, 3, 2009.

Buiter, W. and K. Kletzer (1991). Reflections on the fiscal implications of a common currency. in A. Giovannini and C. Mayer (eds.),European Financial Integration, Cambridge University Press, Cambridge.

Caballero, R. (2006). On the macroeconomics of asset shortage. NBER Working Paper 12753.

Caballero, R., E. Farhi, and P.-O. Gourinchas (2008). An equilibrium model of "Global Imbalances and Low Interest Rates". American Economic Review 98(1), 358-393.

Candelon, B. and H. Lütkepohl (2001). On the reliability of Chow-type tests for parameter constancy in multivariate dynamic models. Economics Letters 73, $155-160$. 
Case, K. E., J. M. Quigley, and R. J. Shiller (2005). Comparing wealth effects: The stock market versus the housing market. B. E. Advances in Macroeconomics 5(1).

Case, K. E. and R. J. Shiller (2003). Is there a bubble in the housing market? Brookings Papers on Economic Activity 2.

Ca'Zorsi, M. and M. Rubaszek (2008). On the empirical evidence of the intertemporal current account for the Euro area countries. ECB Working Paper Series 895 .

Cheung, Y. W. and K. S. Lai (1993). Finite-sample sizes of Johansen's likelihood ratio test for cointegration. Oxford Bulletin of Economics and Statistics 55, 313-328.

Coakley, J., F. Kulasi, and R. Smith (1998). The Feldstein-Horioka Puzzle and capital mobility. International Journal of Finance and Economics 3, 169-188.

Cochrane, J. (1991). A simple test of consumption insurance. The Journal of Political Economy 90, 957-976.

Cooper, R. (2008). Global imbalances, globalization, demography and sustainability. Journal of Economic Perspective 90(3), 93-122.

Corsetti, G., L. Dedola, and S. Leduc (2008). Productivity, external balance and exchange rates: Evidence on the transmission mechanism among G7 countries. The Review of Economic Studies 75, 443-473.

Corsetti, G. and N. Roubini (1992). Tax smoothing discretion versus balanced budget rules in the presence of politically motivated fiscal deficits: the design of optimal fiscal rules for Europe after 1992. in F.Giavazzi and F.Torres (eds.), Monetary Union in Europe, Cambridge University Press, Cambridge.

Curcuru, S., T. Dvorak, and F. Warnock (2008). Cross-border return differentials. Quarterly Journal of Economics 123(4), 1495-1530.

Darvas, Z. and J. Pisani-Ferry (2010). Future developments of global imbalances. Bruegel Working paper.

de Hoyos, R. and V. Sarafidis (2006). testing for cross-sectional dependence in panel data models. The Stata Journal 6, 482-496.

De Santis, R. (2006). The geography of international portfolio flows, international CAPM and the role of monetary policy frameworks. ECB Working Paper Series 678. 
Dees, S., F. Di Mauro, M. H. Pesaran, and L. V. Smith (2007). Exploring the international linkages of the Euro area: A global VAR analysis. Journal of Applied Econometrics 22, 1-38.

Diebold, F. and C. Chen (1996). Testing structural stability with endogenous breakpoint - A size comparison of analytic and bootstrap procedures. Journal of Econometrics 70, 221-241.

Edwards, S. (2005). Is the current account deficit sustainable? And if not, how costly is adjustment likely to be? NBER Working Paper 11541.

Eichengreen, B. (1992). Golden Fetters: The Gold Standard and The Great Depression, 1919-1939. Oxford University Press, UK.

Eichengreen, B. (2001). Capital account liberalization: What do cross-country studies tell us? World Bank Economic Review 15, 341-365.

Erceg, C., L. Guerrieri, and C. Gust (2005). Expansionary fiscal shocks and the US trade deficits. International Finance 8(3), 363-397.

Faruqee, H. and J. Lee (2008). Global dispersion of current accounts: Is the universe expanding? working paper.

Faust, J., J. Rogers, and J. Wright (2003). Exchange rate forecasting: The errors we've really made. Journal of International Economics 60, 35-59.

Feldstein, M. (2008). Resolving the global imbalances: The dollar and the U.S. savings rate. Journal of Economic Perspective 22(3), 113-125.

Feldstein, M. and C. Horioka (1980). Domestic savings and international capital flows. The Economic Journal $90(358)$, 314-329.

Fischer, S. (1998). Capital account liberalization and the role of the IMF. in: Should the IMF pursue capital-account convertibility? Princeton Essays in International Finance 207 Princeton University Press, Princeton.

Frankel, J. (1984). Tests of monetary and portfolio-balance models of exchange rate determination. in J. Bilson and R. Marston (eds.), Exchange rate theory and practice The University of Chicago Press.

Fratzscher, M. and J. Imbs (2007). Risk sharing, finance and institutions in international portfolios. Journal of Financial Economics, forthcoming.

Fratzscher, M., L. Juvenal, and L. Sarno (2007). Asset prices, exchange rates and the current account. European Economic Review, forthcoming. 
Fratzscher, M. and R. Straub (2009). Asset prices and current account fluctuations in G7 economies. IMF Staff Papers 56(3), 633-654.

French, K. and J. Poterba (1991). Investor diversification and international equity markets. American Economic Review 81, 222-226.

Friedman, M. (1937). The use of ranks to avoid the assumption of normality implicit in the analysis of variance. Journal of the American Statistical Association 32, 675-701.

Giannone, D., M. Lenz, and L. Reichlin (2009). Business cycles in the Euro area. ECB Working Paper Series 1010.

Giannone, D. and L. Reichlin (2006). Trends and cycles in the Euro area - How much heterogeneity and should we worry about it? ECB Working Paper Series 595 .

Goldberg, L. and C. Tille (2006). The internationalization of the dollar and the trade balance adjustment. Federal Reserve Bank of New York Staff Report 255.

Gourinchas, O.-P. and H. Rey (2008). International financial adjustment. Journal of Political Economy 155(4).

Gourinchas, P.-O. (2008). Valuation effects and external adjustment: A review. in K. Cowan, S.Edwards and R.Valdes (eds.), Current Account and External Financing, Series on Central Banking, Analysis and Economic Policy, Vol. XII Banco de Chile, 195-236.

Gourinchas, P.-O. and H. Rey (2007). From world banker to world venture capitalist: US external adjustment and the exorbitant privilege. in R. Clarida (ed.), G7 Current Account Imbalances: Sustainability and Adjustment The University of Chicago Press, 11-55.

Greenspan, A. (2004). Remarks by Chairman Alan Greenspan at the Conference on Bank Structure and Competition.

Gros, D. (2010). Adjustment difficulties in the GIPSY club. CEPS Working Document 326 .

Gruber, J. and S. Kamin (2007). Explaining the global pattern of current account imbalances. Journal of International Money and Finance 26, 500-522.

Gupta-Kapoor, A. and U. Ramakrishnan (1999). Is there a J-curve: A new estimation for Japan. International Economic Journal 13(4), 71-79. 
Gust, C. and N. Sheets (2006). The adjustment of global external imbalances: Does partial exchange rate pass-through to trade prices matter? International Finance Discussion Papers 850.

Hallwood, C. and R. MacDonald (2000). International money and finance. Blackwell Oxford.

Hansen, B. (1992). Tests for parameter instability in regressions with I(1) processes. Journal of Business 8 Economic Statistics 10, 321-336.

Harbo, I., S. Johansen, B. Nielsen, and A. Rahbek (1999). Asymptotic inference on cointegrating rank in partial systems. Journal of Business $\&$ Economic Statistics 16, 388-399.

Hau, H. and H. Rey (2004). Can portfolio rebalancing explain the dynamics or equity returns, equity flows, and exchange rates? American Economic Review 94, 126-133.

Henderson, D. and K. Rogoff (1982). Negative net foreign asset positions and stability in a world portfolio balance model. Journal of International Economics 13, 85-104.

Hendry, D. F. (1996). A theory of co-breaking. mimeo, University of Oxford.

Hendry, D. F. and G. E. Mizon (1998). Exogeneity, causality and co-breaking in economic policy analysis of a small econometric model of money in the UK. Empirical Economics 23, 267-294.

Higgins, M. and T. Klitgaard (2007). Financial globalization and the U.S. current account deficit. Current Issues in Economics and Finance. Federal Reserve Bank of New York 13(11), 1-7.

Hirst, P. and G. Thompson (1996). Globalization in Question. Cambridge Polity Press, Cambridge, UK.

Hunt, B. and A. Rebucci (2005). The US dollar and the trade deficit: What accounts for the late 1990s? International Finance 8(3), 399-434.

Imbs, J. (2004). Trade, finance, specialization and synchronization. Review of Economics and Statistics 86, 723-734.

Johansen, S. (1992). Cointegration in partial systems and the efficiency of singleequation analysis. Journal of Econometrics 52, 389-402.

Kasa, K. (1992). Common stochastic trends in international stock markets. Journal of Monetary Economics 29, 95-124. 
Kollmann, R. (1995). Consumption, real exchange rates and the structure of international asset markets. Journal of International Money and Finance 14, $191-211$.

Kool, C. (2009). The sustainability of global financial imbalances. Utrecht University School of Economics Working Paper.

Kool, C. and L. Keijzer (2009). International capital mobility: Linking the Feldstein-Horioka Puzzle and the trade and equity home bias puzzles. Cambridge Journal of Regions, Economy and Society 2:2, 211-228.

Koop, G., M. H. Pesaran, and S. M. Potter (1996). Impulse response analysis in nonlinear multivariate models. Journal of Econometrics 74, 119-147.

Kose, A., E. Prasad, K. Rogoff, and S.-J. Wei (2006). Financial globalization: A reappraisal. IMF Staff Papers 56(1), 8-62.

Kose, A., E. Prasad, K. Rogoff, and S.-J. Wei (2009). Financial globalization and economic policies. CEPR Discussion Paper 7117.

Kose, M., E. Prasad, and M. Terrones (2007). How does financial globalization affect risk-sharing? Patterns and channels. IMF Working Paper 238.

Kouri, P. (1983). Balance of payments and the foreign exchange market: A dynamic partial equilibrium model. MIT Press, Cambridge.

Krugman, P. (2000). How complicated does the model have to be? Oxford Review of Economic Policy 16(4), 33-42.

Krugman, P. (2007). Will there be a dollar crisis? Economic Policy July 2007, $436-467$.

Lane, P. (2001). The new open economy macroeconomics: A survey. Journal of International Economics 54, 235-266.

Lane, P. and G. Milesi-Ferretti (2001). The external wealth of nations: Measures of foreign assets and liabilities for industrial and developing nations. Journal of International Economics 55, 263-294.

Lane, P. and G. Milesi-Ferretti (2002). External wealth, the trade balance, and the real exchange rate. European Economic Review 46, 1049-1071.

Lane, P. and G. Milesi-Ferretti (2003). International financial integration. International Monetary Fund Staff Paper. 
Lane, P. and G. Milesi-Ferretti (2005). A global perspective on external positions. NBER Working Papers 11589.

Lane, P. and G. Milesi-Ferretti (2007). The external wealth of nations mark II: Revised and extended estimates of foreign assets and liabilities, 1970-2004. Journal of International Economics 73, 223-250.

Lane, P. and G. Milesi-Ferretti (2008). International investment patterns. The Review of Economics and Statistics 90(3), 538-549.

Lapp, S. (1996). The Feldstein-Horioka Paradox: A selective survey of the literature. Kiel Working Paper 752. The Kiel Institute for World Economics.

Lee, J. and M. D. Chinn (2006). Current account dynamics and real exchange rate dynamics in G7 countries. Journal of International Money and Finance 25(2), 257-274.

Leibrecht, M. and J. Scharler (2008). Reconsidering consumption risk-sharing among OECD countries: Some evidence based on panel cointegration. Open Economies Review 19, 493-505.

LeRoy, S. and J. Werner (2001). Principles of Financial Economics. Cambridge University Press.

Lettau, M. and S. Ludvigson (2001). Consumption, aggregate wealth, and stock returns. The Journal of Finance 56(3), 815-849.

Lettau, M. and S. Ludvigson (2004). Understanding trend and cycle in asset values: Reevaluating the wealth effect on consumption. The American Economic Review 94(1), 276-299.

Lewis, K. (1996). What can explain the apparent lack of international consumption risk-sharing? The Journal of Political Economy 99, 267-287.

Lewis, K. (1999). Trying to explain home bias in equities and consumption. Journal of Economic Literature XXXVII, 571-608.

Lewis, K. (2000). Why do stocks and consumption imply such different gains from international risk-sharing? Journal of International Economics, 1-35.

Ludvigson, S. and C. Steindel (1999). How important is the stock market effect on consumption. Federal Reserve Bank of New York Economic Policy Review 2951 . 
Ludwig, A. and T. Sløk (2004). The relationship between stock prices, house prices and consumption in OECD countries. Topics in Macroeconomics 4(1, Article 4), $1-26$.

Mace, B. (1991). Full insurance in the presence of aggregate uncertainty. The Journal of Political Economy 99, 928-956.

Meese, R. and K. Rogoff (1988). Was it real? The exchange rate-interest differential over the modern floating-rate period. The Journal of Finance 43(4), 933-948.

Mehra, Y. P. (2001). The wealth effect in empirical life-cycle aggregate consumption equations. Federal Reserve Bank of Richmond Economic Quarterly 87(2), 45-68.

Meissner, C. and A. Taylor (2006). Losing our marbles in the new country? The great rebalancing in historical perspective. NBER Working Paper 12580.

Méliz, J. and F. Zumer (1999). Interregional and international risk-sharing and lessons for EMU. Carnegie-Rochester Conference Series on Public Policy 51, $149-188$.

Meller, B. (2009). The two-sided effects of financial globalization on output volatility. working paper.

Muellbauer, J. and A. Murphy (2008). Housing markets and the economy: The assessment. Oxford Review of Economic Policy 24(1), 1-33.

Nyblom, J. (1989). Testing for the constancy of parameters over time. Journal of the American Statistical Association 84, 223-230.

Obstfeld, M. (1994). Are industrial-country consumption risks globally diversified? in L. Leiderman and A. Razin (eds.), Capital Mobility: The Impact of Consumption, Investment and Growth Cambridge University Press.

Obstfeld, M. (1995). International capital mobility in the 1990s. in P.B. Kenen (ed.), Understanding Interdependence Princeton University Press.

Obstfeld, M. (2001). The six major puzzles in international macroeconomics solved. NBER Macroeconomics Annual 2000 15, 339-390.

Obstfeld, M. (2007). International risk sharing and the costs of trade. The Ohlin Lectures, Stockholm School of Economics.

Obstfeld, M. and K. Rogoff (1995). Exchange rate dynamics redux. Journal of Political Economy 103, 624-640. 
Obstfeld, M. and K. Rogoff (1996). Foundations of International Macroecomomics. MIT Press, Cambridge.

Obstfeld, M. and K. Rogoff (2001). The Six Major Puzzles in International Macroeconomics: Is There a Common Cause? in: NBER Macroeconomics Annual 2000, Volume 15, p. 339-412. National Bureau of Economic Research.

Obstfeld, M. and A. Taylor (2004). Global Capital Markets - Integration, Crisis, and Growth. Cambridge University Press, New York, US.

Park, H. and W. Fuller (1995). Alternative estimators and unit root tests for the autoregression process. Journal of Time Series Analysis 16, 415-429.

Pesaran, M. H. (2004). General diagnostic tests for cross section dependence in panels. Cambridge Working Papers in Economics No. 0435, University of Cambridge.

Pesaran, M. H. (2006). Estimation and inference in large heterogeneous panels with a multifactor error structure. Econometrica 74(4), 967-1012.

Pesaran, M. H., T. Schuermann, and S. M. Weiner (2004). Modeling regional interdependencies using a global error-correcting macroeconometric model. Journal of Business 83 Economic Statistics 22(2), 129-162.

Pesaran, M. H. and Y. Shin (1998). Generalized impulse response analysis in linear multivariate models. Economics Letters 58, 17-29.

Piersanti, G. (2002). Expected future budget deficits, the real exchange rate and current account dynamics in a finite horizon model. Journal of Economics 77(1), 1-22.

Ploberger, W. and W. Krämer (1992). The CUSUM test with OLS residuals. Econometrica 60, 271-286.

Portes, R. and H. Rey (2005). The determinants of cross-border equity flows. Journal of International Economics 65, 269-296.

Poterba, J. and A. Samwick (1995). Stock ownership patterns, stock market fluctuations, and consumption. Brookings Papers on Economic Activity 2, 295357.

Poterba, J. M. (2000). Stock market wealth and consumption. Journal of Economic Perspectives 13, 91-118. 
Prasad, E., K. Rogoff, S.-J. Wei, and M. Kose (2003). Effects of financial globalization on developing countries: Some empirical evidence. IMF Occasional Paper 220.

Quandt, R. (1960). Tests of the hypothesis that a linear regression system obeys two separate regimes. Journal of the American Statistical Association 55, 324330 .

Rey, H. (2005). Discussion: International investors, the U.S. current account, and the dollar. Brookings Paper on Economic Activity 1.

Richards, A. (1995). Comovements in national stock market returns: Evidence of predictability, but not cointegration. Journal of Monetary Economics 36, 631-654.

Rose, A. K. and J. L. Yellen (1989). Is there a J-curve? Journal of Monetary Economics 24, 53-68.

Roubini, N., E. Parisi-Capone, and C. Menegatti (2007). Growth differentials in the EMU: Facts and considerations. RGE Monitor Working paper.

Sachs, J. (1981). The current account and macroeconomic adjustment in the 1970s. Brookings Papers on Economic Activity 1, 201-282.

Samuelson, P. (1964). Theoretical notes on trade problems. Review of Economics and Statistics 46, 145-154.

Shiller, R. (1993). Macro Markets: Creating Institutions for Managing Society's Largest Economic Risks. Oxford University Press.

Sims, C. (1980). Macroeconomics and reality. Econometrica 48, 1-48.

Solnik, B. (1974). An equilibrium model of the international capital markets. Journal of Economic Theory 8, 500-524.

Sørensen, B., Y.-T. Wu, O. Yosha, and Y. Zhu (2007). Home bias and international risk sharing: Twin puzzles seperated at birth. Journal of International Money and Finance 26, 587-605.

Sørensen, B. and O. Yosha (1998). International risk sharing and European monetary unification. Journal of International Economics 45, 211-238.

Sørensen, P. and H. Whitta-Jacobsen (2005). Introducing Advanced Macroeconomics: Growth $\&$ Business Cycles. Maidenhead, UK: Mc Graw Hill. 
Stiglitz, J. (2002). Globalization and its discontents. W. W. Norton and Company, New York.

Stockmann, A. and L. Tesar (1995). Tastes and technology in a two-country model of the business cycle: Explaining international comovements. American Economic Review 85, 168-185.

Stoffels, N. and C. Tille (2007). Why are Switzerland's foreign assets so low? The growing financial exposure of a small open economy. Federal Reserve Bank of New York Staff Reports No. 283.

Summers, L. (2000). International financial crisis: causes, prevention, and cures. American Economic Revies 90(2), 1-16.

Tille, C. (2003). The impact of exchange rate movements on US foreign debt. Current Issues in Economics and Finance 9(1).

Tobin, J. (1969). A general equilibrium approach to monetary theory. Journal of Money, Credit and Banking 1, 15-29.

Yaari, M. (1964). On the consumer's lifetime allocation process. The International Economic Review 5(3).

Yaari, M. (1965). Uncertain lifetime, life insurance, and the theory of the consumer. The Review of Economic Studies 32(2), 137-150. 



\section{Nederlandse Samenvatting (Summary in Dutch)}

Slechts weinigen kunnen een wereld zonder een internationaal financieel systeem voorstellen. Internationale financiële markten zijn een belangrijk onderdeel van ons leven geworden: zowel direct wanneer we onze spaartegoeden investeren, geld lenen of levensverzekeringen afsluiten, maar ook indirect, door de nauwe samenhang tussen financiële markten en de reële economie. De huidige financiële en economische crisis is het meest tastbare voorbeeld van deze samenhang. Deze crisis begon in de Amerikaanse subprime hypotheekmarkt, maar heeft verstrekkende gevolgen op de economische activiteit. We lezen iedere dag over financiële markten in de krant, waar vaak een negatief sentiment gecreëerd wordt en een bijna apocalyptisch beeld van het wereldwijde financiële systeem geschetst wordt. Het is niet verassend dat het huidige wereldwijde financiële systeem onder toenemende druk komt te staan.

Zulk een eenzijdige beeldvorming is niet gerechtvaardigd en onderkent niet de positieve effecten van globalisatie. Daarentegen maakt het des te meer duidelijk dat een beter begrip van het functioneren van financiële markten en in het bijzonder de interacties tussen financiële markten en de reële economie essentieel zijn voor toekomstige welvaartsgroei. Een goed onderbouwde kijk zonder vooroordelen op de kansen en risico's van internationaal geïntegreerde financiële markten is noodzakelijk.

Het doel van mijn proefschrift getiteld "The Wealth of Nations: Global imbalances and adjustments in a financially integrated world" is het begrip van internationaal geïntegreerde financiele markten te vergoten. Dit proefschrift bestaat uit een verzameling van studies die de verstrekkende gevolgen van een wereldwijd financieel systeem voor de nieuwe internationale macro-economische orde analyseren. Deze onderzoeken behelzen zowel theoretisch als empirisch 
werk. De meeste hoofdstukken behandelen niet expliciet de huidige financiële en economische crisis, desalniettemin zijn de resultaten zeker ook relevant voor deze crisis en de huidige beleidskeuzes.

Het huidige financiële stelsel kan het beste gezien worden als een wereldwijd netwerk waarin nationale financiële markten naar elkaar toe groeien en grenzen vervagen. Financiële markten zijn steeds groter geworden, waarbij de grote vooruitgang in informatietechnologie sinds 1990 een belangrijke drijfveer is. Dit proces versnelde doordat barrières voor internationale financiële transacties opgeheven werden en overheden verschaften buitenlandse investeerders steeds meer toegang hun markt. Anno 2010 zijn de mogelijkheden om deel te nemen in financiële markten in drie belangrijke opzichten toegenomen: (1) de diversiteit en het volume van de verhandelde financiële instrumenten, (2) de geografische spreiding waarin deze financiële instrumenten verhandeld worden en (3) het aantal en de gevarieerdheid van de spelers betrokken bij financiële transacties. De individuele hoofdstukken van dit proefschrift moeten tegen deze achtergrond geplaatst worden en ontlenen daar hun relevantie aan.

Hoofdstuk 2 bestudeert de consumptie risicodeling karakteristieken van internationale financiële markten met behulp van longitudinale regressie technieken. Het doel van deze studie is het opnemen van internationale portfolio bezittingen in de discussie over consumptie risicodeling. Om dit te bereiken ontwikkelen we een nieuwe maatstaf voor het meten van de spreiding van internationale effectenportefeuilles. Veel onderzoekers hebben gewezen op het potentiële belang van internationale investeringen, maar zover bekend zijn wij de eersten die gebruik maken van data om dit effect empirisch te testen. In dit opzicht combineert hoofdstuk 2 de literatuur over de internationale spreiding van effectenportefeuilles en internationale consumptie risicodeling. We vinden dat verschillen in internationale effectenportefeuilles weerspiegeld worden in de mogelijkheden van een land om consumptierisico te spreiden door gebruik te maken van internationale financiële markten. Dit resultaat blijft gehandhaafd wanneer we controleren voor de algehele internationale effectenportefeuille van een land en haar absolute internationale financiële integratie. Daarom stellen wij dat er twee kanalen zijn die consumptie risicodeling bevorderen: Het eerste kanaal heeft betrekking op de grootte van buitenlandse effectenportefeuilles terwijl het tweede kanaal betrekking heeft op de bestemming van de buitenlandse effectenportefeuilles. Het eerste kanaal is uitgebreid onderzocht in de literatuur, terwijl toekomstig onderzoek naar het tweede kanaal noodzakelijk. Onze relatieve thuismarkt voorkeursmaatstaf is een eerste innovatie in deze richting en onderstreept het onderzoekspotentieel. Het gezamenlijk behandelen van beide kanalen in een studie schept een beter inzicht in de hoeveelheid consumptie risicodeling die bereikt wordt.

Hoofdstuk 3 beschrijft de empirische relatie tussen particulier bezit, consumptie 
en de handelsbalans voor vijf van de grootste economiën: de Verenigde Staten, het Verenigd Koninkrijk, Frankrijk, Duitsland en Japan. De theorie van het vermogenseffect voorspelt dat de consumptie toeneemt indien bezittingen meer waard worden. Dit effect wordt versterkt wanneer deze waardestijgingen als permanent beschouwd worden. In dit hoofdstuk wordt bekeken hoe de consumptieveranderingen de handelsbalans beïnvloeden. Om dit te onderzoeken wordt gebruik gemaakt van een groot macro-econometrisch model, het Global VAR model, van Pesaran et al (2004). Dit model wordt geschat voor 29 landen met kwartaaldata van 1980 tot en met 2006. Via een handelsmatrix worden de landen aan elkaar gekoppeld om lokale schokken internationaal te verspreiden. Deze handelsmatrix bestaat uit de relatieve gewichten van alle bilaterale handelsrelaties, bijvoorbeeld 40 procent voor Nederland als de handel Nederland-Duitsland 40 procent van de totale Nederlandse handel is. De gemodelleerde variabelen behelzen het bbp, consumptie en investeringen aan de reële kant van de economie. Daarnaast worden de reële wisselkoers, korte en lange rente toegevoegd. Onder particuliere bezittingen worden aandelen en huizenbezit verstaan. Om de waardeontwikkeling te meten zijn de lokale beursindex en de huizenprijsindex voor die landen waarvoor deze volledig beschikbaar is tussen 1980 en 2006 gebruikt. Door middel van Generalized Impulse Response Functions worden de effecten van een positieve schok op de reële wisselkoers en negatieve schokken in aandelenkoersen en huizenprijzen onderzocht voor de vijf eerder genoemde landen. De resultaten laten zien dat de Britse en Amerikaanse handelsbalans sterk beïnvloed wordt door veranderingen in de waarde van bezittingen. Dit effect is kleiner in Frankrijk en lijkt afwezig te zijn in Duitsland en Japan. Een variatie decompositie maakt duidelijk dat de schokken in bezittingen een groter effect hebben op de handelsbalans dan veranderingen in de reële wisselkoers voor Frankrijk, het Verenigd Koninkrijk en de Verenigde Staten.

Hoofdstuk 4 ontwikkelt een portefeuille balansmodel waarin de complexe relaties tussen effectenprijzen, wisselkoersen en waardeveranderingen op netto internationale investeringsposities én de lopende rekening gecombineerd worden. Het model is in overeenstemmingen met de bekende feiten die de hedendaagse internationale financiële markten karakteriseren. Het model borduurt voort op de modellen van Branson (1979), Henderson and Rogoff (1982) en Kouri (1983) en kan gezien worden als een uitbreiding van het meer recente werk vanBlanchard et al. (2005) in verschillende richtingen. Door effectenmarkten te splitsen in aandelen- en obligatiemarkten kan ons model expliciet de verschillende karakteristieken van deze markten modelleren. Daarnaast worden de dynamische aspecten van wisselkoersbewegingen en relatieve prijzen expliciet gemodelleerd in het externe aanpassingsproces. Deze eigenschap van het model is zeer relevant voor het modelleren van de externe positie van de VS, waar risicovollere aandelen 
oververtegenwoordigd zijn, terwijl de schulden in de vorm van laag renderende staatsobligaties zijn. Een ander gerelateerd en innovatief aspect van ons model is de opname van dynamiek in effectenprijzen. Bernanke (2005) benadrukt in zijn discussie van het Blanchard et al. (2005) model dat de exogeniteit van effectenprijzen in portefeuille balansmodellen een belangrijke ontbrekende variabele is, omdat hierdoor geen endogene evolutie van bezit door prijzen mogelijk is als bron van veranderingen in de lopende rekening. Wij nemen relatieve prijzen op en maken deze een integraal onderdeel van het model, waardoor deze een alternatief kanaal vormen dat externe (on)balansen kan beïnvloeden.

De tweede bijdrage is het kalibreren van het model naar de situatie van de VS en twee concurrerende verklaringen van de het Amerikaanse tekort op de lopende rekening te testen: (1) De wereldwijde spaarwaanzin en (2) Binnenlands economisch beleid en ontwikkelingen in de VS. Om dit te testen genereren we een negatieve schok aan de Amerikaanse lopende rekening en een exogene stijging in de vraag naar Amerikaanse staatsobligaties vanuit de rest van de wereld. Zowel individueel als gezamenlijk laat ons model zien dat het waardekanaal van wisselkoersen en relatieve effectenprijsveranderingen een stabiliserend effect hebben op het externe aanpassingsproces en dat de waardestijgingen groot zijn. Simulaties leveren bewijs dat de gezamenlijke modellering van schokken aan de handelsbalans en effectenportefeuilles het dichtst bij de empirische realiteit van de VS komt. De VS heeft een grote netto buitenlandse schuld, terwijl de wisselkoers slechts beperkt deprecieert. In het aanpassingsproces zijn waardestijgingen van buitenlands bezit groter door enerzijds wisselkoersveranderingen en anderzijds door waardestijgingen van buitenlandse aandelen.

Hoofdstuk 5 heeft ook betrekking op externe onbalansen en bestudeert de houdbaarheid van steeds groter wordende externe onbalansen. We veranderen de vraag functie naar Amerikaans schuldpapier en aandelen in het portefeuille balansmodel van hoofdstuk 4 om antwoorden te krijgen op de vraag: Wat gebeurt er als buitenlandse investeerders niet meer laagrenderende Amerikaanse staatsobligaties willen kopen en hun internationale effectenportefeuilles beginnen te verschuiven? We onderscheiden twee scenario's: (1) Buitenlandse investeerders stappen massaal uit Amerikaanse staatsobligaties en (2) Buitenlandse investeerders verkleinen hun tolerantie van Amerikaanse buitenlandse schuld. In beide scenario's stappen buitenlandse investeerders uit Amerikaanse obligaties, maar ze verschillen met betrekking tot de timing. Het eerste scenario betreft een permanente verandering in de vraag functie, terwijl het tweede scenario een tijdelijk karakter heeft en de vraagfunctie koppelt aan de netto buitenlandse schuldpositie van de VS.

Het belangrijkste resultaat laat zien hoe een kleine verandering in de vraagfunctie van buitenlandse investeerders een sterke verkleining in externe onbalansen teweeg kan brengen. Dit proces wordt beïnvloed door het waardekanaal van 
wisselkoersen en effectenprijzen. Een andere belangrijke bevinding is dat het verlies in het bezit van de rest van de wereld vrij klein is, afhankelijk van de investeringsvoorkeuren van buitenlanders na de schok. Ons model laat zien dat de bezorgdheid onder veel academici en beleidsbepalers dat een desinvestering van Aziatische centrale banken uit Amerikaanse obligaties extreme waardeverliezen creëert niet correct is wanneer een strategie waarin buitenlandse investeerders zorgen voor een geleidelijke aanpassing gekozen wordt.

Hoofdstuk 6 bespreekt de verschillen tussen interne en externe balansen van landen in het Noorden en Zuiden van het eurogebied gedurende de periode 19922007. We vinden steeds groter wordende verschillen, een proces dat ingezet lijkt sinds de introductie van de eenheidsmunt. De wortels van dit proces liggen in het spaar- en investeringsgedrag van de particuliere sector. We verwerpen het gebruikelijke argument dat onbalansen een tijdelijk resultaat zijn van het Europese convergentie proces en beargumenteren dat toekomstig onderzoek een sterkere nadruk moet leggen op verschillen in gedrag tussen landen in het Noorden en het Zuiden. Dit is noodzakelijk om volledig de economische ontwikkelingen in het eurogebied te begrijpen en welafgewogen beleidsconsequenties te trekken. Als startpunt schetsen we een open economie model dat de bekende feiten modelleert. In het bijzonder moeten twee karaktereigenschappen in dit model opgenomen worden: (1) Landen in het Zuiden consumeren meer dan de landen in het Noorden, dat resulteert in een kortere planningshorizon en (2) Een hogere schuldtolerantie van de private en publieke sector in het Zuiden. 



\section{Short Curriculum Vitae}

Nils Holinski was born on February 25, 1979 in Bielefeld, Germany. He attended primary school from 1985 to 1989 in Schloss Holte, Germany, and high school from 1989 to 1998 in Bielefeld. Following graduation from high school in 1998, Nils provided his one-year community service in Bielefeld working with mentally and physically handicapped people. In 1999 he joined Dresdner Bank AG in Bielefeld as an apprentice obtaining the degree Bankkaufmann (banker) in 2002. In the same year Nils started his studies at Maastricht University, the Netherlands, where he followed the Bachelor's program in International Economic Studies. In 2005 he obtained the corresponding degree with distinction. During that time Nils worked as a teaching assistant giving classes in Quantitative Economics and studied one semester at the University of California at Santa Barbara, USA. Subsequently, he followed the one-year Master's program in International Economic Studies until 2006. After graduation Nils joined the Department of Economics at Maastricht University as a $\mathrm{PhD}$ candidate under the supervision of Professors Joan Muysken and Clemens Kool until 2010. During that time he also worked as a visiting researcher at Trinity College Dublin, Ireland, from August to November 2008. Nils has presented his academic work at numerous international conferences. 